\title{
Emerging Trends in Nanomaterials for Antibacterial Applications
}

\author{
Sibidou Yougbaré ${ }^{1,2, *}$ \\ Chinmaya Mutalik',* \\ Goodluck Okoro (iD ${ }^{3, *}$ \\ I-Hsin $\mathrm{Lin}^{4}$ \\ Dyah Ika Krisnawati ${ }^{5}$ \\ Achmad Jazidie ${ }^{6,7}$ \\ Mohammad Nuh ${ }^{7,8}$ \\ Che-Chang Chang $\mathbb{1}^{9,10, *}$ \\ Tsung-Rong Kuo (D) ${ }^{1,3, *}$ \\ 'International Ph.D. Program in Biomedical \\ Engineering, College of Biomedical \\ Engineering, Taipei Medical University, \\ Taipei, I I03 I, Taiwan; ${ }^{2}$ Institut de Recherche \\ en Sciences de la Santé (IRSS-DRCO)/ \\ Nanoro, Ouagadougou, Burkina Faso; \\ ${ }^{3}$ Graduate Institute of Nanomedicine and \\ Medical Engineering, College of Biomedical \\ Engineering, Taipei Medical University, \\ Taipei, I I03 I, Taiwan; ${ }^{4}$ School of Biomedical \\ Engineering, College of Biomedical \\ Engineering, Taipei Medical University, \\ Taipei, I I03I, Taiwan; ${ }^{5}$ Dharma Husada \\ Nursing Academy, Kediri, 64I I4, Indonesia; \\ ${ }^{6}$ Department of Electrical Engineering, \\ Institut Teknologi Sepuluh Nopember, \\ Surabaya, 60III, Indonesia; ${ }^{7}$ Universitas \\ Nahdlatul Ulama Surabaya, Surabaya, 60237, \\ Indonesia; ${ }^{8}$ Department of Biomedical \\ Engineering, Institut Teknologi Sepuluh \\ Nopember, Surabaya, 60I II, Indonesia; \\ ${ }^{9}$ The Ph.D. Program for Translational \\ Medicine, College of Medical Science and \\ Technology, Taipei Medical University, Taipei, \\ I I03I, Taiwan; ${ }^{10}$ International Ph.D. \\ Program for Translational Science, College \\ of Medical Science and Technology, Taipei \\ Medical University, Taipei, I I03I, Taiwan \\ *These authors contributed equally to this \\ work
}

Correspondence: Che-Chang Chang;

Tsung-Rong Kuo

Tel +886-2-2736166I ext.7630;

+886-2-2736I66I ext. 7706

Email ccchang168@tmu.edu.tw;

trkuo@tmu.edu.tw

\begin{abstract}
Around the globe, surges of bacterial diseases are causing serious health threats and related concerns. Recently, the metal ion release and photodynamic and photothermal effects of nanomaterials were demonstrated to have substantial efficiency in eliminating resistance and surges of bacteria. Nanomaterials with characteristics such as surface plasmonic resonance, photocatalysis, structural complexities, and optical features have been utilized to control metal ion release, generate reactive oxygen species, and produce heat for antibacterial applications. The superior characteristics of nanomaterials present an opportunity to explore and enhance their antibacterial activities leading to clinical applications. In this review, we comprehensively list three different antibacterial mechanisms of metal ion release, photodynamic therapy, and photothermal therapy based on nanomaterials. These three different antibacterial mechanisms are divided into their respective subgroups in accordance with recent achievements, showcasing prospective challenges and opportunities in clinical, environmental, and related fields.
\end{abstract}

Keywords: nanomaterials, metal ions, photodynamic, photothermal, antibacterial mechanism, reactive oxygen species

\section{Introduction}

Nanotechnology as a tool has rapidly taken over several fields of life including the health sector. ${ }^{1}$ Applications of nanotechnology in the health sector are diverse and range from diagnostics to therapies. One of the therapeutic challenges at a global scale remains the treatment of bacterial infections. Indeed, the long-term use and misuse of antibiotics have led to antibiotic resistance, which threatens public health through different pathways like livestock, food, and water. ${ }^{2-4}$ Metal ion release, photodynamic therapy (PDT), and photothermal therapy (PTT) are important methods for different biological applications. Multiple metal and carbon-based complexes (both organic and inorganic) such as copper, bismuth, silver, iron, gallium, gold, titanium, molybdenum, selenium, chitosan, polyvinylpyrrolidone, polyvinylidene fluoride, polyvinyl chloride, carboxymethyl cellulose, graphene etc, have been investigated in clinical studies for treating malaria, neurodegenerative diseases, cancer, and bacterial infections. ${ }^{5-32}$ The variety of metals, their diverse physicochemical properties, their inherited photochemical properties, their shapes, and ligand types make them suitable for widespread use in new antimicrobial designs. ${ }^{33-35}$

Moreover, metal atoms easily become positively charged ions through the loss of electrons, and they can then dissolve in biological fluids. Because of their electron deficiency, metal ions have a high affinity for electron-rich biomolecules, 


\section{Graphical Abstract}

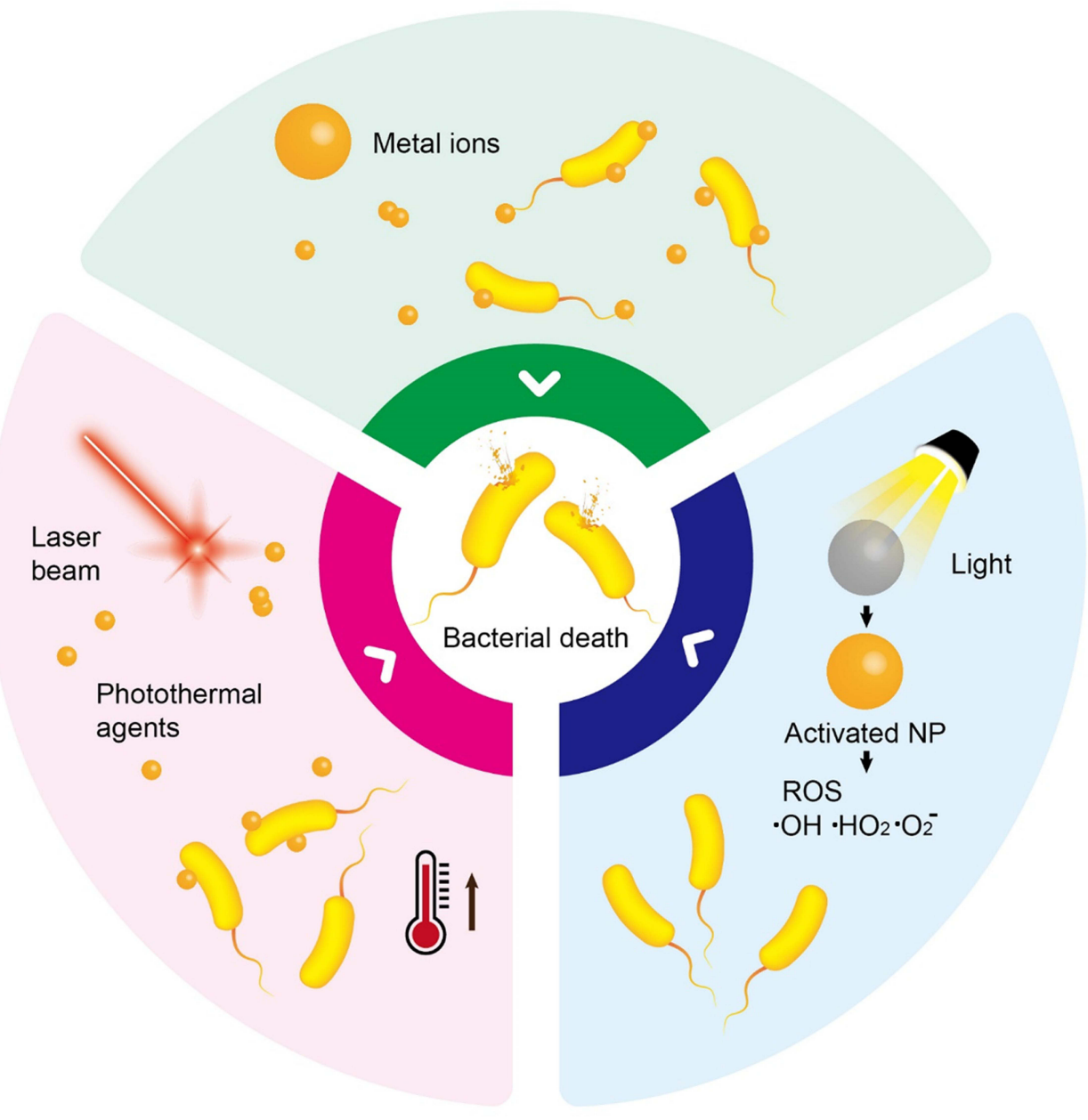

such as DNA and proteins, with which they form complexes. The formation of complexes leads to the inactivation of proteins, DNA damage, membrane impairment, and ultimately bacterial death. Furthermore, PDT and PTT use light to trigger a cascade of events leading to bacterial death. Different antibacterial phototherapy modalities exist based on how light-responsive nanomaterials act. The PDT employs photosensitizers or their precursors which can absorb visible light and produce reactive oxygen species (ROS) that are toxic to cells due to stress oxidation. Nanomaterials for PDT applications include metals, upconversion nanoparticles, carbon-based nanomaterials, two-dimensional (2D) nanomaterials, quantum dots (QDs), etc. ${ }^{36-41}$ PDT can be used to treat infectious diseases without the specter of drug resistance like with antibiotic treatment. $^{42,43}$ In this way, PDT can be applied to all types of microorganisms including bacteria. ${ }^{44,45}$ PTT uses photothermal nanomaterials which can absorb light followed by its conversion into heat leading to hyperthermia which kills cells. With this therapy, a near-infrared (NIR) laser is preferable as a light source due to its advantages in clinical applications such as deeper tissue penetration, safety, and high absorption by photothermal agents (PTAs). ${ }^{46}$ In this literature review, we summarize three ways of fighting bacterial infections using materials or composites at the nanometer scale: metal ion release, PDT, and PTT. Thereafter, a brief overview of trends with new approaches for antibacterial drugs is provided.

\section{Metal Ion Release}

\section{Overview of Metal Ion Release in}

\section{Antibacterial Applications}

The ability of metal/metal oxide nanoparticles (NPs) to release metal ions in aqueous media has recently been 
extensively explored especially the aspect of their biomedical application and particularly focusing on the antibacterial properties of these metal/metal oxide NPs. The bactericidal properties of these NPs and their resulting metal ions have been extensively reported in recent years, and it was observed that metal ions are to a large extent implicated when describing the toxic mechanisms of these metal/metal oxide NPs against bacteria. These NPs can be oxidized when in biological media, releasing metal ions which can generate ROS or create oxidative stress that in turn leads to biocidal effects which can range from ribosome destabilization, DNA, protein, mitochondrial, and cell wall damage to electron transport disruption and cell death (Figure 1). ${ }^{47-50}$ Many metal ions were reported to exert toxicity against bacteria, such as $\mathrm{Ca}^{2+}, \mathrm{Zn}^{2+}, \mathrm{Mg}^{2+}, \mathrm{Fe}^{2+}, \mathrm{Fe}^{3+}, \mathrm{Ni}^{2+}$, and $\mathrm{Cu}^{2+}$, which at lower concentrations are very useful in bacterial metabolic processes but at higher concentrations become toxic to bacteria and hence have a bactericidal effect. ${ }^{51}$ The effects of these metal ions are primarily attributed to their natural affinity for certain cellular components. ${ }^{52}$ This is not the case with other metal ions such as $\mathrm{Ag}^{+}$which exerts a very strong bactericidal effect even at very low concentrations. These metal ions are known to have a great affinity for thiol groups, which for example bind to cysteine and then indirectly trigger disruption of a cell's enzyme functions, metabolism, or general physiology through their ability to destroy a cell's disulfide bonds which help to maintain tertiary and quaternary protein structures.

Different modes of bacterial execution mechanisms have been identified for different kinds of metal/metal oxide NPs. Some examples include reorganization of the histone-like nucleoid structuring protein of bacteria, which was observed when Escherichia coli (E. coli) was treated with an $\mathrm{Ag}^{+}$solution, ${ }^{53}$ and bacterial death by the release of metal ions and generation of ROS via destruction of cell membranes and DNA damage, observed as antibacterial effects of $\mathrm{Fe}_{3} \mathrm{O}_{4} @$ copper (II) metal-organic framework core-shell magnetic microspheres and $\mathrm{Ru}_{2} \mathrm{O}$ nanocomplexes. ${ }^{54,55}$ Furthermore, it is important to also note that these metal ions possibly trigger these toxic effects on cells via a coordinated Haber-Weiss reaction, Fenton reaction, or Fenton-like reaction in which all three reactions yield hydroxyl radicals that adversely affect bacterial cells. ${ }^{56-58}$ The nanomaterials in these cases serve as powerful catalysts by enhancing ROS production through any of the above-mentioned pathways.

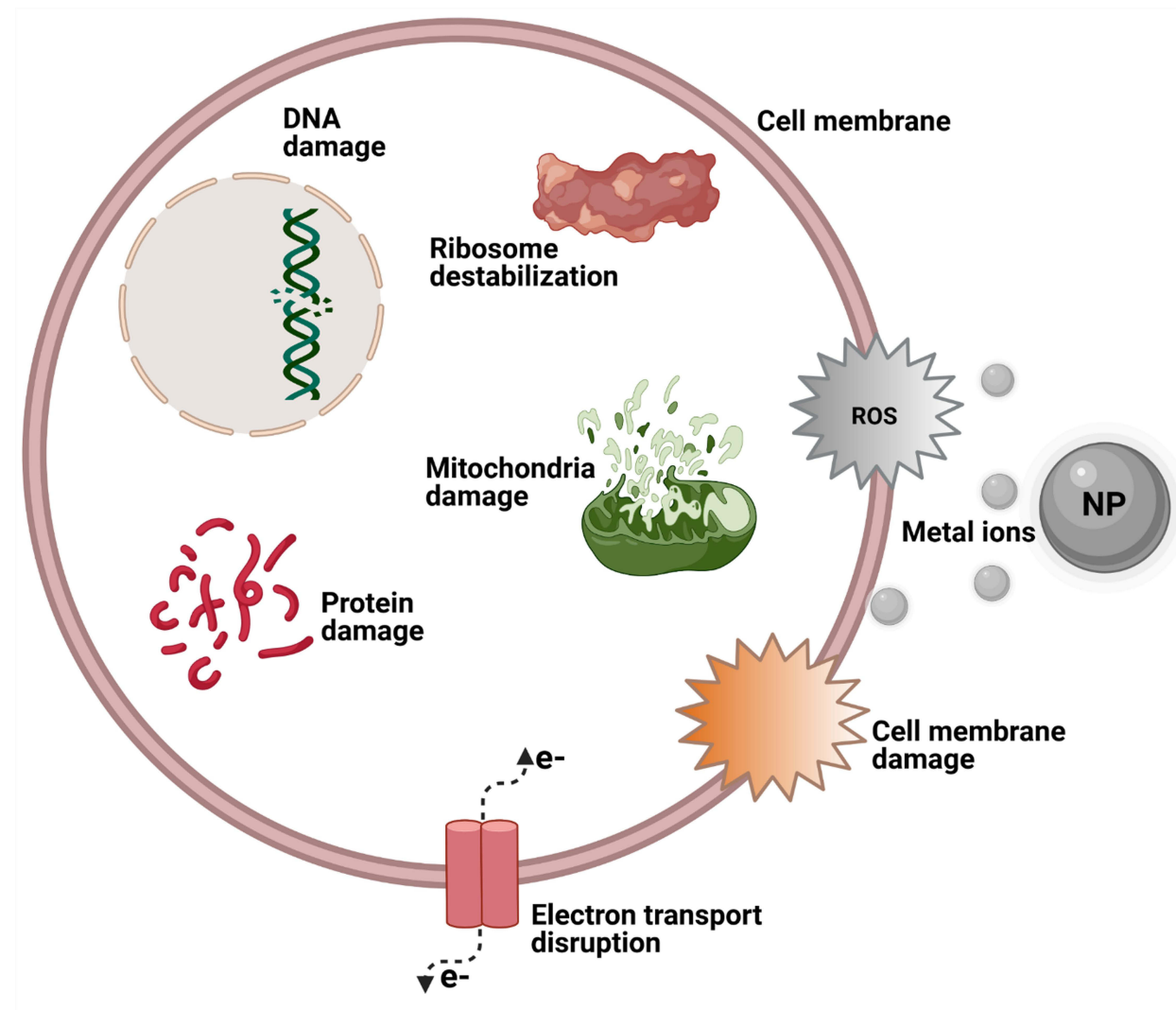

Figure I Schematic illustration showing some toxic effects of metal ions from NPs. 
Several key factors have been identified that influence the generation of ROS and hence the evident toxicity exhibited by some nanomaterials. These factors include solubility, shape, size, oxidation status, surface area, surface coating, surface species, and the degree of agglomeration and aggregation of a nanomaterial. ${ }^{59-61}$ These chemical and physical factors can to a great extent influence the mode of action of these NPs in terms of how they are able to enhance catalytic properties by converting less-toxic oxidants into more-reactive free radicals, which in turn have destructive effects on bacteria, just as $\mathrm{Ag}^{+}, \mathrm{Cu}^{2+}$, and $\mathrm{Zn}^{2+}$ exert bactericidal properties by inducing the generation of ROS. ${ }^{62}$ Furthermore, when in aqueous solution, multicomponent metal ions act synergistically to produce increased antibacterial effects than single metal ions in solution. This increased synergistic effect occurs as a result of Fenton reactions and ROS production via electron transfer in enzymes. ${ }^{63}$

Recently, the concept of metal ion release has been incorporated into antimicrobial-based biomedical applications. For example, ionic solutions/colloidal suspensions of metallic NPs of $\mathrm{Ag}, \mathrm{Cu}$, and $\mathrm{Li}$ were incorporated into some dental materials, and the resulting metal ions had an antibacterial effect on Staphylococcus aureus (S. aures). ${ }^{64}$ Other application include pit and fissure sealants designed with antibacterial properties, ${ }^{65}$ wound healing, ${ }^{66-68}$ implant technology, ${ }^{69,70}$ improved disinfection materials, ${ }^{71}$ eco-friendly design of NPs with antibacterial properties, ${ }^{72}$ and antibacterial-Ag/plasma polymer nanocomposites for cotton fabrics, ${ }^{73}$ among others. The antibacterial capabilities of Ag ions can be preserved while the harmful effect on biological environment is reduced by synthesizing $\mathrm{Ag}$ with hydroxyapatite from phosphorus-deficient precursors using carbonate substitution, Ag containing calcium phosphate, and Ag NPs carriers of hydroxyapatite powder. ${ }^{74-76}$ In general, the release of metal ions in aqueous solutions has been explored for quite exciting biomedical applications especially in antibacterial-based biodesigns.

\section{NP Dissolution and Metal lon Release}

NP dissolution in either a biological system or in an aqueous medium results in the release of ionic species which can elicit bacteria toxicity via specialized pathways. Horie et al assessed the physicochemical properties of 24 metal oxide NPs and their cellular effects. ${ }^{77}$ They discovered that metal oxides which dissolved in media, such as $\mathrm{ZnO}, \mathrm{CuO}, \mathrm{NiO}, \mathrm{Sb}_{2} \mathrm{O}_{3}, \mathrm{CoO}, \mathrm{MoO}_{3}$ and $\mathrm{Gd}_{2} \mathrm{O}_{3}$, released metal ions which caused detrimental cellular effects. Conversely, other metal oxide NPs which were barely able to dissolve in the media exerted very weak cellular effects. Interestingly, the authors discovered that $\mathrm{Y}_{2} \mathrm{O}_{3}$, a metal oxide NP which released metal ions in solution and also expressed increased ROS levels, showed no level of toxicity toward cells. Schiavo et al also reported similar findings with zinc oxide $(\mathrm{ZnO})$ NPs toward three marine organisms: Dunaliella tertiolecta, Vibrio fischeri, and Artemia salina ${ }^{78}$ They however discovered that the toxicity of $\mathrm{ZnO}$ toward these organisms was a result of $\mathrm{Zn}^{2+}$ release and also the $\mathrm{ZnO}$ particles themselves, but the toxicity level was dependent on the exposure time. The particular physicochemical properties of NPs must be considered when assessing the exact bactericidal mechanism of a given NP. It is also noteworthy that although metal ion release arising from NP dissolution cannot solely be used to explain bactericidal properties of metal/metal oxide NPs, many NPs' toxicity is greatly accelerated by dissolution. For example, Xia et al assessed the toxicity mechanism of $\mathrm{ZnO}$ and cerium oxide NPs and focused on their dissolution and oxidative stress properties; they clearly described how the key mechanism of $\mathrm{ZnO}$ toxicity greatly depended on its excellent dissolution property. ${ }^{79}$

NP dissolution plays a very interesting role in the release of metal ions in biological environments. This concept is instrumental in releasing toxic metal ions to kill bacteria or other pathogens as evidenced by several reported findings (Figure 2). Furthermore, understanding the kinetics of NP dissolution can be very useful in designing safe NPs, and also in describing the etiology of some occupational health-related issues. For example, the dissolution property of $\mathrm{ZnO}$ was linked to pulmonary toxicity in zinc fume fever in welders. ${ }^{80}$ Similarly, the toxicity and biopersistence of carbon nanotubes can be reduced by improving their solubility through a surface functionalization process with polyethylene glycol. ${ }^{81}$ Interestingly, it was observed that the shedding of $\mathrm{Zn}^{2+}, \mathrm{Cu}^{2+}, \mathrm{Cd}^{2+}$, and $\mathrm{Ag}^{+}$during intracellular dissolution can trigger mitochondrial perturbation, lysosomal damage, calcium flux, cytoskeletal alterations, oxidative stress, and cell death. ${ }^{82-84}$ In general, when released in solution, these ions can either be endocytosed by bacteria, be adsorbed onto the surface of the NPs, or undergo hydrolysis which yields insoluble metal hydroxides. ${ }^{85-88}$ These actions would directly or indirectly result in disruption of bacterial cellular processes through halting cell wall synthesis, disintegrating bacterial membranes, disrupting biofilms, destabilizing ribosomes, degrading DNA, peroxidizing lipids, or by disrupting membrane permeability. ${ }^{89}$ 


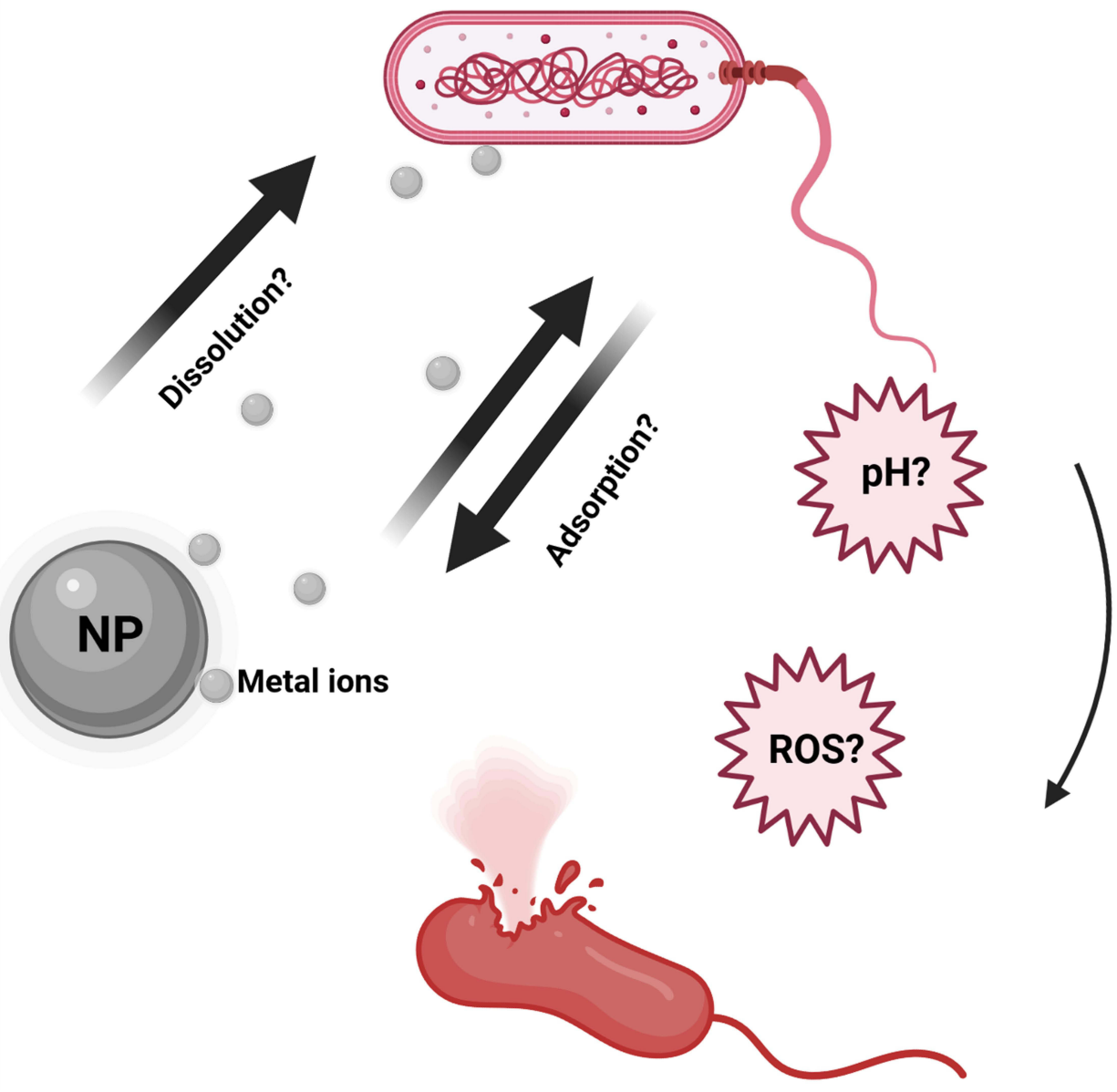

Figure 2 Illustration of possible NP toxicity mechanisms.

Wang et al reported that NP dissolution, adsorption, and hydrolysis are key factors which are likely to influence how metal ions are released by metal oxide NPs
(Figure 3). ${ }^{90}$ According to that study, the concentration of NPs in solution is initially correlated with the released metal ion concentrations; however, the free metal ion

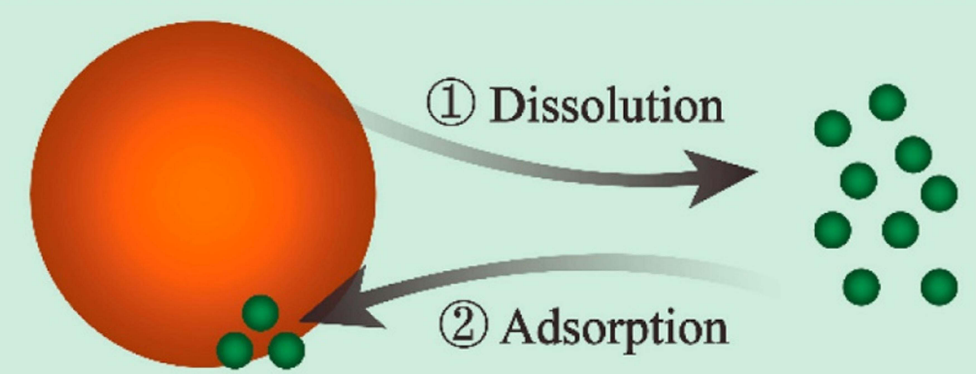

(3) Hydrolysis

$\odot(\mathrm{OH}) \mathrm{n}$

Figure 3 Schematic illustration of NPs dissolution, adsorption and hydrolysis. Reprinted from J Hazard Mater, 308, Wang D, Lin Z, Wang T, et al. Where does the toxicity of metaloxide nanoparticles come from: the nanoparticles, the ions, or a combination of both? 328-334, Copyright (2016), with permission from Elsevier. ${ }^{90}$ 
concentrations in the media at some point becomes limited via a hydrolysis process by the formation of insoluble metal hydroxides. Furthermore, the study showed that when the concentration of NPs in a medium is low, more metal ions are released, because dissolution is increased, but with a higher NP concentration, NP adsorption tends to occur and metal ions are adsorbed onto the surface of the NPs, thereby leading to a decline in available metal ions in the aqueous medium. It was observed by Wang et al that when the $\mathrm{CuO} N \mathrm{NP}$ concentration exceeded $180 \mathrm{mg} / \mathrm{L}$, there were declines in both free $\mathrm{Cu}^{2+}$ in the supernatant and the resultant antibacterial activity. In a related study, Baek et al while studying the effects of free ions released by a group of NPs in liquid media, discovered that the dissolution rate of the NPs in the aqueous medium decreased with an increase in the NP concentration; this they attributed to aggregation of the NPs in the medium. ${ }^{91}$ Given that the modes of bactericidal effects of some NPs still remain unclear, any study to assess the bactericidal mechanisms of NP dissolution, adsorption, or aggregation properties must be carefully designed to consider other physicochemical properties which also influence the release of metal ions from NPs in biological media.

\section{NP Size/Surface Morphology and Metal Ion Release}

NP surface morphology, size, surface area, surface coatings, and the degree of aggregation and agglomeration were identified as some factors that can determine the rate of ROS generation and toxicity of a nanomaterial (Figure 4). ${ }^{92}$ Several studies tried to explain how the size and surface morphology affect particle dissolution. For example, some studies reported that particles of different sizes and shapes of the same material at an equivalent dissolved solute concentration dissolved at different rates. ${ }^{93,94} \mathrm{NP}$ dissolution is a dynamic process defined by the migration of dissolving NPs

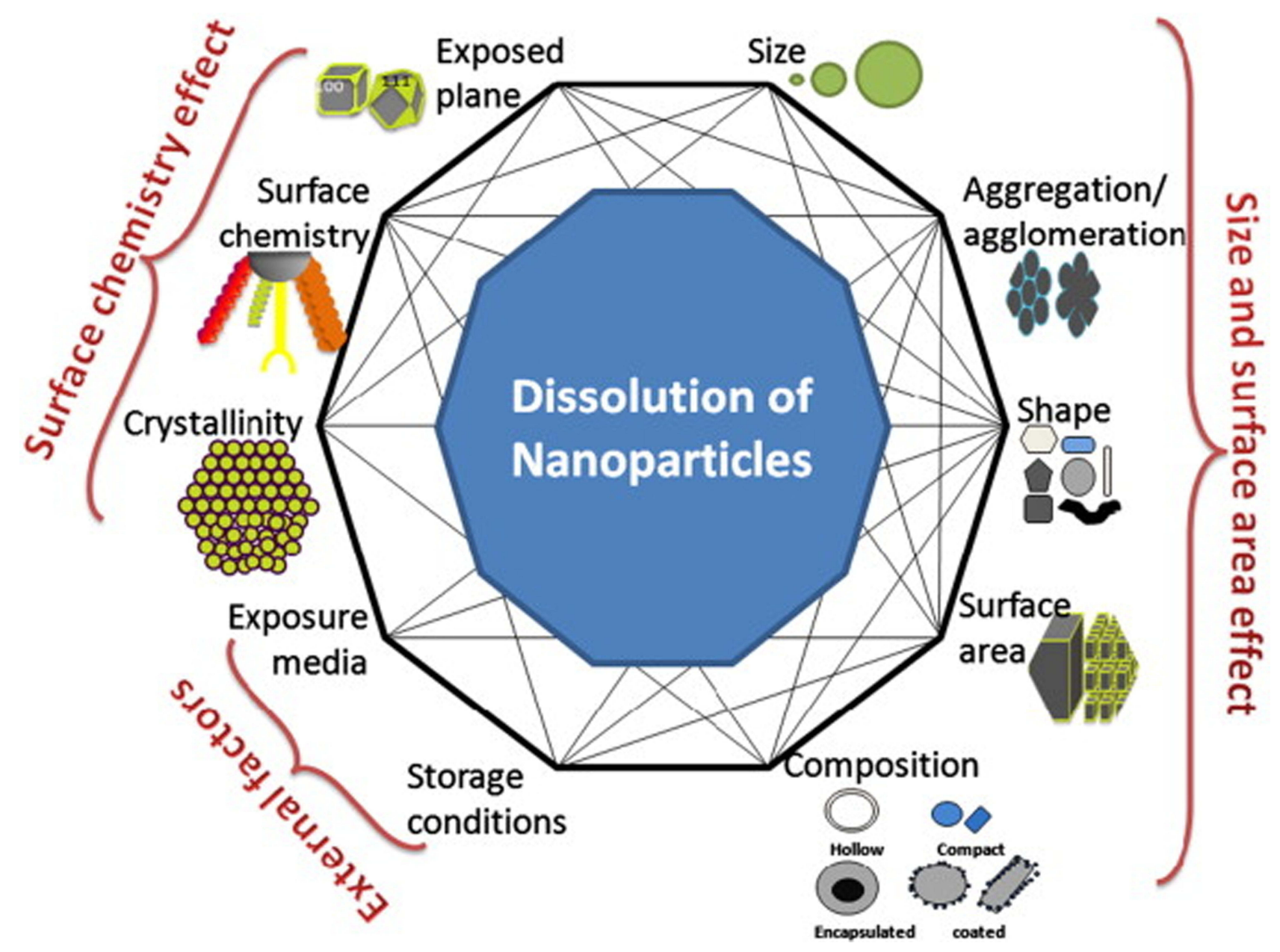

Figure 4 Schematic representation of several factors that can influence NPs behavior in solutions. Reprinted from Sci Total Environ, 438, Misra SK, Dybowska A, Berhanu D, et al. The complexity of nanoparticle dissolution and its importance in nanotoxicological studies. 225-232. Copyright 2012, with permission from Elsevier. ${ }^{92}$ 
through a diffusion/stagnant layer. ${ }^{95}$ The diffusion layer is simply an interface between the NP surface and the aqueous environment. This layer is very important because in addition to the intrinsic solubility of the NPs, dissolution also depends on the concentration gradient that exists across this layer. In other words, as the concentration in the aqueous solution reaches equilibrium, the dissolution process decreases and hence metal ion release declines. The kinetics of NP dissolution in aqueous medium can be described using the NoyesWhitney equation. This equation shows that the dissolution rate constant is dependent on the surface area of the NP. It was reported that a decreasing particle size is directly proportional to a decrease in the thickness of the diffusion layer, hence solvated molecules move faster throughout the bulk solution. In other words, with a larger surface area morphology, faster dissolution of NPs is expected as a result of a thinner diffusion layer; however, with thicker diffusion layers, dissolution will be slower. This can contextually explain why snowflake $\mathrm{ZnO}$ particles seem to be the most active when compared to other $\mathrm{ZnO}$ morphologies. ${ }^{96} \mathrm{ZnO}$ nanocrystals with a hexagonal plate-like morphology showed better activity than those with a rod-shaped morphology. ${ }^{97}$ Similarly, Cha et al also reported that when compared to nanoplates and nanospheres, $\mathrm{ZnO}$ nanopyramids showed superior antibacterial activity against methicillin-resistant Staphylococcus aureus (MRSA). ${ }^{98}$

Those studies provide clues as to how different NP morphologies can influence antibacterial activity. Dissolution studies alone cannot satisfactorily be used to explain why some morphologies of NPs exert greater antibacterial effects than others or why NPs that are smaller in size have higher antibacterial activity than larger ones. ${ }^{99,100}$ This is because not all NPs show good dissolution characteristics in aqueous media, yet these NPs show bactericidal properties. In other words, for less-soluble NPs, other factors with or without metal ion release can contribute to their toxicity and ability to generate ROS (Figure 5). Other critical factors which were also identified include the presence of

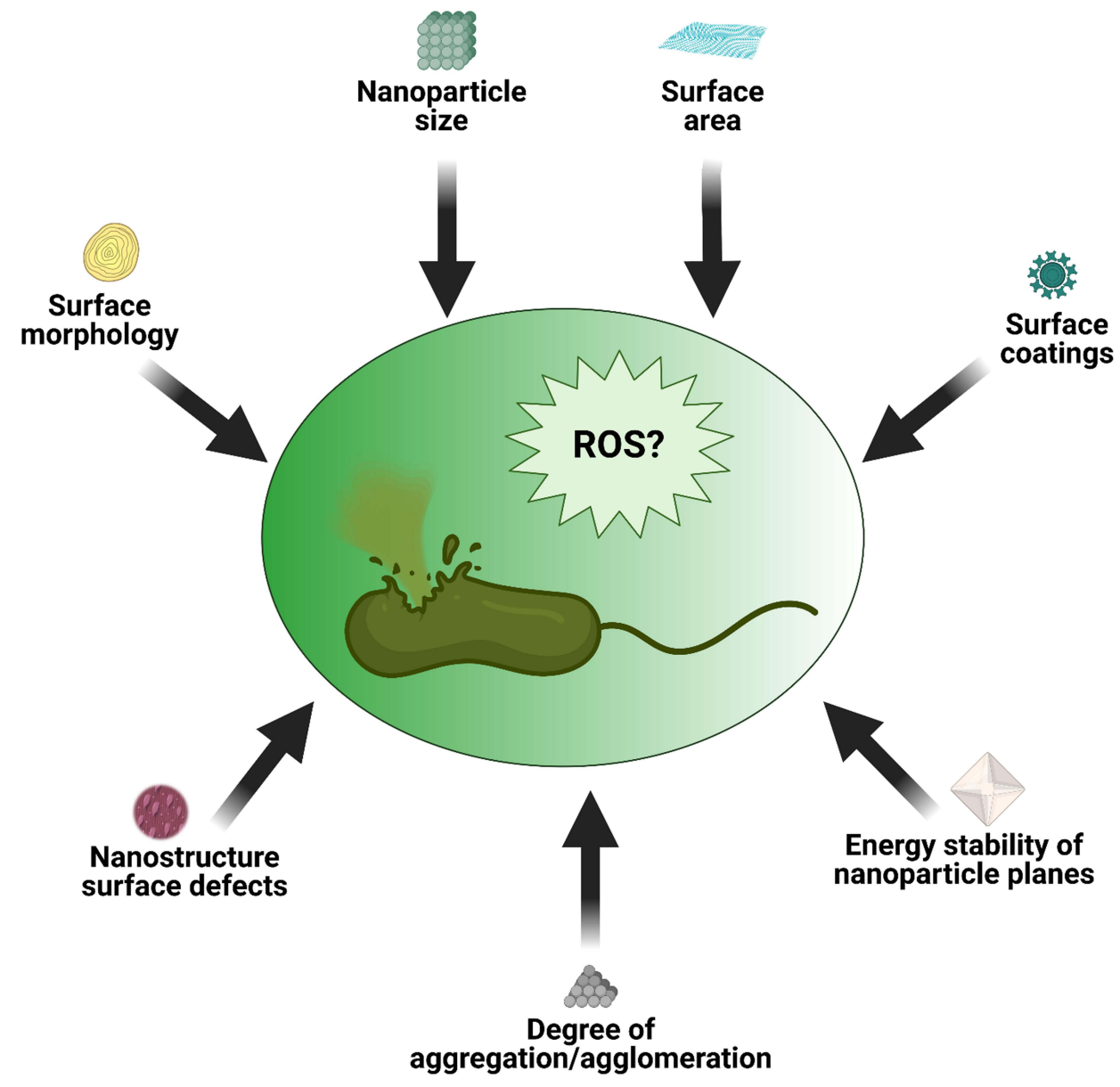

Figure 5 Schematic illustration of some NP characteristics capable of inducing ROS and subsequent bacteria death. 
surface defects on the nanostructure of the NPs and the energy stability of the NP planes. ${ }^{101,102}$ According to those studies, surface defects on the NP nanostructure increases the surface area-to-volume ratio which influences ROS generation, whereas analysis of exposed facets (which explains why less-stable planes require less energy to form oxygen vacancies) was utilized to link the bactericidal effects of some NP to the stability of planes.

\section{NP Charge and Metal lon Release}

It was also observed that the degree of electrostatic interaction between the NP and bacterial surface can also influence the bactericidal effects. It was reported that positively charged NPs can alter the function of the bacterial electron transport chain. In a study where $\mathrm{TiO}_{2}$ and gold (Au) NPs were surface-modified, greater toxicity toward microbial cells was observed. ${ }^{103,104}$ The NPs of Ag and Zn for example are known to exert their bactericidal effects by the respective release of $\mathrm{Ag}^{+}$and $\mathrm{Zn}^{2+105,106}$ These positively charged ions are electrostatically attracted to negatively charged lipopolysaccharide (LPS) in bacterial cell walls causing disruption of the electrochemical gradient across the bacterial membrane leading to cell death. $\mathrm{Ag}^{+}$, for example, can interact with sulfhydryl groups in microbial cells making them dysfunctional, which in turn can lead to cell death. Furthermore, exposure of bacteria to positively charged NPs can generate ROS which induce oxidative stress in bacteria. ${ }^{107,108}$ In order to predict the electrostatic behavior of an NP toward an organism, it is vital to consider the NP's point of zero charge. This point of zero charge is defined as the $\mathrm{pH}$ at which the charge on the surface of the NP becomes neutral. For example, at a $\mathrm{pH}$ value which is below the NP's point of zero charge, a metal oxide NP has a positively charged surface, whereas at a $\mathrm{pH}$ value above this point of zero charge, the NP has a negatively charged surface. This is very important when predicting antibacterial effects of an NP, because positively, neutrally, and negatively charged NPs respectively
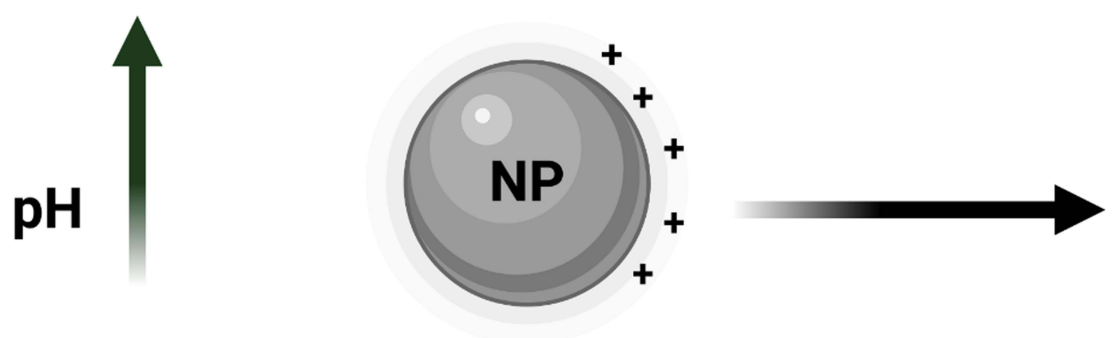

\section{Point of Zero Charge}
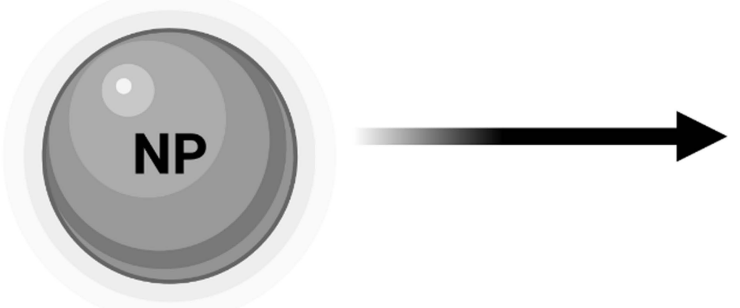
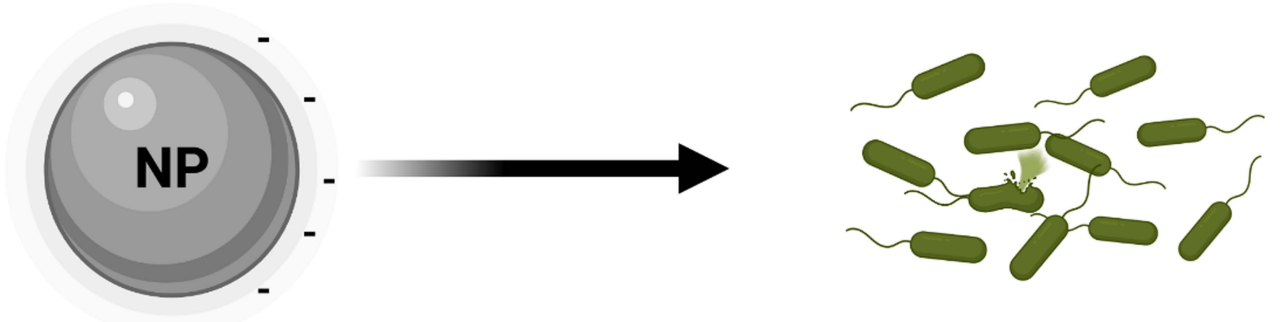

Figure 6 Schematic illustration of point of zero charge/NPs surface charge affects NPs bactericidal effects. 
exhibit strong, medium, and low bactericidal effects (Figure 6).

The $\mathrm{pH}$ value of the environment in which the NP exists was shown to influence the bactericidal outcome of the NP. Wang et al reported that $\mathrm{ZnO}$ NPs exhibited excellent dissolution properties at lower $\mathrm{pH}$ values. In other words, $\mathrm{Zn}^{2+}$ was rapidly released in aqueous media whose $\mathrm{pH}$ was acidic than in neutral and alkaline solutions. ${ }^{109}$ Similarly, Bian et al earlier described how a lower $\mathrm{pH}$ favors high dissolution and hence metal ion release. ${ }^{110}$ However, $\mathrm{MgO}$ and $\mathrm{CaO}$ were found to exert very strong bactericidal characteristics at very high $\mathrm{pH}$ conditions. Dong et al showed that at $\mathrm{pH} 10, \mathrm{a} \mathrm{Mg}$ $(\mathrm{OH})_{2}$ NP suspension triggered strong bactericidal effects on E. coli; ${ }^{111}$ the same was also observed with a $\mathrm{Ca}(\mathrm{OH})_{2}$ suspension. ${ }^{112}$ The high alkalinity of $\mathrm{MgO}$ and $\mathrm{CaO}$ which results in their strong bactericidal properties could be linked to their instability in water, which leads to the formation of the hydroxides, $\mathrm{Mg}(\mathrm{OH})_{2}$ and $\mathrm{Ca}(\mathrm{OH})_{2}$, in the presence of water, hence, reactive oxygen species are easily generated and are toxic to bacteria.

\section{Metal Ions Release and Infection Sites}

One of the recent bioapplications of metal ion release is in the design of pit and fissure sealants which yielded high fluoride ion release and a strong antimicrobial performance. Fei et al reported a very good antibacterial effect against Streptococcus mutans (S. mutans) biofilms from a pit and fissure sealant which was designed by combining calcium fluoride NPs and dimethylaminohexadecyl (DMAHDM). ${ }^{65}$ This combination yielded more ions, increased biofilm $\mathrm{pH}$, and improved antibacterial action against $S$. mutans biofilms compared to existing commercial units, hence making it a promising dental material for dental caries prevention. Similarly, Zhou et al also reported a multifunctional composite containing DMAHDM and amorphous calcium phosphate NPs as a dental material against recurrent dental caries. $^{113}$ This composite inhibited the growth of $S$. mutans biofilms, and yielded less enamel demineralization and good enamel hardness. Furthermore, Rawashdeh et al incorporated an ionic solution/colloidal suspension of metallic NPs of Ag, $\mathrm{Cu}$, and $\mathrm{Li}$ with some dental materials and tested the resulting antibacterial effect on $S$. aureus. They reported a dental material-dependent antibacterial outcome. The metal ionincorporated dental materials showed high antibacterial effects which were attributed to the release of $\mathrm{Ag}^{+}, \mathrm{Cu}^{2+}$, and $\mathrm{Li}^{+}$metal ions from the dental materials.

Kumar et al also reported fabrication of polyvinyl alcoholand CS-loaded AgNP hydrogels with good mechanical strength, antibacterial properties, and biocompatibility for wound dressings. ${ }^{66}$ The material showed good inhibition toward $S$. aureus and E. coli. Li et al showed that silver NPloaded collagen chitosan (CS) dressing (AgNP-CCD) can yield excellent antibacterial effects and play a good role in the healing of a second-degree burns. ${ }^{67}$ In that study, AgNPCCD showed an antibacterial rate of $>99 \%$ against $E$. coli, Sta. aureus, and Pseudomonas aeruginosa when the concentration of silver NPs exceeded $0.3 \mathrm{mg} / \mathrm{cm}^{2}$. Similarly, Paterson et al reported the use of copper-containing mesoporous glass NPs with antibacterial and proangiogenic effects for chronic wounds. ${ }^{68}$ The efficacy of this material was attributed to the release of $\mathrm{Cu}^{2+}$ ions which showed both proangiogenic and antibacterial properties.

The concept of metal ion release was incorporated into the design of implants with improved bactericidal properties. Hengel et al explored the synergistic antibacterial capabilities of $\mathrm{Ag}$ and $\mathrm{Cu}$ NPs by functionalizing $\mathrm{TiO}_{2}$ surfaces with those NPs. ${ }^{69}$ They observed a 10-fold reduction in the concentration of silver ions while sustaining the same level of antibacterial activity on MRSA. Their work sheds light on how the synergistic antibacterial properties of some metal ions can be harnessed to design more-biocompatible implants with efficient antibacterial effects. It was also observed that reinforcing alloys with silicon carbide ( $\mathrm{SiC}$ ) which is hemocompatible and biocompatible and has good antibacterial qualities, can be very useful in improving the performance of some medical equipment. Javadhesari et al showed that $\mathrm{TiCu} / \mathrm{SiC}$ nanocomposites showed good bactericidal effects against $E$. coli and $S$. aureus. $^{70}$ This observed bactericidal effect was due to the release of $\mathrm{Cu}^{2+}$ which was directly proportional to the amount of $\mathrm{SiC}$. At the end of this part, we have collected recent achievements by the uses of metal ion release in antibacterial applications as shown in Table 1.

\section{Photodynamic Antibacterial Activity Overview of Photodynamic Therapy}

Light-activated materials have long been in use to treat diseases, and for the past 100 years, this has been called photodynamic therapy (PDT). PDT needs two elements to be functional: light and a material or chemical entity that can be sensitized by ultraviolet (UV) or visible regions of the electromagnetic spectrum of light irradiation. The mechanism of action is characterized by two kinds of oxygen molecules: the triplet state of oxygen (type I reaction mechanism) and the singlet state of oxygen (type II 
Table I Summary of NPs and Their Reported Mechanisms of Toxicity

\begin{tabular}{|c|c|c|}
\hline Nanomaterial & Mechanism of Toxicity & Reference \\
\hline $\mathrm{Ag}_{2} \mathrm{O}$ & Metal ion release, direct contact with the bacterial cell envelope, ROS generation & [52] \\
\hline $\mathrm{CuO}$ & Metal ion release, direct contact with the bacterial cell envelope, ROS generation & {$[52,114]$} \\
\hline $\mathrm{Cu}_{2} \mathrm{O}$ & Metal ion release, direct contact with the bacterial cell envelope, ROS generation & {$[52,114]$} \\
\hline $\mathrm{Al}_{2} \mathrm{O}_{3}$ & Direct contact with the bacterial cell envelope, ROS generation & {$[52]$} \\
\hline $\mathrm{NiO}$ & Metal ion release, ROS generation & [77] \\
\hline $\mathrm{MoO}_{3}$ & Metal ion release, ROS generation & [77] \\
\hline $\mathrm{WO}_{3}$ & Metal ion release, ROS generation & {$[77]$} \\
\hline $\mathrm{Y}_{2} \mathrm{O}_{3}$ & Protein adsorption ability, ROS generation & [77] \\
\hline $\mathrm{Co}_{3} \mathrm{O}_{4}$ & Effect from nanoparticles & {$[90]$} \\
\hline $\mathrm{Cr}_{2} \mathrm{O}_{3}$ & Effect from nanoparticles & [90] \\
\hline $\mathrm{MgO}$ & Direct contact with the bacterial cell envelope, ROS generation, high alkalinity & {$[111]$} \\
\hline $\mathrm{CaO}$ & Direct contact with the bacterial cell envelope, ROS generation, high alkalinity & [112] \\
\hline $\mathrm{ZnO}$ & Metal ion release, direct contact with the bacterial cell envelope, ROS generation & {$[115-117]$} \\
\hline $\mathrm{Fe}_{2} \mathrm{O}_{3}$ & Metal ion release, ROS generation & {$[118,119]$} \\
\hline
\end{tabular}

Abbreviations: $\mathrm{Ag}_{2} \mathrm{O}$, silver oxide; $\mathrm{ZnO}$, zinc oxide; $\mathrm{Fe}_{2} \mathrm{O}_{3}$, iron(III) oxide; $\mathrm{CuO}$, copper (II) oxide; $\mathrm{Cu}_{2} \mathrm{O}$, copper (I) oxide; $\mathrm{Al}_{2} \mathrm{O}_{3}$, aluminum oxide; $\mathrm{MgO}$, magnesium oxide; $\mathrm{CaO}$, calcium oxide; $\mathrm{NiO}$, nickel oxide; $\mathrm{MoO}_{3}$, molybdenum trioxide; $\mathrm{WO}_{3}$, tungsten trioxide; $\mathrm{Y}_{2} \mathrm{O}_{3}$, yttrium (III) oxide; $\mathrm{Co}_{3} \mathrm{O}_{4}$, cobalt tetraoxide; $\mathrm{Cr}_{2} \mathrm{O}_{3}$, chromium (III) oxide.

reaction mechanism). The type I reaction mechanism of triplet oxygen under light irradiation can generate ROS like hydroperoxyl $\left(\mathrm{HO}_{2}\right)$ and anionic superoxide $\left(\mathrm{O}_{2}^{-}\right)$ radicals and requires higher activation energy. The type II mechanism produces hydroxyl (OH) radicals and requires lower activation energy and is more readily available. Some metallic nanostructures and metal-organic frameworks (MOFs) have been extensively utilized due to their superior photocatalytic properties, low cost, and effective antibacterial activities. NPs under visible light irradiation is believed to be effective photocatalysts and can generate ROS for effective antibacterial activity (Figure 7). ${ }^{120-124}$

\section{Metallic Nanocomposites}

Nanocomposites of silver-zinc oxide $(\mathrm{Ag} / \mathrm{ZnO})$ showed notable bacteriostatic effects under visible light irradiation. ${ }^{125} \mathrm{In} \mathrm{Ag} / \mathrm{ZnO}$ nanocomposites, due to the localized surface plasmon resonance (SPR) property of silver, there is a very efficient electron-hole generation and reduction in the bandgap of $\mathrm{ZnO}$ which enhances the photocatalytic activity to counter bacterial growth by producing ROS. $^{126}$ The mechanism of action of $\mathrm{Ag} / \mathrm{ZnO}$ nanocomposites under visible light irradiation is the creation of oxygen vacancies on $\mathrm{ZnO}$ NPs to produce $\mathrm{H}_{2} \mathrm{O}_{2}$, and this was enhanced by combining with silver NPs. Oxygen from the atmosphere is absorbed onto the oxygen-vacant surface of the nanocomposite that bears electrons which react to produce superoxide radicals $\left(\mathrm{O}_{2}{ }^{-}\right)$. $\mathrm{O}_{2}{ }^{-}$undergoes a reaction with water $\left(\mathrm{H}_{2} \mathrm{O}\right)$ to form hydroperoxyl radicals $\left(\mathrm{HO}_{2}\right)$, and two $\mathrm{HO}_{2}$ molecules combine again to produce $\mathrm{H}_{2} \mathrm{O}_{2}$ in a cyclically repeating process. $\mathrm{H}_{2} \mathrm{O}$ splits into $\mathrm{H}^{+}$and $\mathrm{OH}^{-}$ions, and $\mathrm{OH}^{-}$ions generate hydroxyl $(\mathrm{OH})$ radicals (Figure 8). Electron paramagnetic resonance (EPR) studies validated the above-proposed mechanism for the efficient photocatalytic antibacterial activity of $\mathrm{Ag} / \mathrm{ZnO}$ nanocomposites. Furthermore, the rupture of cell membranes of both gram-positive and gramnegative bacteria is due to the destruction of the lipid layer by peroxidation after ROS are generated as determined by lipid peroxidation assays. ${ }^{127-131} \mathrm{Ag} / \mathrm{ZnO}$ nanocomposites were effective and promising antibacterial agents under visible light irradiation compared to bare $\mathrm{ZnO}$.

Recently, Mutalik et al reported that titanium dioxideiron disulfide $\left(\mathrm{TiO}_{2}-\mathrm{FeS}_{2}\right)$ nanocomposites are an efficient photocatalyst for antibacterial applications. ${ }^{132}$ The 


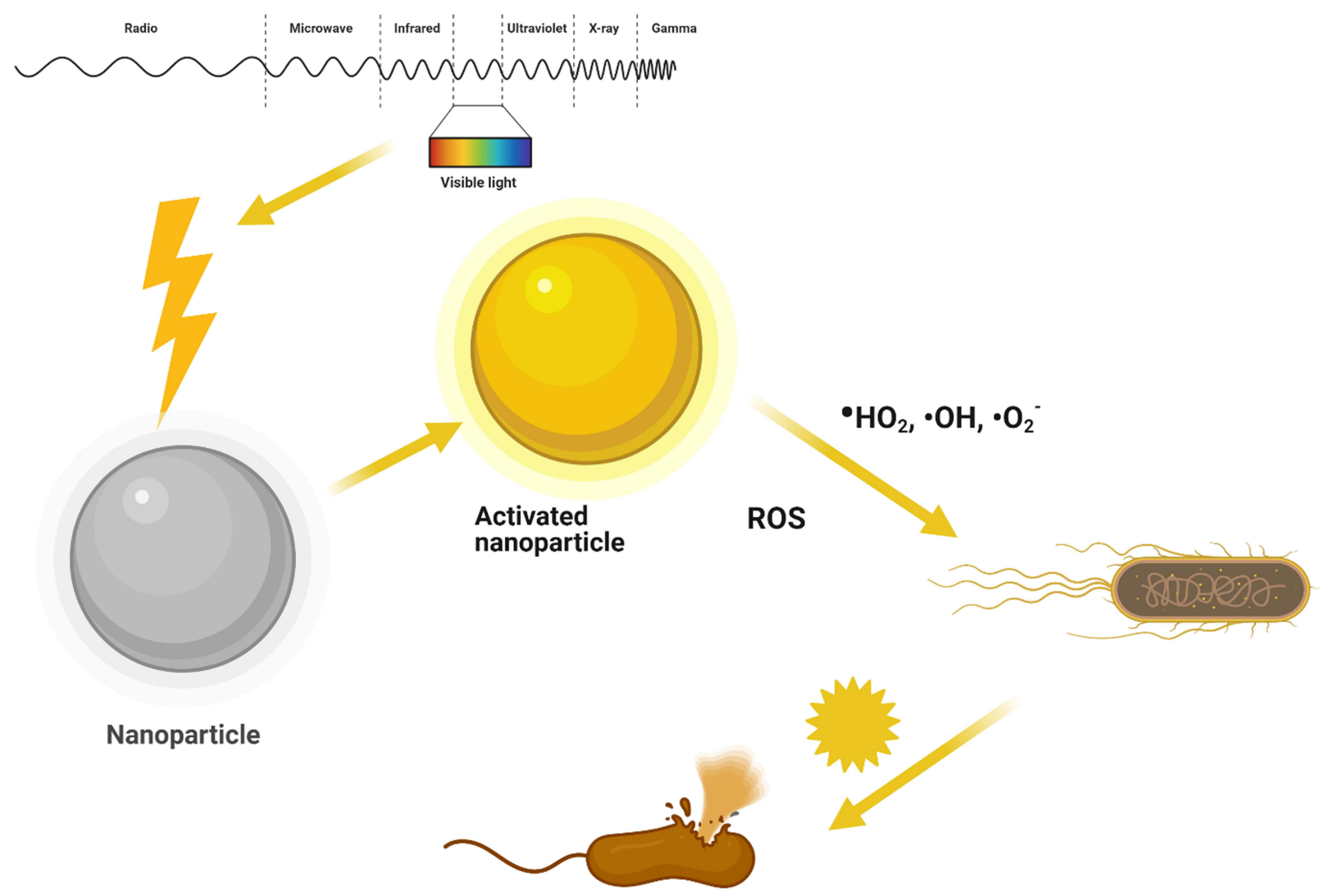

Figure 7 Schematic illustration of NP action of mechanism under light irradiation.

mechanism of action of the photocatalytic antibacterial activity is based on the conversion of anatase titanium dioxide to rutile titanium dioxide NPs by combining iron sulfide nanocrystals to form $\mathrm{TiO}_{2}-\mathrm{FeS}_{2}$ nanocomposites, which also expands the absorption of the nanocomposite from the UV region to the visible-near infrared (NIR) region of the electromagnetic spectrum. The bandgap of $\mathrm{FeS}_{2}$ is $0.95 \mathrm{eV}$ and that of $\mathrm{TiO}_{2}$ is $3.2 \mathrm{eV}$ when combined and irradiated with simulated solar light, and due to the reduction in the bandgap of $\mathrm{TiO}_{2}$, there was a substantial increase in the photocatalytic property which was shown to be effective in bacteriostasis against $E$. coli. The facile transfer of electrons from the valence band to the conduction band in $\mathrm{TiO}_{2}-\mathrm{FeS}_{2}$ nanocomposites effortlessly generates ROS to produce an efficient antibacterial effect. The $\mathrm{TiO}_{2}$ in $\mathrm{TiO}_{2}-\mathrm{FeS}_{2}$ nanocomposites was observed to intensify the absorption of the visible region of light from the UV region of the electromagnetic spectrum to produce light-prompted ROS radicals like $\mathrm{O}_{2}^{-}$and $\mathrm{OH}$ (Figure 9). The $\mathrm{O}_{2}^{-}$and $\mathrm{OH}$ radicals generated from $\mathrm{TiO}_{2}-\mathrm{FeS}_{2}$ nanocomposites were effective in inhibiting E. coli, compared to their counterparts used in those studies, by causing damage to the microbial cell envelope. ${ }^{133-138}$

Nanocomposites of Ag-ZnO-magnetite $\left(\mathrm{F}_{3} \mathrm{O}_{4}\right)$ showed better photocatalytic abilities for antibacterial applications under light-emitting diode (LED) irradiation. ${ }^{139} \mathrm{An} \mathrm{Ag-}$ $\mathrm{ZnO}-\mathrm{F}_{3} \mathrm{O}_{4}$ nanocomposite was synthesized using a green method. The reported mechanisms by which ROS are generated include the effective influence of the Fenton reaction of magnetite and SPR of silver under LED light irradiation, and these ROS substantially damage bacterial cell walls. In Figure 10, the SPR effect of silver and silver combined with $\mathrm{ZnO}$ induce the production of superoxide radicals and narrows the bandgap of $\mathrm{ZnO}$ for swift and easy electron transfer from the valence band to the conduction band of $\mathrm{ZnO}$. The effortless heterojunction transfer of electrons with magnetite facilitates the easy generation of hydroxyl radicals under LED illumination. The $\mathrm{O}_{2}{ }^{-}$and $\mathrm{OH}$ radicals produced by the Ag- $\mathrm{ZnO}-\mathrm{F}_{3} \mathrm{O}_{4}$ nanocomposite under LED light irradiation were efficient 


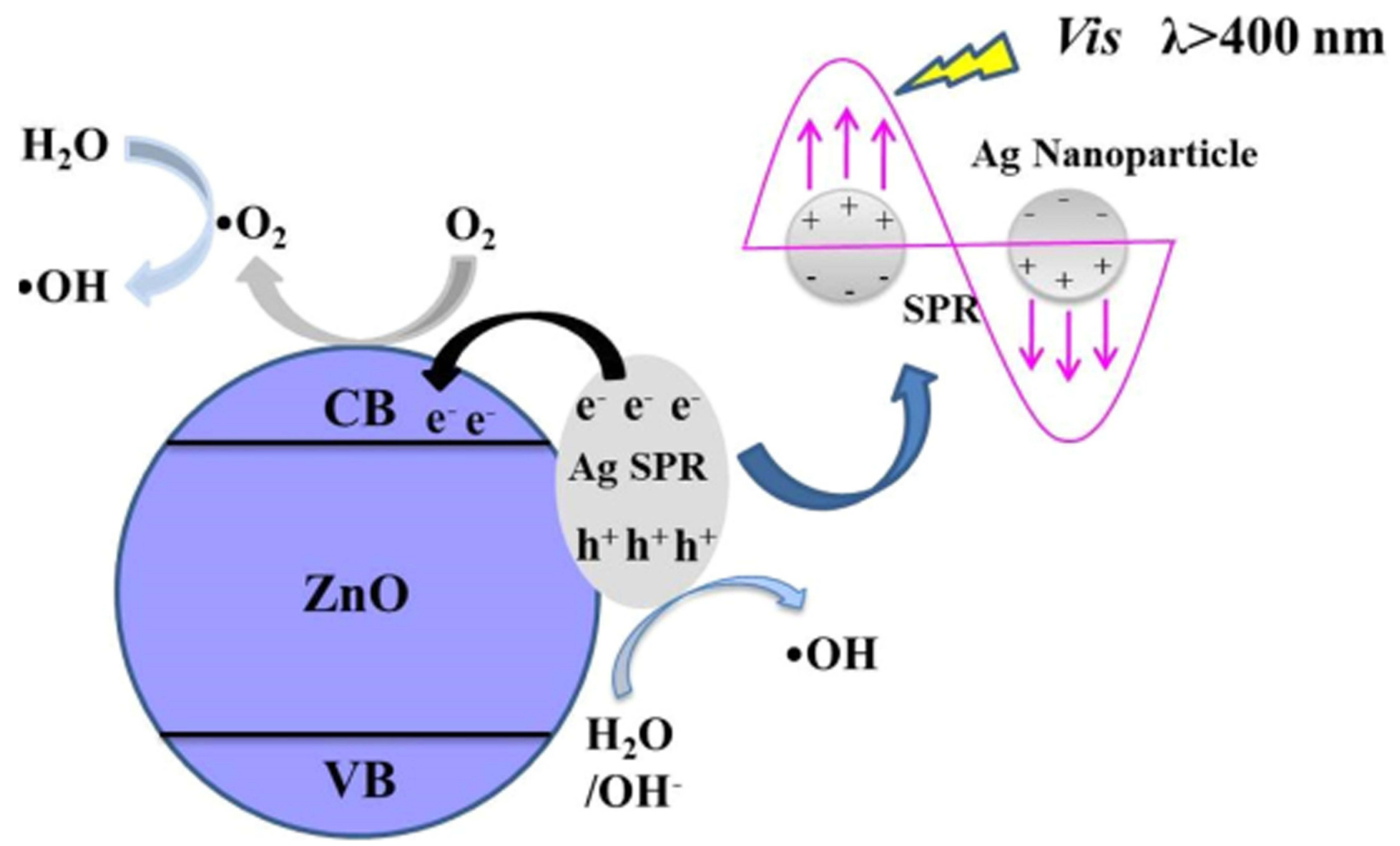

Figure 8 Antibacterial mechanism of Ag/ZnO nanocomposites under light visible light irradiation. Reprinted from Catal Today, 339, Liu Q, Liu E, Li J, et al. Rapid ultrasonicmicrowave assisted synthesis of spindle-like $\mathrm{Ag} / \mathrm{ZnO}$ nanostructures and their enhanced visible-light photocatalytic and antibacterial activities. $39 \mathrm{I}-402$. Copyright 2020 , with permission from Elsevier. ${ }^{125}$

Abbreviations: VB, valence band; $C B$, conduction band; SPR, surface plasmon resonance.

in inhibiting MRSA and Sta. epidermidis. Electrons and hole pairs are enhanced, and $\mathrm{H}_{2} \mathrm{O}_{2}$ is the end product of the $\mathrm{Ag}-\mathrm{ZnO}-\mathrm{F}_{3} \mathrm{O}_{4}$ nanocomposite due to the presence of silver, which in turn enhances the antibacterial efficiency. The Fenton reaction generated $\mathrm{OH}$ radicals to support and enhance the bacterial inhibition under LED irradiation for 3 h. $^{140-145}$

Nanocomposites of Ag NPs and bismuth vanadium tetraoxide $\left(\mathrm{BiVO}_{4}\right)$ nanosheets cultivated on the surface of silver vanadium trioxide $\left(\mathrm{AgVO}_{3}\right)-\left(\mathrm{Ag} @ \mathrm{AgVO}_{3} / \mathrm{BiVO}_{4}\right)$ showed elevated photocatalytic efficiency against rhodamine B dye, E. coli, and Sta. aureus under simulated solar light irradiation. ${ }^{146}$ Figure $11 \mathrm{~A}-\mathrm{C}$ exhibit a general proposal for a mechanism to eliminate bacteria under visible light irradiation. In Figure 11A, the SPR effect of Ag NPs is showcased as a primary cause of the antibacterial effect under visible light irradiation. In Figure 11B, after combining and arranging $\mathrm{Ag} \mathrm{NPs}$ with $\mathrm{BiVO}_{4}$ and $\mathrm{AgVO}_{3}$, the photocatalytic efficiency improved under visible light irradiation. In Figure 11C, the Z-scheme arrangement of
$\mathrm{Ag} @ \mathrm{AgVO}_{3} / \mathrm{BiVO}_{4}$ nanocomposites showed improved light-activated antibacterial activity by generating active $\mathrm{O}_{2}{ }^{-}$and $\mathrm{OH}$ radicals under visible light irradiation, that was not possible in the former arrangement of $\mathrm{Ag} @ \mathrm{AgVO}_{3} / \mathrm{BiVO}_{4}$ nanocomposites. An increase in the concentration of $\mathrm{Ag} @ \mathrm{AgVO}_{3} / \mathrm{BiVO}_{4}$ nanocomposites also showed an improvement in the photo-activated antibacterial effect. Under light irradiation, the $\mathrm{Ag} @ \mathrm{AgVO}_{3} / \mathrm{BiVO}_{4}$ nanocomposite (molar ratio $=0.2$ ) and $\mathrm{z}$-scheme arrangement produced microbial cell wall destruction of $E$. coli and Sta. aureus and dye degradation. ${ }^{147-152}$

Recently, ZnO-selenium (Se) nanocomposites showed effective photocatalytic activity in antibacterial applications under visible light irradiation. ${ }^{153}$ Figure 12 shows penetration of the cell envelope of the pathogen Sta. aureus, the impairing mechanism by $\mathrm{ZnO}$-Se nanocomposites under visible light irradiation due to ROS generation, and a biological pathway. Furthermore, ZnO-Se nanocomposites were found to be more efficient against Sta. aureus compared to $\mathrm{ZnO}$ NPs alone, as evaluated by the zone of 


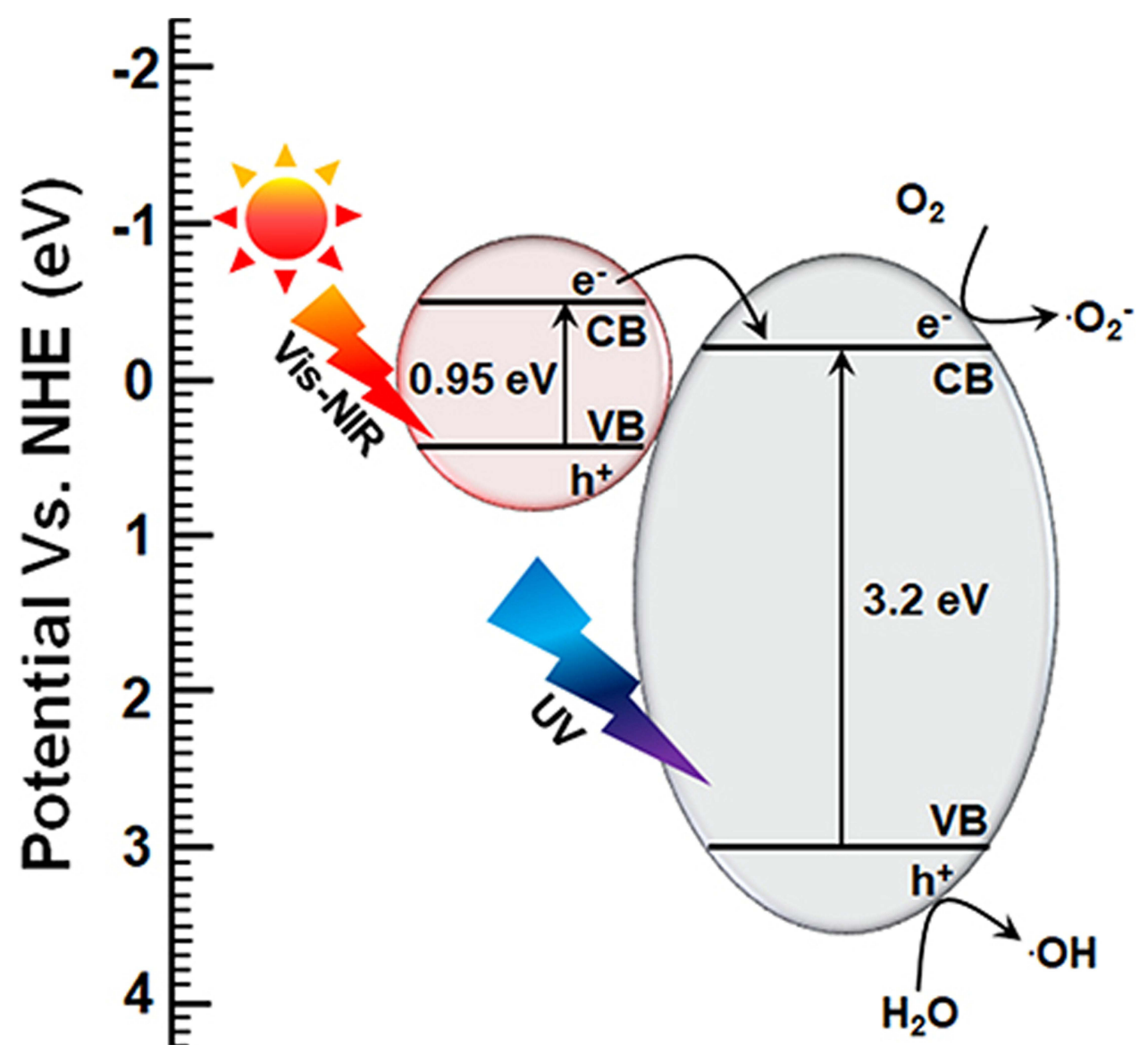

Figure 9 Antibacterial mechanism of $\mathrm{TiO}_{2}-\mathrm{FeS}_{2}$ nanocomposites under visible light irradiation by narrowing bandgap. Reproduced with permission from Dove Medical Press Limited. Mutalik C, Hsiao YC, Chang YH, et al. High uv-vis-nir light-induced antibacterial activity by heterostructured TiO2-FeS2 I470nanocomposites. Int J Nanomed. 2020;15:8911..'32

Abbreviations: VB, valence band; $C B$, conduction band.

inhibition which was found to be significantly greater in the case of $\mathrm{ZnO}-\mathrm{Se}$ nanocomposites under visible light irradiation. Moreover, bacterial cell death by selenium is believed to be internally induced by proteins, and ROS generated by $\mathrm{ZnO}$ cause substantial rupture of microbial cell walls under visible light irradiation. ${ }^{154-157}$

\section{Carbon-Based Nanocomposites}

In Figure 13, nanocomposites of graphitic carbon nitride/chromium $\left(\mathrm{g}-\mathrm{C}_{3} \mathrm{~N}_{4} / \mathrm{Cr}\right.$ )- $\mathrm{ZnO}$ showed exceptional photocatalytic properties in antibacterial applications. ${ }^{158}$ Under simulated solar irradiation, g- $\mathrm{C}_{3} \mathrm{~N}_{4} / \mathrm{Cr}-\mathrm{ZnO}$ nanocomposite showed an improved photocatalytic mechanism by reducing the bandgap and improved electron-hole regeneration to generate ROS to eradicate bacteria by substantially damaging bacterial cell

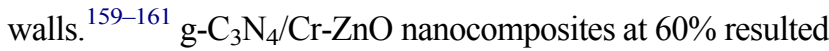
in more-efficient inhibition of E. coli, Sta. aureus, Bacillus subtilis, and Str. salivarius compared to its $60 \% \mathrm{~g}^{-} \mathrm{C}_{3} \mathrm{~N}_{4} / \mathrm{ZnO}$, $5 \% \mathrm{Cr}-\mathrm{ZnO}, \mathrm{g}_{-} \mathrm{C}_{3} \mathrm{~N}_{4}$, and $\mathrm{ZnO}$ counterparts under visible light irradiation. The photogenerated holes and electrons react with oxygen and water molecules present on the surface of the g- $\mathrm{C}_{3} \mathrm{~N}_{4} / \mathrm{Cr}-\mathrm{ZnO}$ nanocomposite to generate $\mathrm{O}_{2}{ }^{-}$and $\mathrm{OH}$ radicals. The ideal separation of electron-hole pairs and also less dense $\mathrm{g}_{-} \mathrm{C}_{3} \mathrm{~N}_{4}$ sheets induce effortless electron transfer from the valence band to the conduction band for effective generation of ROS under visible light irradiation. ${ }^{160,162}$ The g- $\mathrm{C}_{3} \mathrm{~N}_{4} /$ $\mathrm{Cr}-\mathrm{ZnO}$ nanocomposite exhibited better photocatalytic performance under visible light irradiation, and the increased existence of electron-hole pairs enhanced ROS generation to eliminate bacteria and also degrade organic dyes responsible for pollution.

A recently reported copper sulfide-conjugated protonated $\mathrm{C}_{3} \mathrm{~N}_{4}(\mathrm{CuS} / \mathrm{PCN})$ composite showed enhanced antibacterial activity under the dual effects of visible light irradiation and a photothermal effect. ${ }^{163}$ The antibacterial mechanism of CuS/PCN was observed against both grampositive and gram-negative bacteria under visible light irradiation. In Figure 14, the mechanism of ROS 


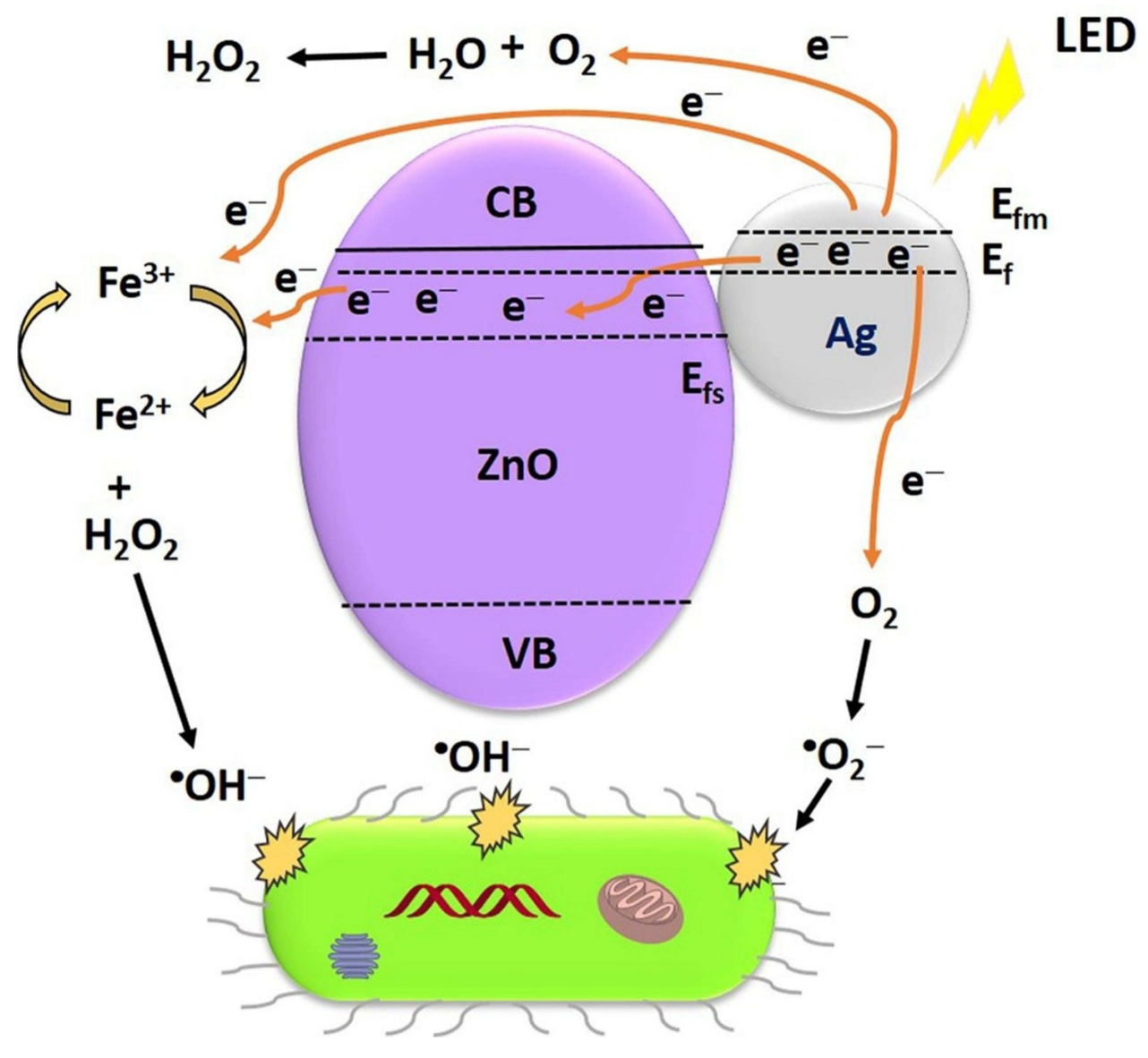

Figure 10 Antibacterial mechanism of $\mathrm{Ag}-\mathrm{ZnO}-\mathrm{F}_{3} \mathrm{O}_{4}$ nanocomposites under LED light irradiation. Reprinted from Appl Surf Sci. 527, Abutaha N, Hezam A, Almekhlafi FA, et al. Rational design of Ag-ZnO-Fe3O4 nanocomposite with promising antimicrobial activity under led light illumination. 146893, Copyright 2020, with permission from Elsevier. ${ }^{139}$

Abbreviations: VB, valence band; $C B$, conduction band; SPR, surface plasmon resonance.

generation under visible light irradiation is demonstrated. $\mathrm{CuS}$ and PCN form heterojunctions for the effortless transfer of electrons, and this combination reduces the bandgap. Electron transfer from the valence band to the conduction band facilitates charge separation in CuS/PCN composites under visible light irradiation. The adsorbed atmospheric oxygen molecules on both $\mathrm{CuS}$ and PCN during electron transfer are changed into $\mathrm{O}_{2}{ }^{-}$and $\mathrm{OH}$ radicals under visible light irradiation causing observable destruction of microbial cell membranes. The lower bandgap of $\mathrm{CuS}$ influences the higher bandgap of PCN to enhance the photocatalytic properties and production of ROS from $\mathrm{CuS} / \mathrm{PCN}$ composites under visible light irradiation. Electron spin resonance (ESR) studies confirmed and validated the photodynamic ROS production from $\mathrm{CuS} / \mathrm{PCN}$ composites. The photoactive $\mathrm{CuS} / \mathrm{PCN}$ composite had effective bacteriostatic properties against both Sta. aureus and E. coli. ${ }^{164-167}$

$\mathrm{Fe}_{3} \mathrm{O}_{4} @ \mathrm{SiO} @ \mathrm{Ag}_{3} \mathrm{PO}_{4} / \mathrm{ZnO}-10 \% \quad\left(\mathrm{Ag}_{3} \mathrm{PO}_{4}-10 \quad\right.$ wt $\left.\%\right)$ (FSZA2-10\%) microspheres showed enhanced photocatalytic efficiency against Sta. aureus and E. coli under visible light irradiation. ${ }^{168}$ Figure 15A and B explain the mechanistic pathway for the generation of ROS and components that induce effective ROS generation under visible light irradiation. In Figure 15A, two $\mathrm{Ag}_{3} \mathrm{PO}_{4}$ and $\mathrm{ZnO}$ nanohybrid composites are involved in generating desired radicals which cause substantial microbial cell wall damage (Figure 15B). ZnO NPs generate electrons and are transferred at heterojunctions with their partner $\mathrm{Ag}_{3} \mathrm{PO}_{4} \mathrm{NPs}$ that in turn generate $\mathrm{O}_{2}{ }^{-}$radicals under visible light irradiation and adsorb surface atmospheric oxygen. $\mathrm{Ag}_{3} \mathrm{PO}_{4} \mathrm{NPs}$ in combination with $\mathrm{ZnO}$ NPs in FSZA2-10\% microspheres generate electron holes to form 


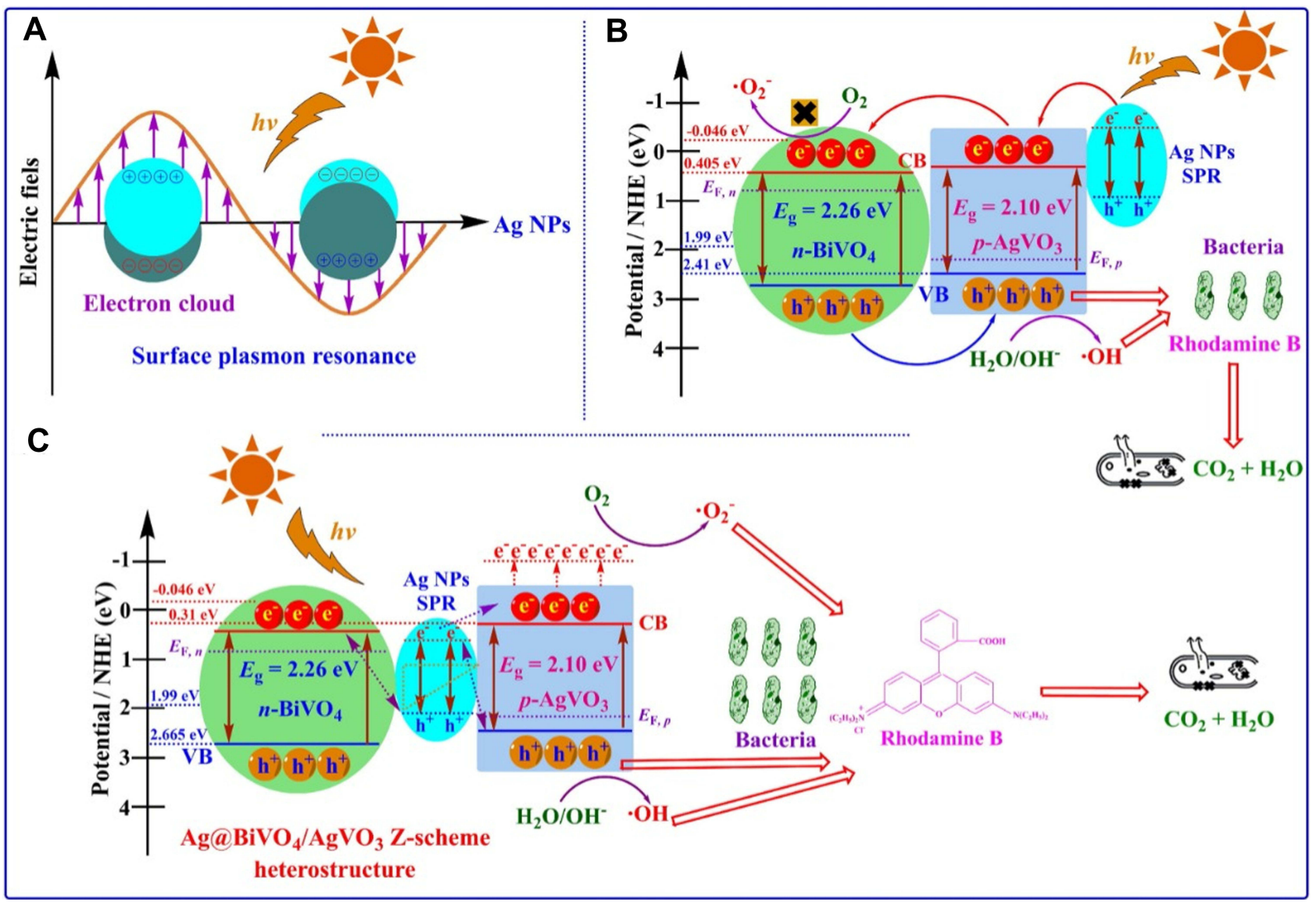

Figure I I Schematic illustration of SPR effect from $\mathrm{AgNPs}$ under visible light irradiation (A), the $\mathrm{Ag}$ position in $\mathrm{Ag} @ \mathrm{AgVO}_{3} / \mathrm{BiVO}{ }_{4}$ nanocomposites and performance under visible light irradiation (B), and Z-scheme arrangement of $\mathrm{Ag}$ in $\mathrm{Ag@AgVO} / \mathrm{BiVO}_{4}$ nanocomposites and performance under visible light irradiation (C). Reprinted from J Colloid Interface Sci. 579, Ju P, Wang Y, Sun Y, et al. In-situ green topotactic synthesis of a novel z-scheme Ag@agvo3/bivo4 heterostructure with highly enhanced visible-light photocatalytic activity. $43 \mathrm{I}-447$, Copyright 2020 , with permission from Elsevier. ${ }^{146}$

$\mathrm{OH}$ radicals under visible light irradiation. In FSZA2-10\% microspheres, $\mathrm{Ag}_{3} \mathrm{PO}_{4}$ and $\mathrm{ZnO}$ nanohybrids showed better electron-hole separation, and there was a narrowing of the valence band and conduction band for easy electron transfer and electron-hole generation at heterojunctions of $\mathrm{Ag}_{3} \mathrm{PO}_{4}$ $\mathrm{ZnO}$ which effectively produced ROS under visible light irradiation. Overall, FSZA2-10\% microspheres were effectively photoactive leading to bacterial cell membrane damage in Sta. aureus and $E$. coli under visible light irradiation and showed effective bacteriostasis for up to six cycles of reuse. ${ }^{169-172}$

Nanocomposites of $\mathrm{Ag} / \mathrm{Ag}_{3} \mathrm{PO}_{4}$ were combined with MOFs (MOF-5 or IRMOF-1), and a zinc-based MOF was synthesized by a hydrothermal process followed by a liquid chemical reduction method for antibacterial application under visible light irradiation. ${ }^{173}$ In Figure 16, the mechanistic pathway is functionalized by three components of $\mathrm{Ag}, \mathrm{Ag}_{3} \mathrm{PO}_{4}$, and IRMOF-1, and showed enhanced photocatalytic efficiency in producing bactericidal properties against $E$. coli and $S$. aureus. Nanocomposites of $\mathrm{Ag} / \mathrm{Ag}_{3} \mathrm{PO}_{4}$-IRMOF-1 radiated with light for $2 \mathrm{~h}$ at a concentration $200 \mu \mathrm{g}$ showed complete inhibition of gram-positive and gram-negative bacteria. In $\mathrm{Ag} / \mathrm{Ag}_{3} \mathrm{PO}_{4}$-IRMOF-1 nanocomposites, $\mathrm{Ag}$ operates through the SPR effect leading to the formation of synergistic electrons which are directly supplied to the IRMOF1 surface to activate ROS production to generate $\mathrm{O}_{2}{ }^{-}$ radicals and electron-holes generated by $\mathrm{Ag}_{3} \mathrm{PO}_{4}$ under simulated light irradiation. $\mathrm{Ag} / \mathrm{Ag}_{3} \mathrm{PO}_{4}$-IRMOF-1 showed sustained release of $\mathrm{Ag}^{+}$and $\mathrm{Zn}^{2+}$ ions under light irradiation to eliminate $E$. coli and Sta. aureus by disrupting their cell walls. To sum up, $\mathrm{Ag} / \mathrm{Ag}_{3} \mathrm{PO}_{4}$-IRMOF-1 nanocomposites were efficient at photo-actively inhibiting $E$. coli and $S$. aureus under visible light irradiation compared to their counterparts. ${ }^{174-179}$ In Table 2, we have summarized several examples according to light-driven nanomaterials for antibacterial applications. 


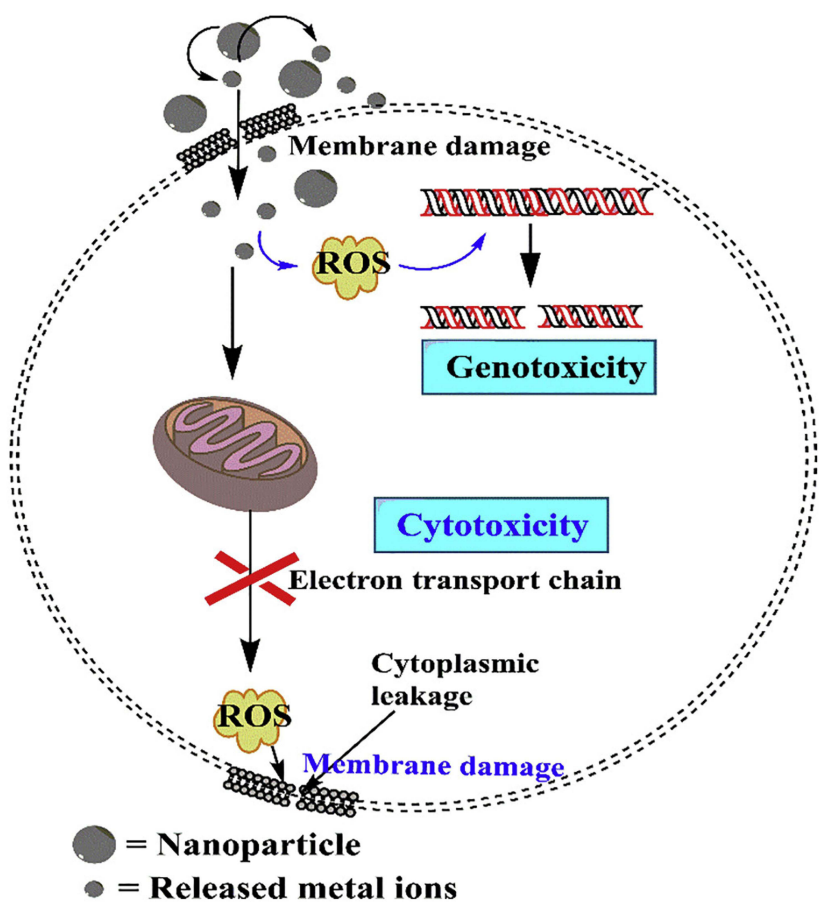

Figure 12 Schematic representation of antimicrobial mechanism of ZnO-Se nanocomposites under light irradiation. Reprinted from J Photochem Photobiol B, 203, Ahmad A, Ullah S, Ahmad W, et al. Zinc oxide-selenium heterojunction composite: synthesis, characterization and photo-induced antibacterial activity under visible light irradiation. III743, Copyright 2020, with permission from Elsevier. ${ }^{153}$

\section{Photothermal Therapy}

\section{Overview of Photothermal Therapy}

Among multiple methods developed as an alternative way to fight bacterial infections in response to antibiotic resistance, PTT occupies a prominent place. ${ }^{191-193}$ When photo-responsive agents are activated with a convenient NIR laser, the surface plasmon band leads to the conversion of electromagnetic radiation to heat. The resulting heat can reach temperatures able to destroy bacterial cells. The photothermal effect results in membrane damage followed by protein inactivation and/or leakage leading to bacterial death. ${ }^{194,195}$ PTT against bacteria is efficacious on both gram-positive and gram negative types and regardless of antibiotic resistance. In addition to its efficiency, it is fast, noninvasive, and can be modulated by the laser intensity and time of irradiation. More interestingly, PTT can be combined with other therapies such as PDT, chemotherapy, radiotherapy, and so on for better treatment results. Therefore, multiple photothermal NPs or nanostructures are being developed to eradicate bacterial infections. These photothermal NPs are also called PTAs and are grouped into five categories of metals, metal sulfides, oxides, carbon-based nanocomposites, small molecule-based nanomaterials, and polymeric nanomaterials. ${ }^{196,197}$ A set of transition metals and their oxide and sulfide forms can advantageously absorb more laser energy compared to inorganic PTAs. ${ }^{198,199}$ For instance, in our previous investigation of the photothermal effects on $E$. coli of gold nanorods (AuNRs) and gold nanobipyramids (AuNBPs), $100 \mu \mathrm{g} / \mathrm{mL}$ of AuNRs and $25 \mu \mathrm{g} / \mathrm{mL}$ of AuNBPs were used to kill $E$. coli with an efficiency of $100 \%$ after $808-\mathrm{nm}$ laser illumination for $7 \mathrm{~min} .^{200}$ The principle of antibacterial PTT is illustrated in Figure 17. Among the different approaches to reducing the heat effect with good efficiency, targeted delivery of PTAs, controlled release of PTAs, and combined therapy are described below.

\section{Approaches for the Targeted Delivery of PTAs}

Molybdenum disulfide $\left(\mathrm{MoS}_{2}\right)$ nanosheets are one of the nanomaterials with efficient photothermal performance. In addition to the efficiency, this nanomaterial can be stabilized when conjugated with other biomolecules. So, Wenbo Cao and colleagues fabricated molybdenum disulfide coated with polyethylenimine ( $\left.\mathrm{MoS}_{2}-\mathrm{PEI}\right)$ by means of covalent bonds in order to evaluate their photothermal antibacterial 


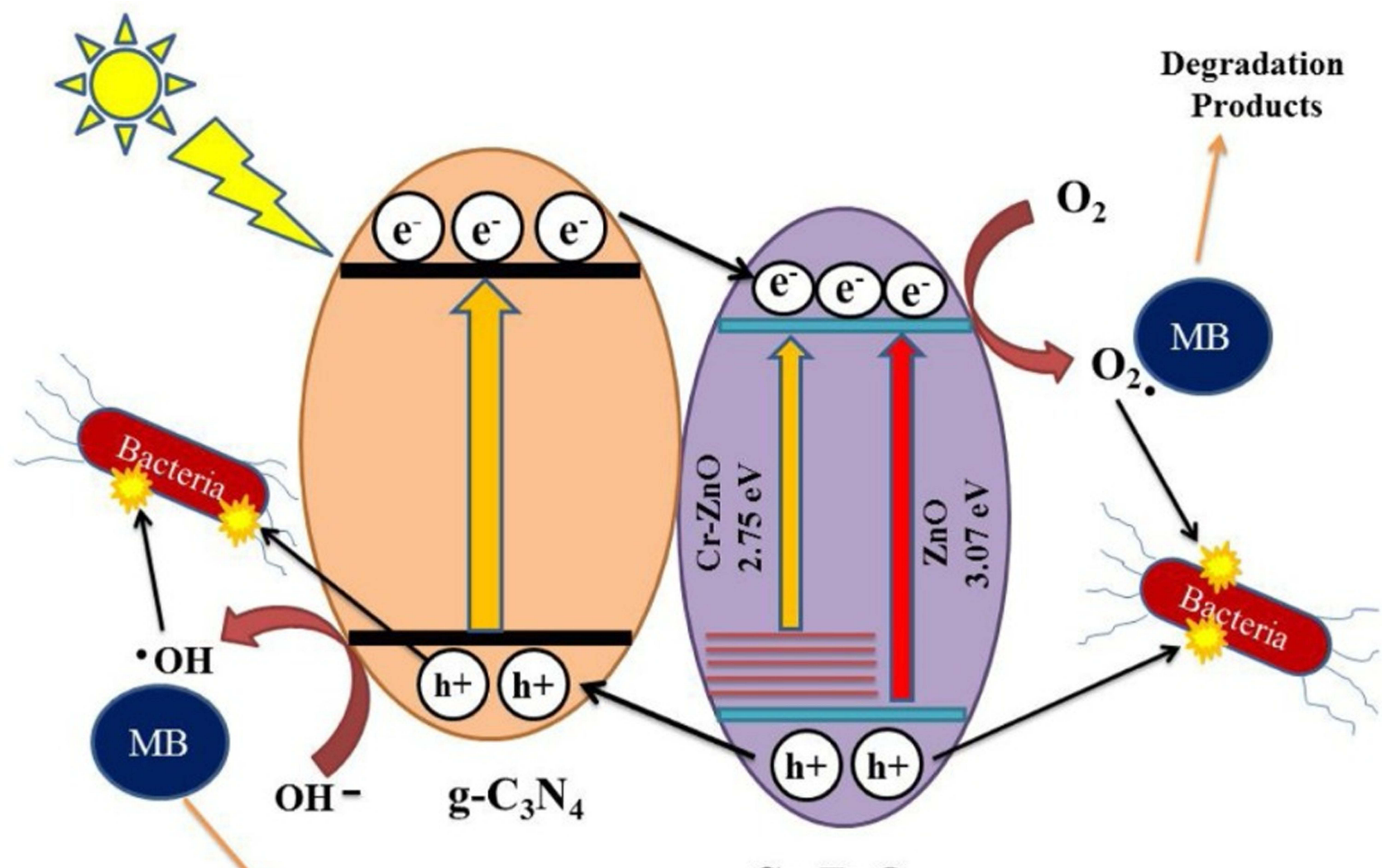

Degradation

$\mathrm{Cr}-\mathrm{ZnO}$

Products

Figure 13 Schematic representation of antibacterial mechanism of $\mathrm{g}-\mathrm{C}_{3} \mathrm{~N}_{4} / \mathrm{Cr}$ - ZnO nanocomposites under simulated solar light irradiation. Reprinted from J Photochem Photobiol A, 40I, Qamar MA, Shahid S, Javed M, et al. Highly efficient g-C3N4/cr-ZnO nanocomposites with superior photocatalytic and antibacterial activity. II2776, Copyright 2020, with permission from Elsevier. ${ }^{158}$

effect as illustrated in Figure 18. ${ }^{201}$ So, S. aureus and E. coli suspensions were mixed to different concentrations of 20 80 $\mu \mathrm{g} / \mathrm{mL}$ of $\mathrm{MoS}_{2}$, PEI, and $\mathrm{MoS}_{2}$-PEI. After $10 \mathrm{~min}$ of irradiation under an $808-\mathrm{nm}$ laser $\left(1 \mathrm{~W} / \mathrm{cm}^{2}\right)$, the mixture was incubated for $5 \mathrm{~h}$ and cultured on LB agar and then incubated at $37{ }^{\circ} \mathrm{C}$ overnight. In $10 \mathrm{~min}$, a weight concentration of $\mathrm{MoS}_{2}$-PEI at $80 \mu \mathrm{g} / \mathrm{mL}$ induced the temperature to increase to $67{ }^{\circ} \mathrm{C}$. The intrinsic antibacterial effect of $\mathrm{MoS}_{2}$ was better than that of PEI and reduced bacterial viability to $46.0 \%$ for $E$. coli and $45.6 \%$ for $S$. aureus. Meanwhile, inhibition rates of the $\mathrm{MoS}_{2}$-PEI nanocomposite were $68.1 \%$ and $66.2 \%$, respectively. Under NIR laser irradiation, the antibacterial effects of $\mathrm{MoS}_{2}$ and PEI improved. $\mathrm{MoS}_{2}$ reduced $E$. coli and $S$. aureus viability to $53.8 \%$ and $52.3 \%$, respectively. By fluorescence microscopy, the synergistic effect of the $\mathrm{MoS}_{2}$-PEI nanocomposite was proven using the live/dead method. The results revealed that upon NIR irradiation, $\mathrm{MoS}_{2}$-PEI induced severe damage to bacterial membranes. This bactericidal effect could be attributed to the positive charge and the captive agent property of $\mathrm{MoS}_{2}$-PEI.

Huajuan Wang and co-authors designed gold NPs (AuNPs) conjugated with a peptide and dimethylmaleic anhydride (Pep-DA) which they named Pep-DA/Au. ${ }^{202}$ Pep-DA/Au has a particular characteristic of being charge-convertible and can target bacteria. This synthesized nanocomposite has negative charges in normal physiological conditions of $\mathrm{pH}$ 7.4. But in a bacterial infection environment at $\mathrm{pH} 6.0$, the DA is hydrolyzed by the acidity. In this situation, the amino groups on the peptide are displayed leading to a positive charge. So, the new Pep-DA/Au with positive charges can interact with negative charges of bacterial cell surfaces allowing the nanocomposite to attach to the bacteria. Under NIR laser illumination, the generated heat from the AuNPs will kill the bacteria and precisely minimize damage to surrounding tissues. The principle is shown schematically in Figure 19. In the SEM images of MRSA treated 


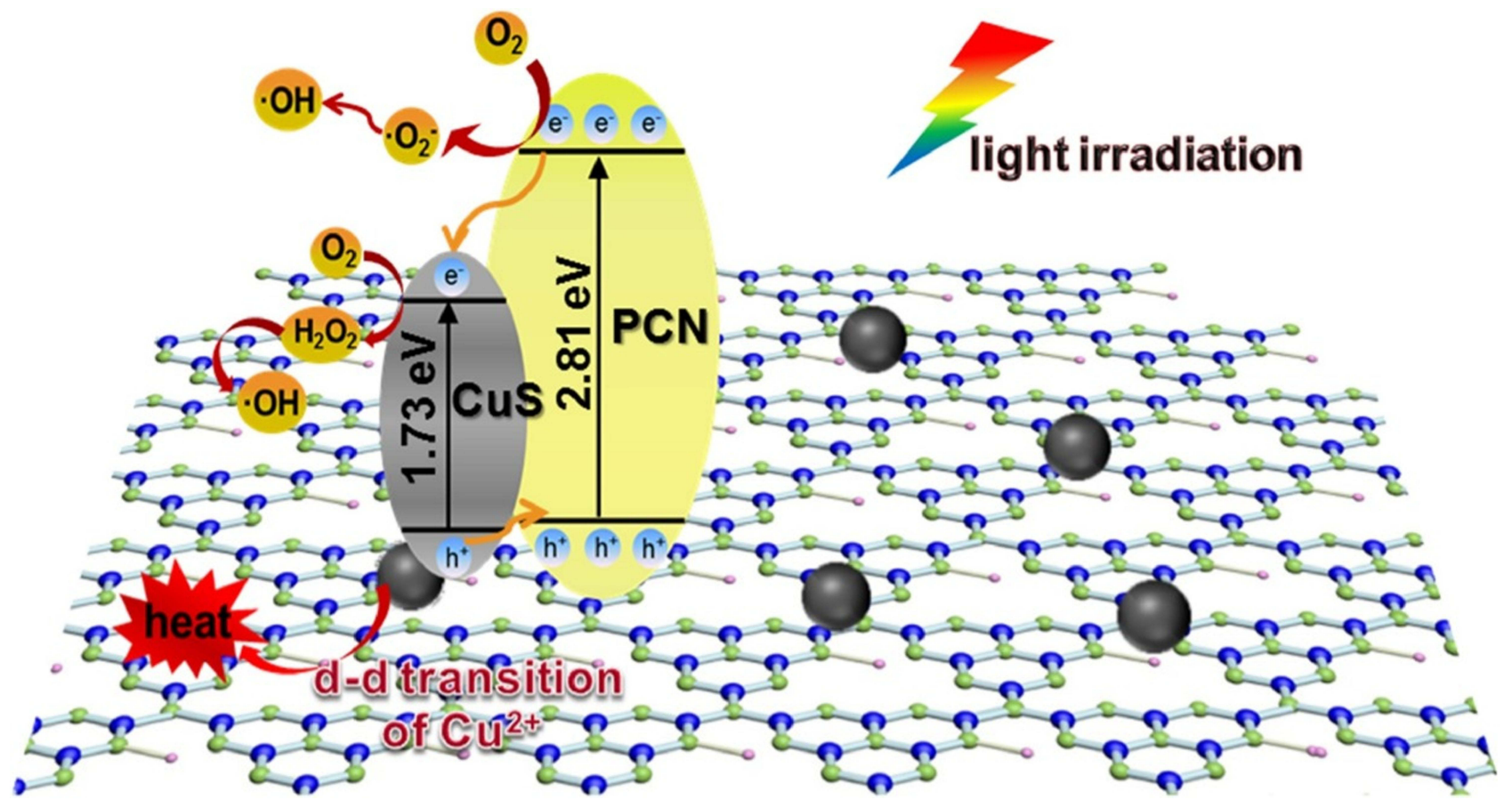

Figure 14 Schematic representation of the antibacterial mechanism of CuS/PCN composites under visible and laser light irradiation. Reprinted from J Hazard Mater. 393, Ding H, Han D, Han Y, et al. Visible light responsive CuS/protonated g-C3N4 heterostructure for rapid sterilization. 122423, Copyright 2020, with permission from Elsevier. $^{163}$

with a control and Pep-DA/Au under irradiation and the bacteria cultured on agar plates after treatment, the survival rate of bacteria confirmed the efficiency of the anti-MRSA photothermal effect of the investigated nanocomposite. More interesting, in a mouse model, in vivo wound healing was evaluated and has provided consistent results compared to in vitro results.

Polymeric antimicrobials such as guanidine NPs can efficiently adhere to bacteria. This adhesion occurs through electrostatic bonds between the positive charges of polymeric antimicrobials and negative charges of bacterial cell walls. ${ }^{203,204}$ However, the drawback of cationic NPs is their interactions with protein corona once in the peripheral blood. ${ }^{205,206}$ To overcome this disadvantage, Congyu Wang and co-workers used a strategy based on charge reversal to design caged guanidine NPs (CGNs). These CGNs were synthesized through two main steps: first, preparation of amphiphilic diblock copolymers denoted P(GEMADA-co-DMA)-b-PBMA utilizing N,Ndimethylacrylamide (DMA), and 2-aminoethyl methacrylate hydrochloride (AEMA) and second, conjugation of the hydrophilic block (DMA) with dimethylmaleic anhydride (DA) for the final P(GEMADA-co-DMA)-b-PBMA as described in Figure $20 .^{207}$ By means of confocal laser scanning microscopic imaging, CGNs were seen to effectively accumulate in bacterial biofilms. Under NIR irradiation, CGNs revealed about a $\sim 40.9 \%$ photothermal conversion efficiency. They were also an efficient treatment in mouse models with catheters infected with Sta. aureus biofilm where they exhibited a $99.6 \%$ bacteria inhibition ratio. The mechanisms of nanocomposite preparation and bacterial killing are given in Figure 20.

To combat food-borne diseases, Shimayali and colleagues developed a nanocomposite for rapid bacterial detection and NIR laser-reinforced antibacterial activity. Graphene oxide (GO), polyethylene glycol (PEG), gold NPs (AuNPs), and specific bacterial antibodies (Abs) were used to design a composite called Ab-PEG-GO-AuNPs. GO with multiple functional groups on its surface, such as carboxyl, epoxy, and hydroxyl, facilitates diverse functionalization of the surface. ${ }^{208,209}$ Due to the presence of the Abs and AuNPs, the designed nanoprobe was able to combine bacterium-specific targeting and photothermal ablation properties as summarized in Figure 21. ${ }^{210}$ E. coli and S. typhimurium as foodborne bacteria were used to test the specificity through colorimetric detection. The results confirmed the performance of this investigated nanoprobe in terms of specificity and color change. Using bicinchoninic acid and fluorescence methods, the amount of $\mathrm{Ab}$ functionalized with PEG-GO-AuNPs was greater than that on PEG-AuNPs. That is why the limit of 


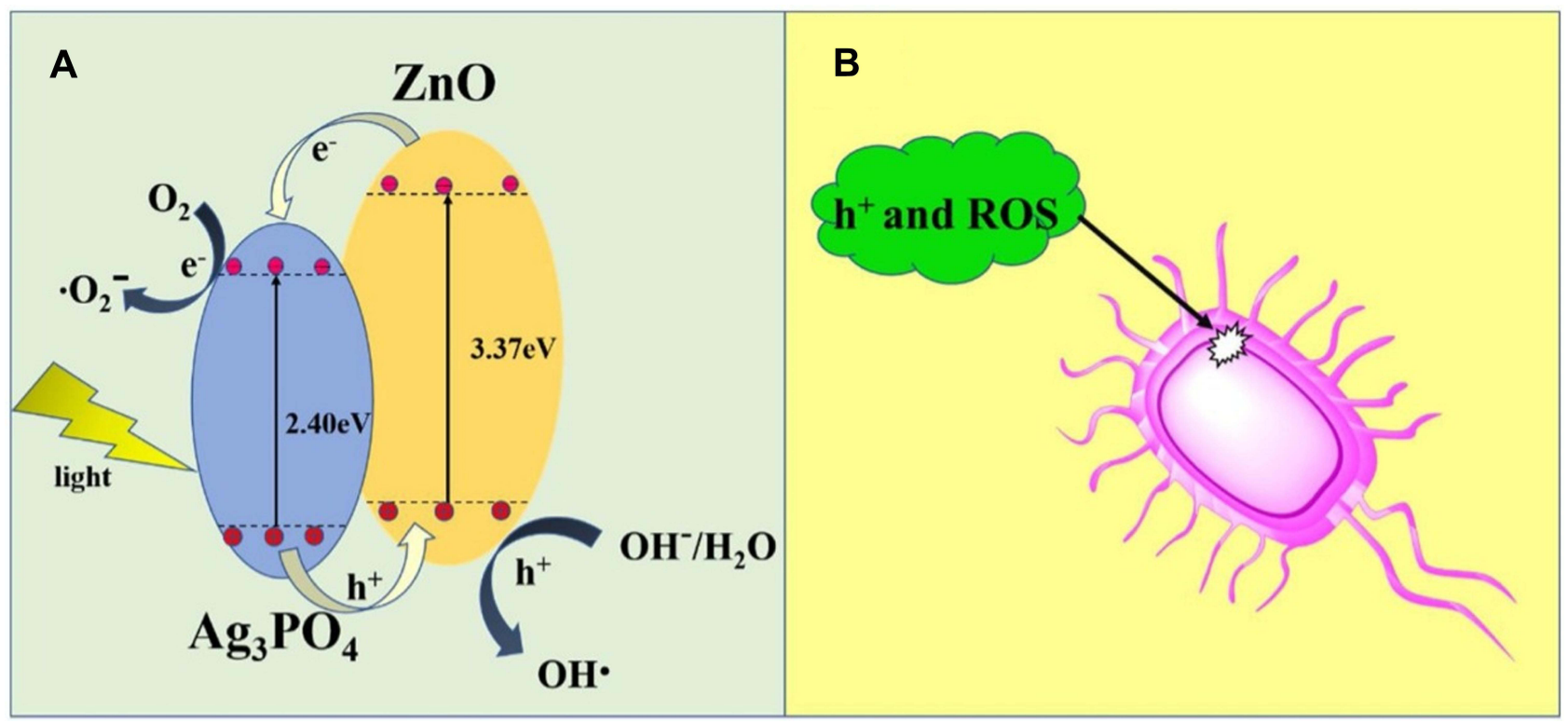

Figure 15 (A) Schematic representation of antibacterial mechanism of $\mathrm{Fe}_{3} \mathrm{O}_{4} @ S \mathrm{SiO} @ \mathrm{Ag}_{3} \mathrm{PO}_{4} / \mathrm{ZnO}-10 \%\left(\mathrm{Ag}_{3} \mathrm{PO}_{4}-10\right.$ wt\%) (FSZA2-10\%) microspheres under visible light irradiation and (B) bacterial cell wall damage by ROS generation. Reprinted from Colloids Surf, A Physicochem Eng Asp, 603, Mao K, Zhu Y, Zhang X, et al. Effective loading of well-dopedZnO/ag3po4 nanohybrids on magnetic core via one step for promotingits photocatalytic antibacterial activity. 125187, Copyright 2020, with permission with Elsevier. ${ }^{168}$

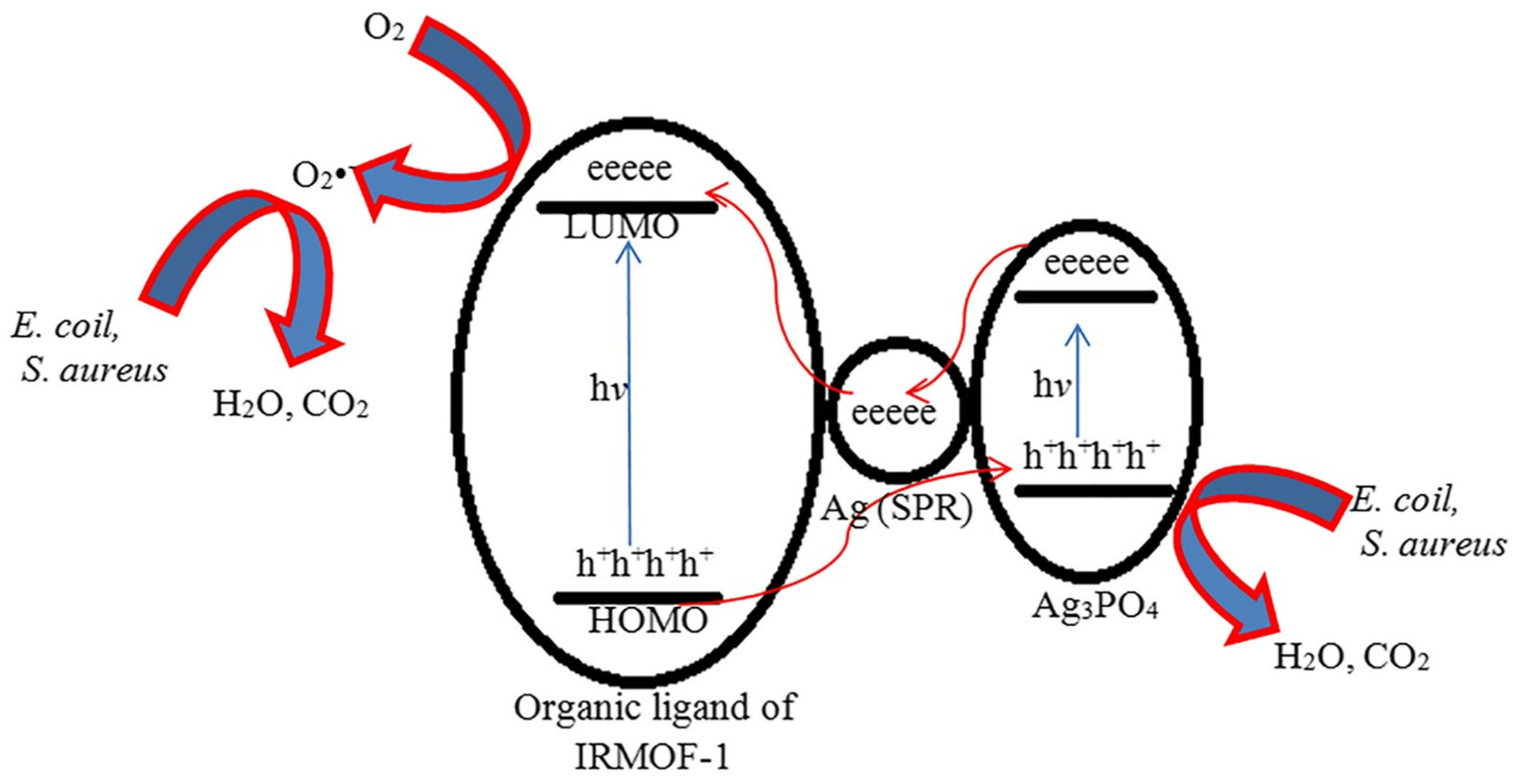

Figure 16 Schematic representation of antibacterial mechanism of $\mathrm{Ag} / \mathrm{Ag}_{3} \mathrm{PO}_{4}$ combined MOF (MOF-5 or IRMOF-I) nanocomposites under visible light irradiation. Reproduced from Naimi Joubani M, Zanjanchi MA, Sohrabnezhad S. A novel Ag/ag3po4-irmof-I nanocomposite for antibacterial application in the dark and under visible light irradiation. Appl Organomet Chem.2020;34:e5575. (C) 2020 John Wiley \& Sons, Ltd. ${ }^{173}$ 
Table 2 Light-Driven Nanomaterials for Antibacterial Applications

\begin{tabular}{|c|c|c|c|c|}
\hline Nanomaterial & Type & Light Source & Bacteria & Reference \\
\hline $\mathrm{Ag} / \mathrm{PSCN}$ nanocomposite & $\mathrm{CMN}$ & Visible light & E. coli & {$[180]$} \\
\hline B-Bi ${ }_{2} \mathrm{O}_{3} @ \mathrm{BiOBr}$ core/shell & Metallic nanocomposite & LED light & $\begin{array}{l}\text { E. coli } \\
\text { S. aureus }\end{array}$ & {$[181]$} \\
\hline $\mathrm{Ag}$-doped spindle-like $\mathrm{BiFeO}_{3}$ nanocomposites & Metallic nanocomposite & Visible light & $\begin{array}{l}\text { E. coli } \\
\text { M. luteus }\end{array}$ & {$[182]$} \\
\hline $\mathrm{Ag} @ \mathrm{AgCl}-\mathrm{CA} / \mathrm{SF}$ composite film & CMN & Visible light & $\begin{array}{l}\text { E. coli } \\
\text { S. aureus }\end{array}$ & [183] \\
\hline $\mathrm{Ag}-\mathrm{TiO}_{2}$ nanocomposite & Metallic nanocomposite & Visible light & $\begin{array}{l}\text { E. coli } \\
\text { S. aureus }\end{array}$ & [184] \\
\hline $\mathrm{VS}_{4} / \mathrm{Ag}_{2} \mathrm{WO}_{4}$ nanocomposite & Metallic nanocomposite & Visible light & $\begin{array}{l}\text { E. coli } \\
\text { B. subtilis }\end{array}$ & [185] \\
\hline Gd-doped nickel spinel ferrite NPs & Metallic nanocomposite & Visible light & $\begin{array}{l}\text { E. coli } \\
\text { S. aureus }\end{array}$ & [186] \\
\hline 5 wt $\%$ cubic AgNPs-RGO & $\mathrm{CMN}$ & Visible light & $\begin{array}{l}\text { E. coli } \\
\text { S. aureus } \\
\text { B. subtilis }\end{array}$ & [187] \\
\hline $\mathrm{ZnO} / \mathrm{Ag}$ nanocomposite & Metallic nanocomposite & Visible light & $\begin{array}{l}\text { E. coli } \\
\text { S. aureus }\end{array}$ & [188] \\
\hline $\mathrm{Ag}_{3} \mathrm{PO}_{4}-\mathrm{FeTiO}_{3}$ heterostructure/glycol chitosan & $\mathrm{CMN}$ & LED light & $\begin{array}{l}\text { E. coli } \\
\text { S. aureus }\end{array}$ & [189] \\
\hline $\mathrm{I}-\mathrm{ZnO}-\mathrm{n}$ & Metallic nanocomposite & Visible Light & E. coli & 190] \\
\hline
\end{tabular}

Abbreviations: $\mathrm{CMN}$, carbon-based metallic nanostructure; Ag/PSCN, silver/phosphorus- and sulfur-doped carbon nitride; $\mathrm{B}-\mathrm{Bi}_{2} \mathrm{O}_{3} @ \mathrm{BiOBr}$, core/shell- beta-bismuth oxide-doped bismuth oxybromide; $\mathrm{Ag}-\mathrm{BiFeO}_{3}$ nanocomposite, silver-doped spindle-like bismuth ferrite; $\mathrm{Ag} @ \mathrm{AgCl}-\mathrm{CA} / \mathrm{SF}, \mathrm{Ag} @ \mathrm{AgCl}-\mathrm{cellulose}$ acetate-doped silk fibroin composite film; $\mathrm{Ag}-\mathrm{TiO}_{2}$ nanocomposite, silver-doped titanium dioxide; $\mathrm{VS}_{4} / \mathrm{Ag}_{2} \mathrm{WO}_{4}$ nanocomposite, silver tungstate-doped vanadium tetrasulfide nanoplate nanocomposite; $\mathrm{Cd}$-Gd-doped nickel spinel ferrite nanoparticle, cadmium- and gadolinium-doped nickel spinel ferrite nanoparticle; $\mathrm{RGO}$, reduced graphene oxide; $\mathrm{Ag}_{3} \mathrm{PO}_{4}$-FeTiO ${ }_{3}$ heterostructure/glycol chitosan, silver phosphate and iron titanate heterostructure-doped glycol chitosan; I-ZnO-n, lodine modified zinc oxide-nanomaterial; LED, lightemitting diode.

visual detection was ten-fold higher for GO-PEG-GO-AuNPs compared to PEG-AuNPs. The results showed that the GO coating of the AuNPs enhanced the photothermal performance with a rise in temperature of up to $76^{\circ} \mathrm{C}$ under 808-nm laser irradiation for $30 \mathrm{~s}$. As to the photothermal ablation of bacteria, results showed effective bacterial killing up to $95 \%$ within $15 \mathrm{~min}$.

\section{Approach of the Controlled Release of PTAs}

One of challenges with antibacterial treatment is the efficient delivery of drugs into sites of infection. Biomimicry, in situ polymerization and porous nanomaterial techniques are some of methods to resolve this issue. ${ }^{211}$ The uses of nanomaterials as nanocarriers are rapidly cleared by the immune system, thereby reducing the treatment efficiency. The biomimicking technique uses specific cell membranes such as red blood cells (RBCs), ${ }^{212}$ macrophages, ${ }^{213}$ platelets, ${ }^{214}$ and stem cells ${ }^{215}$ in drug biominimization to bypass the immune system. RBC membranes (RBCMs) possess immunomodulatory markers, and their use as nanomaterial camouflage improves the circulation time of NPs in the body. With this logic Luoxiao Ran and coauthors designed a biomimic nanoantibiotic using gentamicin (GM), gold-silver (AuAg) alloy NPs, polydopamine (PDA), and RBCMs. This nanoantibiotic was named RBCM-NW-G, and a summary of it preparation and treatment under 808-nm NIR laser irradiation is given in Figure 22. ${ }^{216}$ The biomimic nanocomposite revealed photothermal performance, effective accumulation in 


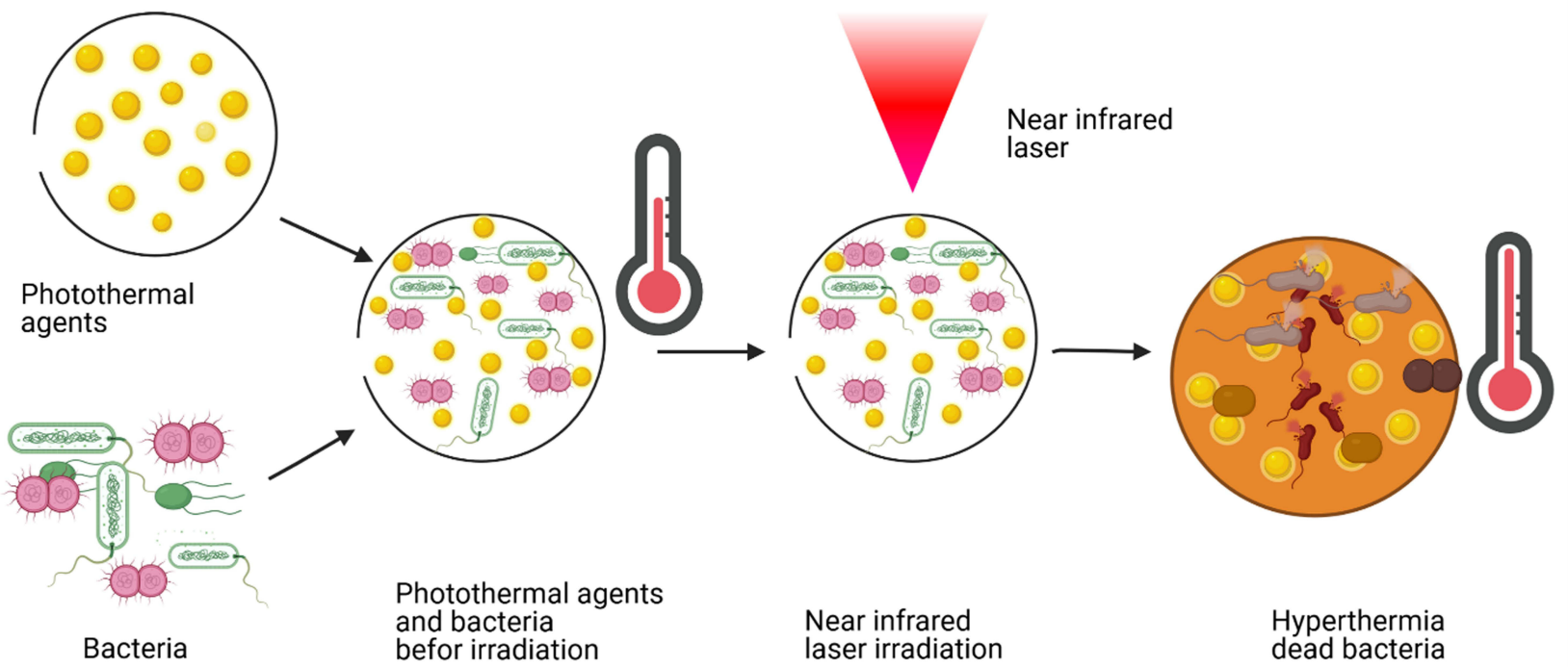

Figure 17 Principle of antibacterial photothermal therapy.

infected areas, and longer blood circulation times with good biocompatibility. With the synergistic effect of photothermal treatment, silver ions, and gentamicin, the prepared nanoantibiotic showed antibacterial potential highlighted in in vitro and mouse models against $E$. coli and $S$. aureus.

Xueqin Yang and co-workers produced a photothermal nanoantibiotic (PTNA) by means of oxidative polymerization of pyrrole and anionic vesicles formed from sodium bis-(2-ethylhexyl) sulfosuccinate (AOT). ${ }^{217}$ They examined the antibacterial and antibiofilm activities on multidrug-resistant (MDR) S. typhimurium. The entire process is shown in schematic form in Figure 23. Bacterial death was confirmed in two ways; bacterial growth on agar plates was inhibited and scanning electron microscopy clearly showed bacterial membrane damage. PTNA
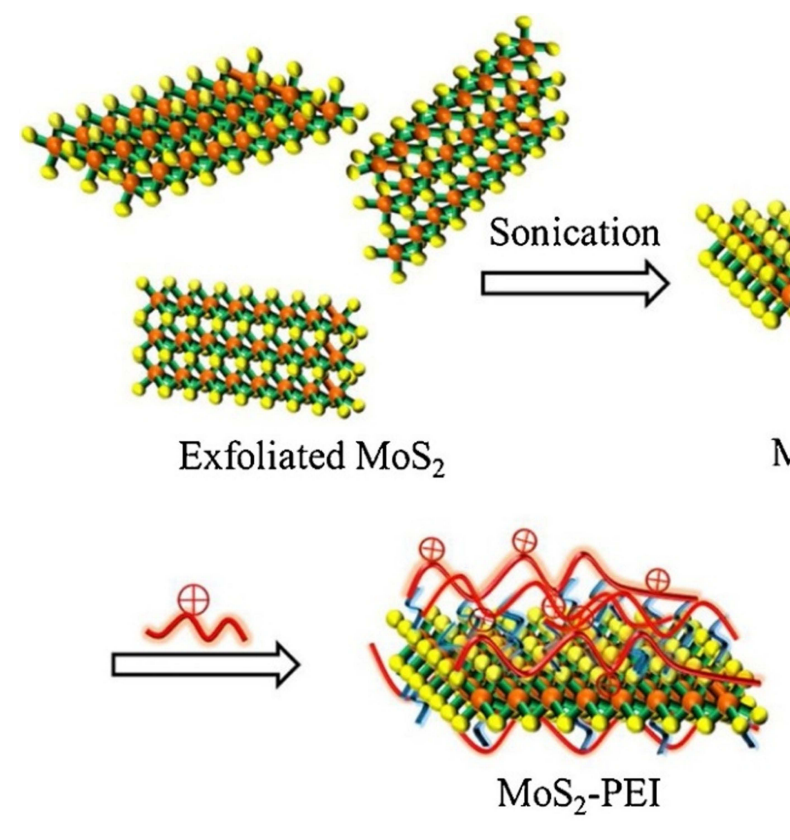

$\mathrm{MoS}_{2}$ Nanosheet

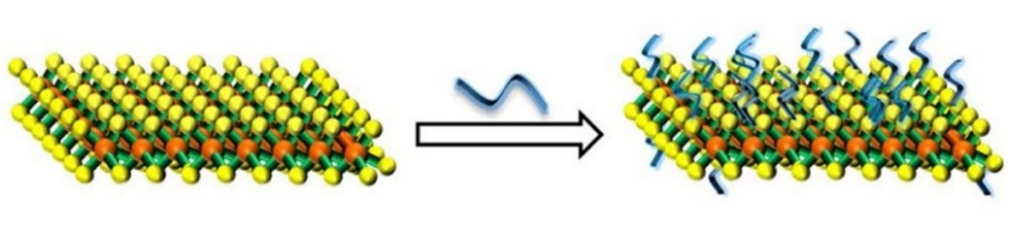

$\mathrm{MoS}_{2}-\mathrm{COOH}$
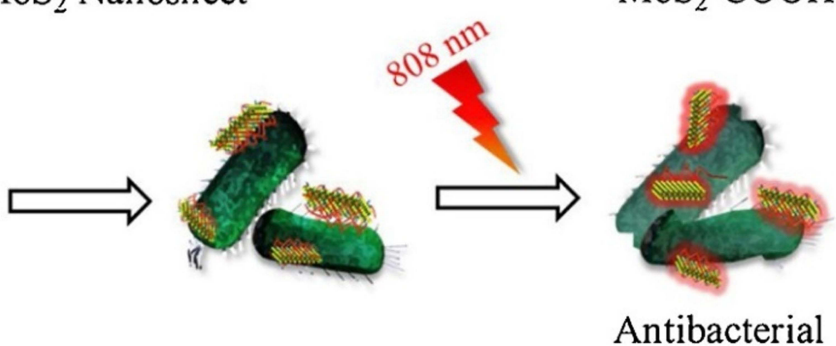

Antibacterial

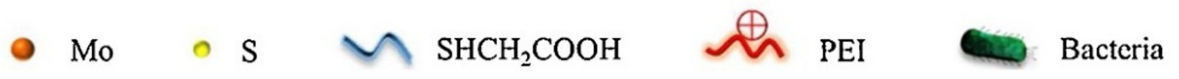

Figure I 8 Schematic illustration of preparation and synergistic photothermal antibacterial activity of MoS 2 -PEI nanocomposite. Reprinted from J Photochem Photobiol A, 40I, Cao W, Yue L, Khan IM, et al. Polyethylenimine modified MoS2nanocomposite with high stability and enhanced photothermal antibacterial activity. II2762, Copyright 2020, with permission from Elsevier. ${ }^{201}$ 
(1)

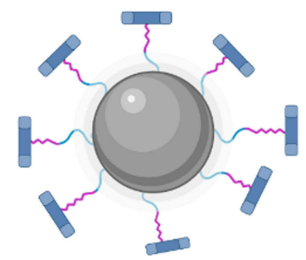

Pep-DA/AuNPs

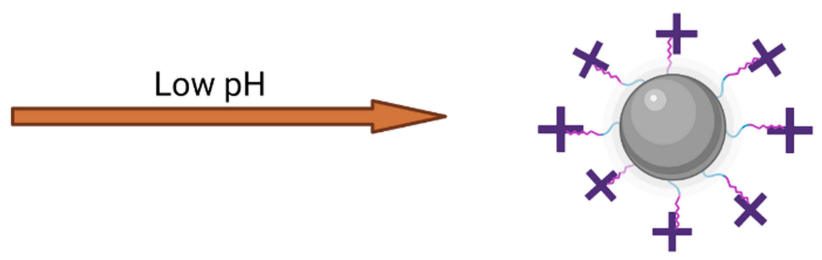

Pep-DA/AuNPs in bacterial infected environment (charge conversion)

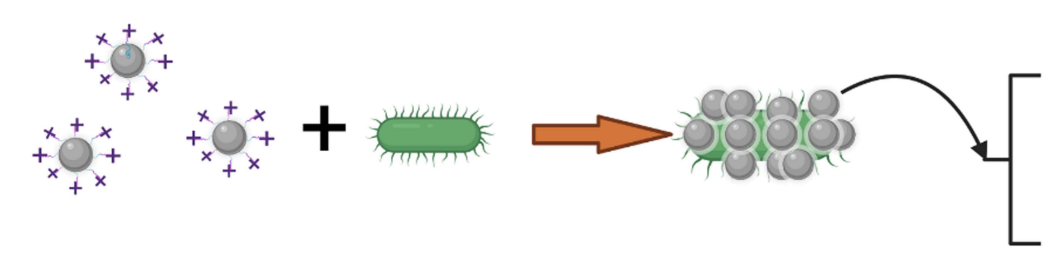

(2)

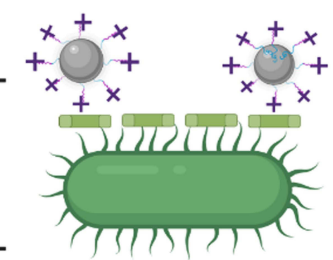

Aggregation of nanocomposite on bacteria via electrostatic attraction

(3)
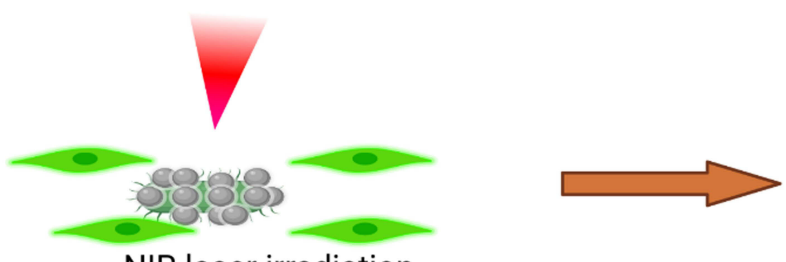

NIR laser irradiation

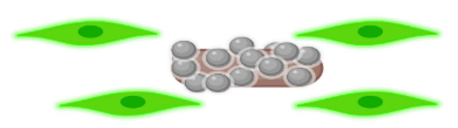

Selective killing of bacteria

Figure 19 Photothermal bacterial selective killing therapy: (I) The charge conversion of Pep-DA/Au. (2) Bacterial targeting by nanocomposite. (3) Photothermal selective killing of bacteria.

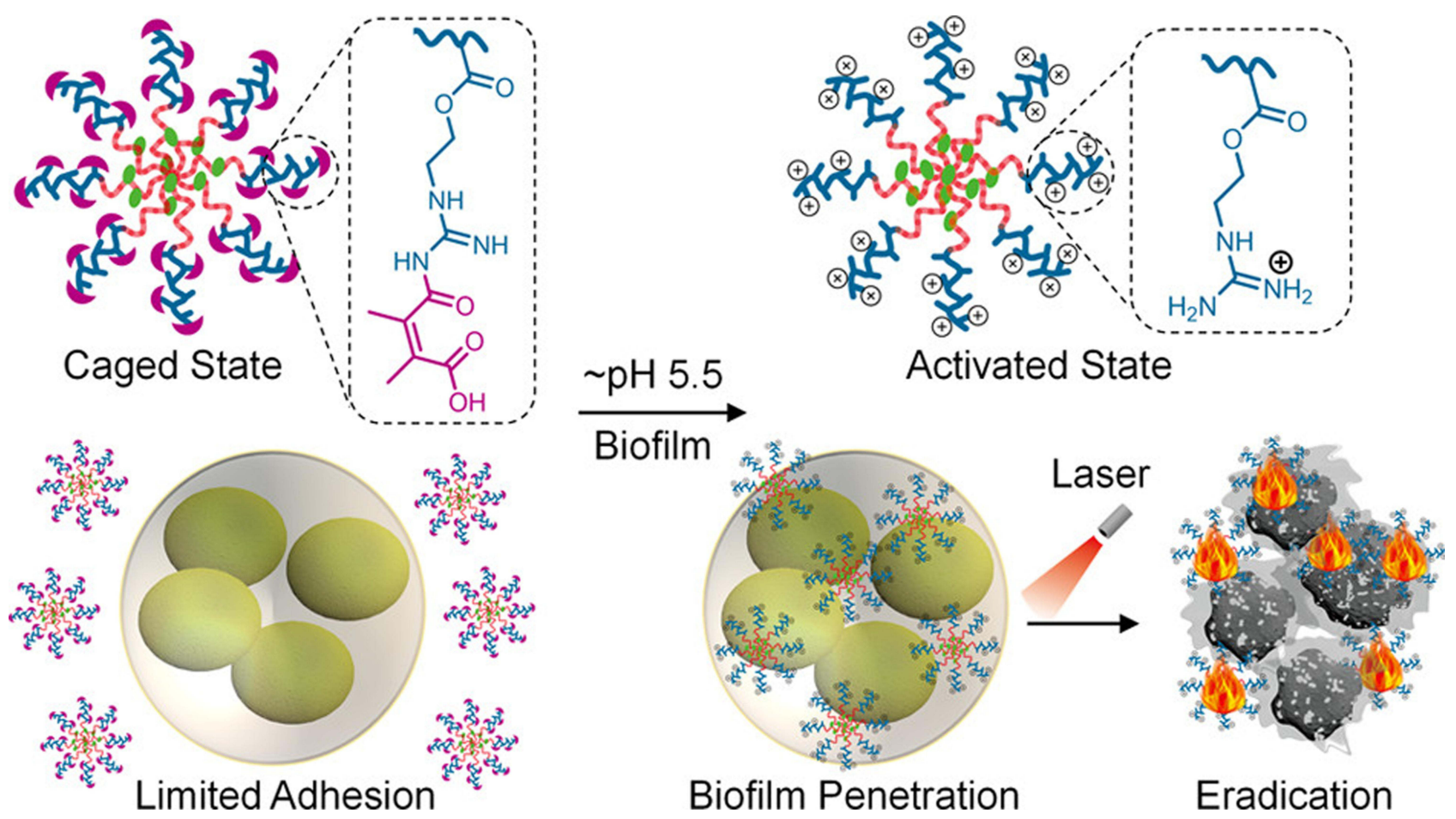

Figure 20 Synthesis of Caged Guanidine NPs and in vivo biofilm eradication via NIR irradiation. Reprinted with permission from Wang C, Zhao W, Cao B, et al. Biofilmresponsive polymeric nanoparticles with self-adaptive deep penetration for in vivo photothermal treatment of implant infection. Chem Mater.2020;32:7725-7738. Copyright (2020) American Chemical Society. ${ }^{207}$ 


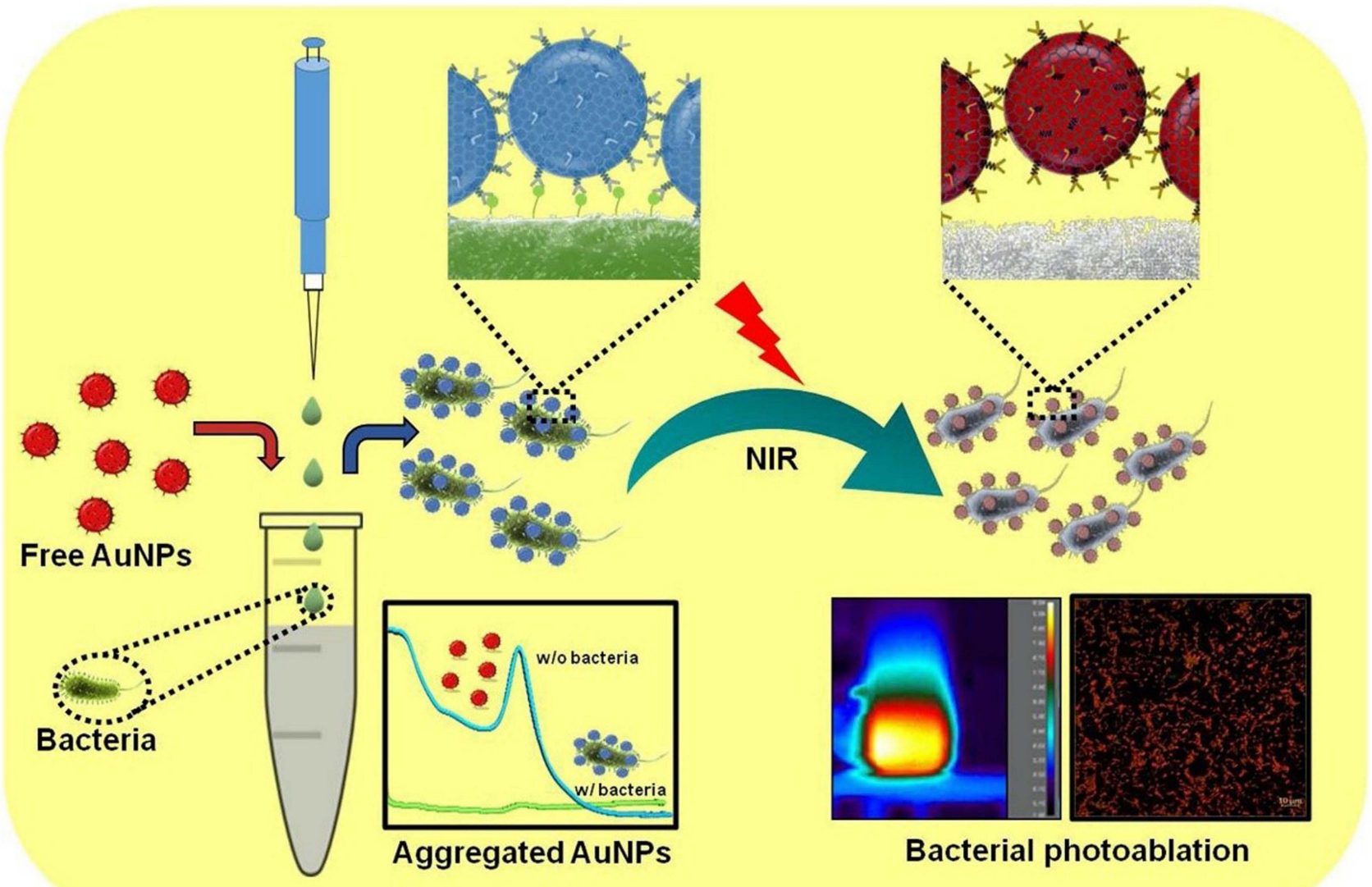

Figure 2 I Schematic representation of specific bacterial recognition through Ab-PEG-GO-AuNPs via colorimetric detection and its photothermal ablation upon NIR irradiation. Reprinted from Sens Actuators B Chem, 329, Kaushal S, Pinnaka AK, Soni S, et al. Antibody assisted grapheneoxide coated gold nanoparticles for rapid bacterial detection and near infrared light enhanced antibacterial activity. 2021;329:129141, Copyright 2021, with permission from Elsevier. ${ }^{210}$

revealed an intrinsic antibacterial effect, with a reduction of $S$. typhimurium to $2 \log ^{10}(\mathrm{CFU} / \mathrm{mL})$. However, after laser irradiation (at $1 \mathrm{~W} / \mathrm{cm}^{2}$ for $10 \mathrm{~min}$ ), PTNA reduced the bacterial viability by $6 \log ^{10}(\mathrm{CFU} / \mathrm{mL})$ confirming reinforcement of the antibacterial effect. Both effects were compared to a control and the nanocomposite without irradiation. The in vivo antibacterial potential of PTNA was also assessed in that work by determining the survival rate of mice that orally received $100 \mu \mathrm{L}$ of $10^{9}$ CFU of S. typhimurium. Twenty-four hours later, the mice received treatment with phosphate-buffered saline (PBS), light irradiation, PTNA, and PTNA with light irradiation. Mice under treatment with light or PBS did not survive beyond day 6 or 5 . Those treated with PTNA were alive beyond 6 days but did not reach day 15 . However, $50 \%$ of mice treated with PTNA followed by irradiation under a 1064-nm laser $\left(1 \mathrm{~W} / \mathrm{cm}^{2}\right)$ for $10 \mathrm{~min}$ remained alive by day 15.

Patel and co-authors developed a nanocomposite consisting of AuNRs coated with mesoporous silica. ${ }^{218}$ This complex played a role of nanocarrier onto which the antituberculotic medicine, bedaquiline (BDQ), was loaded. The entire composite was wrapped in thermo-sensitive liposomes (TSLs) under the name GNR@MSNP@BDQ@TSL@NZX with NZX responsible for the bond between the nanocomposite and mycobacteria. This engineered nanomaterial possessed three interesting features: targeted delivery of a nanoantibiotic to mycobacteria due to the affinity between NZX and the bacterial surface; a synergistic effect from BDQ and PTT; and the remotely triggered release of a synthesized bacterial drug under an NIR laser. The designed nanoantibiotic was shown to be 20-times more efficient than an equivalent amount of the free drug against $M$. smegmatis. It induced $99.9 \%$ inhibition of intracellular mycobacteria in lung A549 cells. A schematic illustration is shown in Figure 24.

\section{Approach to Combinational Therapy}

Due to the heat effect of PTT, several strategies were developed to reduce the heat and also to include targeted synergistic therapies, deliver and control the release of PTAs, and regulate 

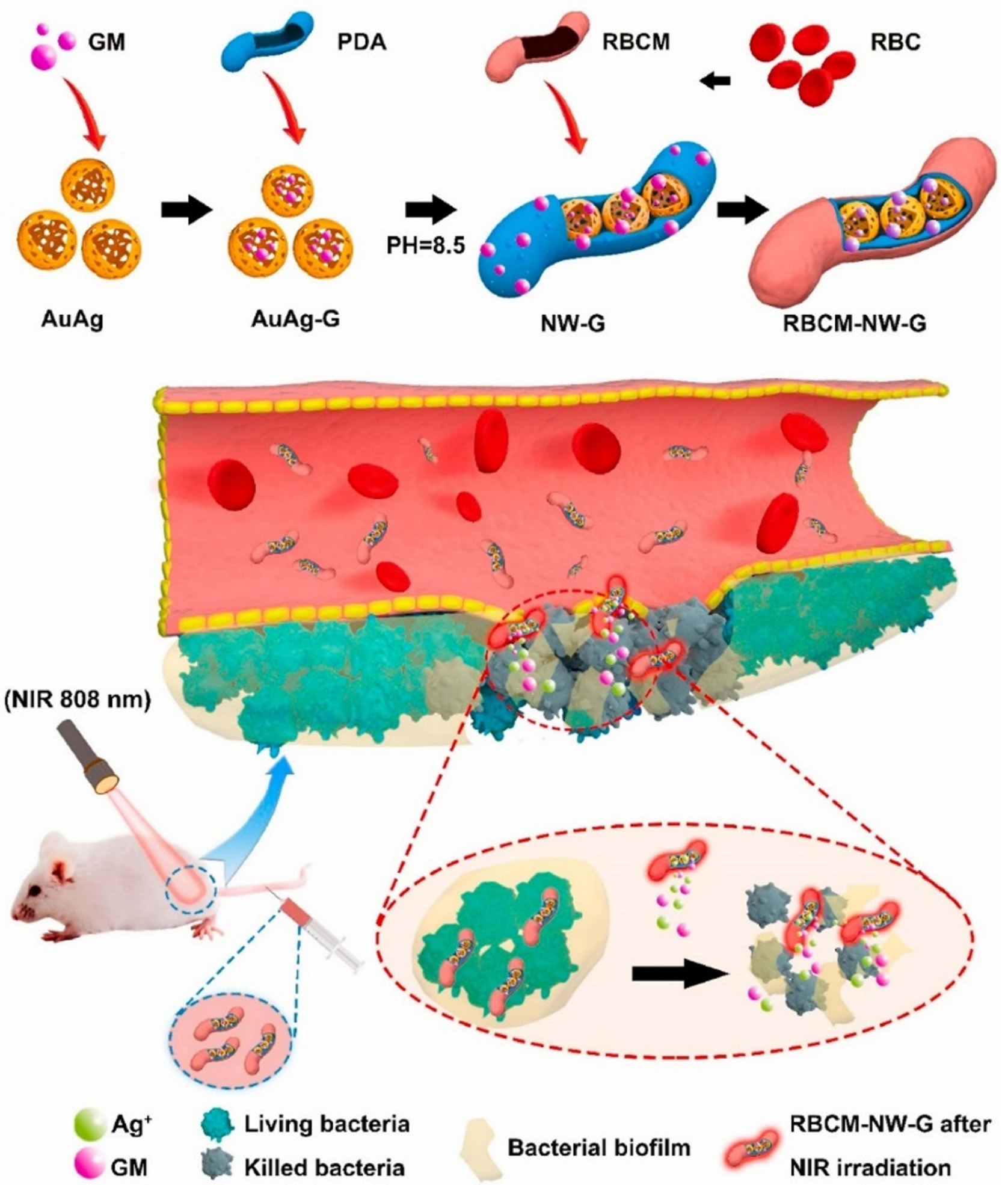

Figure 22 Diagram of RBCM-NW-G preparation and the treatment principle of bacterial infections in vivo. Reprinted from Bioact Mater, 6, Ran L, Lu B, Qiu H, et al. Erythrocyte membrane-camouflaged nanoworms with on-demand antibiotic release for eradicating biofilms using near-infrared irradiation. 2956-2968, Copyright 202I, with permission from KeAi Publishing. ${ }^{216}$ 


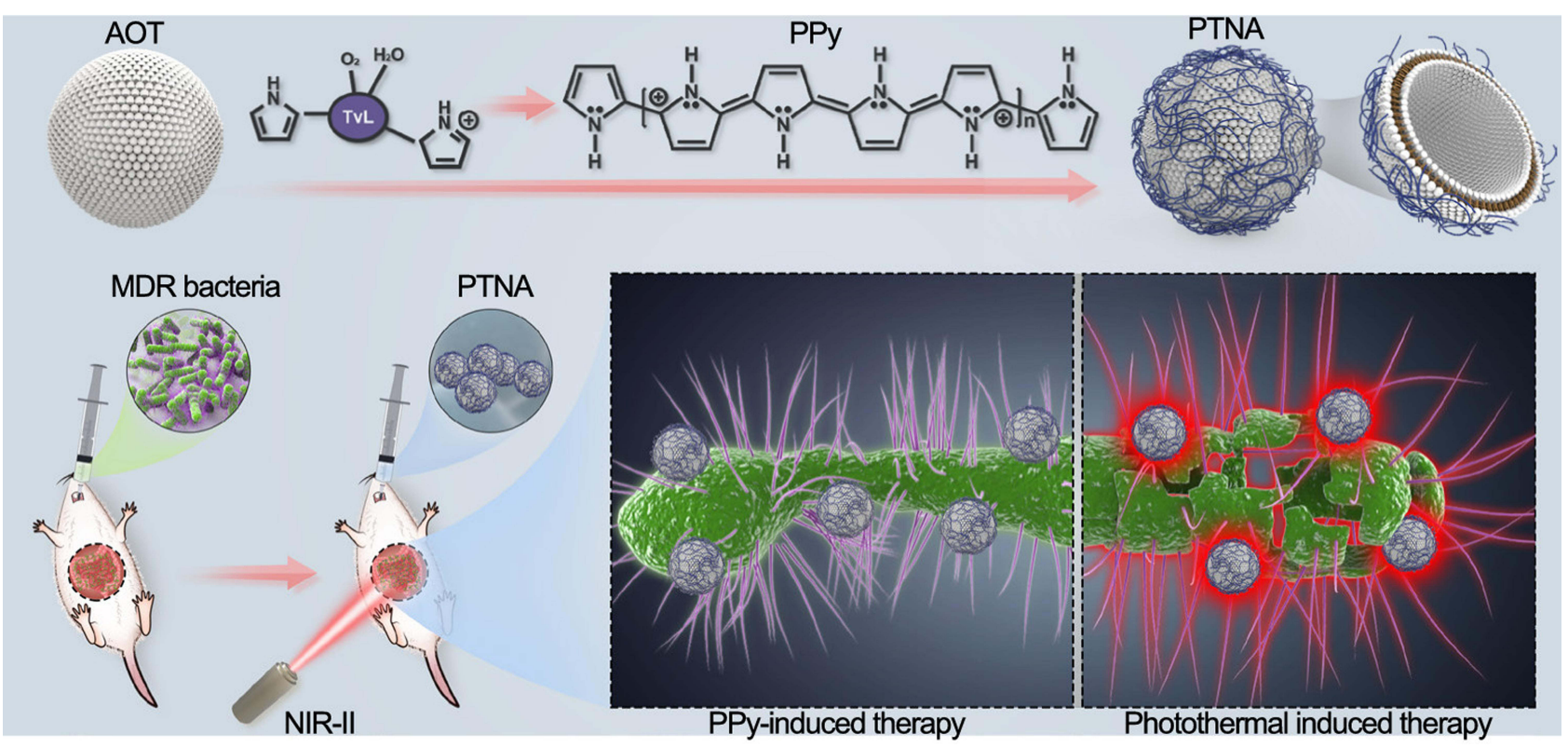

Figure 23 PPy-based photothermal nano-antibiotic (PTNA) for the treatment of multidrug-resistant bacterial infection. Reprinted with permission from Yang $X$, Xia $P$, Zhang Y, et al. Photothermal nano-antibiotic for effective treatment of multidrug-resistant bacterial infection. ACS Appl Bio Mater. 2020;3:5395-540. Copyright (2020). American Chemical Society. ${ }^{217}$

irradiation. ${ }^{219}$ Black phosphorus (BP) is one of the attractive photosensitizers (PSs) for phototherapeutic applications. ${ }^{220-}$ 222 To develop a nanostructure with a synergistic effect, Aksoy and collaborators synthesized BP and AuNPs nanocomposites to fight pathogenic bacteria especially E. faecalis in planktonic form and as a biofilm. The principle is summarized in Figure 25. They found that the photothermal antibacterial activity of the nanocomposite was better than those of $\mathrm{BP}$ and a nanocomposite without irradiation. By a densitometric method at a weight concentration of $128 \mu \mathrm{g} / \mathrm{mL}$ and under 808-nm NIR laser irradiation, the BP/Au nanocomposite inhibited the growth of E. faecalis. Moreover, the BP/ AuNPs composite also inhibited E. faecalis biofilm formation with and without light irradiation to $58 \%$ and $33 \%$, respectively. In view of this investigation, the antibacterial activity of nanocomposites was due to membrane damage, and photothermal and photodynamic effects. The membrane damage was due to $\mathrm{BP} / \mathrm{AuNPs}$ disrupting bacterial membranes due to the sharp edges of the BP nanosheets through simple contact. $^{223}$

Amino-conjugated GO (AGO) nanosheets were fabricated by Bo-Yao $\mathrm{Lu}$ and co-authors to simultaneously exploit three properties: the natural power of AGO to cut bacteria, positive charges for bacterium targeting, and effective photothermal performance. ${ }^{224-226}$ With this synthesized nanoantibiotic, the antibacterial effect was investigated on S. mutans, the main cause of dental caries. The positive charge of AGO due to the presence of amino groups favored electrostatic attraction with bacterial cell surfaces possessing negative charges. With $30 \mathrm{~min}$ of incubation, $100 \mu \mathrm{g} / \mathrm{mL}$ of AGO killed $27 \%$ of the bacteria. Under NIR laser irradiation for $5 \mathrm{~min}$, the synergistic effect from the three properties of AGO caused 98\% bacterial death. An illustration of this engineered nanosheet is summarized in Figure 26. ${ }^{227}$

Yingnan Liu and colleagues constructed a nanocomposite with antimonene nanosheets (AMNSs) incorporated in chitosan (CS) and named them CS/AMNSs hydrogels. CS can attach to bacteria via electrostatic forces, van der Waals forces, and hydrophobic interactions with cell membranes, and it also possesses an intrinsic antibacterial effect. ${ }^{228}$ Furthermore, the photothermal performance of AMNSs was confirmed under an NIR laser. ${ }^{229}$ In this design, the hydrogel acts as a carrier of the nanomaterials. CS-based hydrogels have various advantages such as low cost, biocompatibility, biodegradability, and an intrinsic antibacterial 


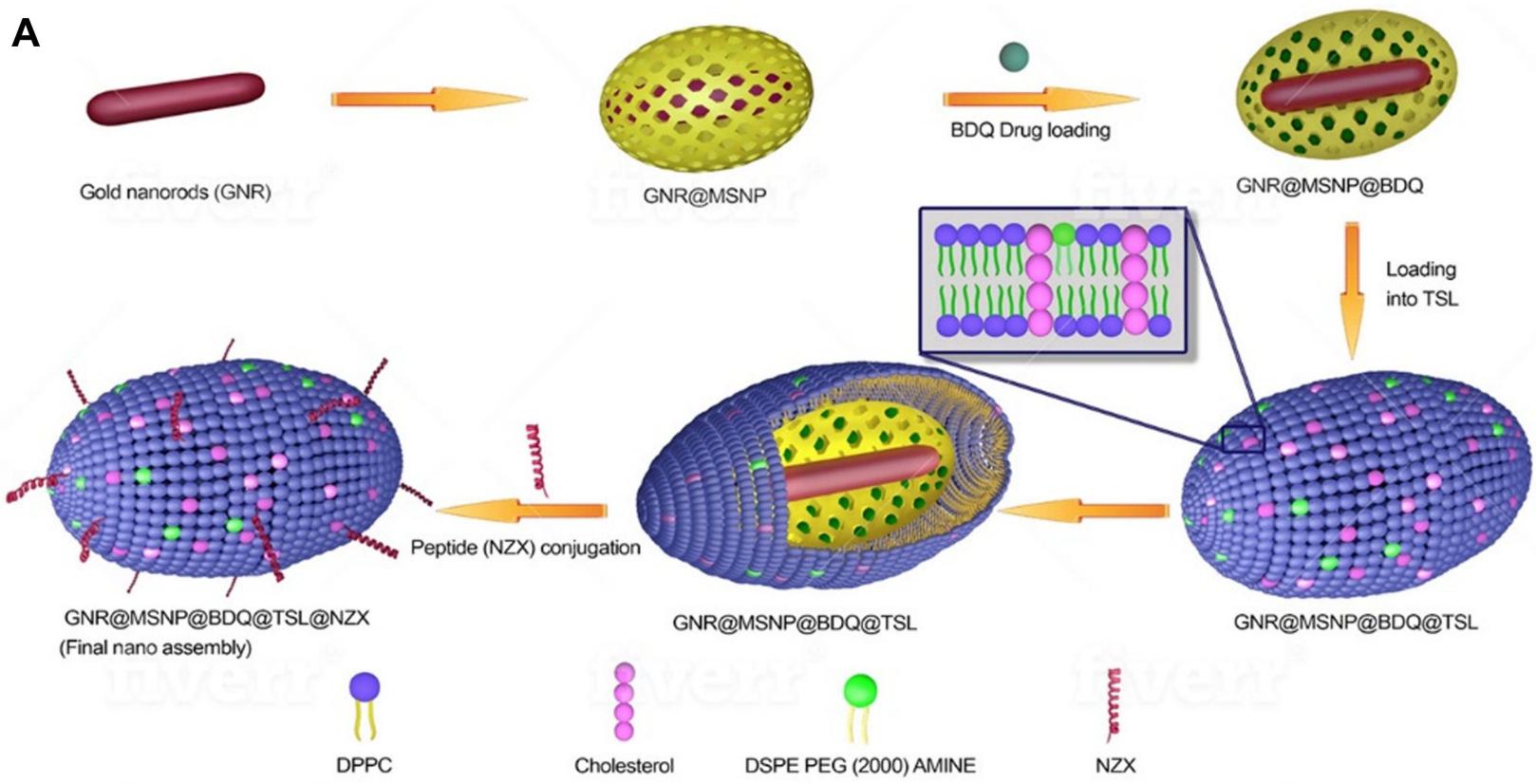

B
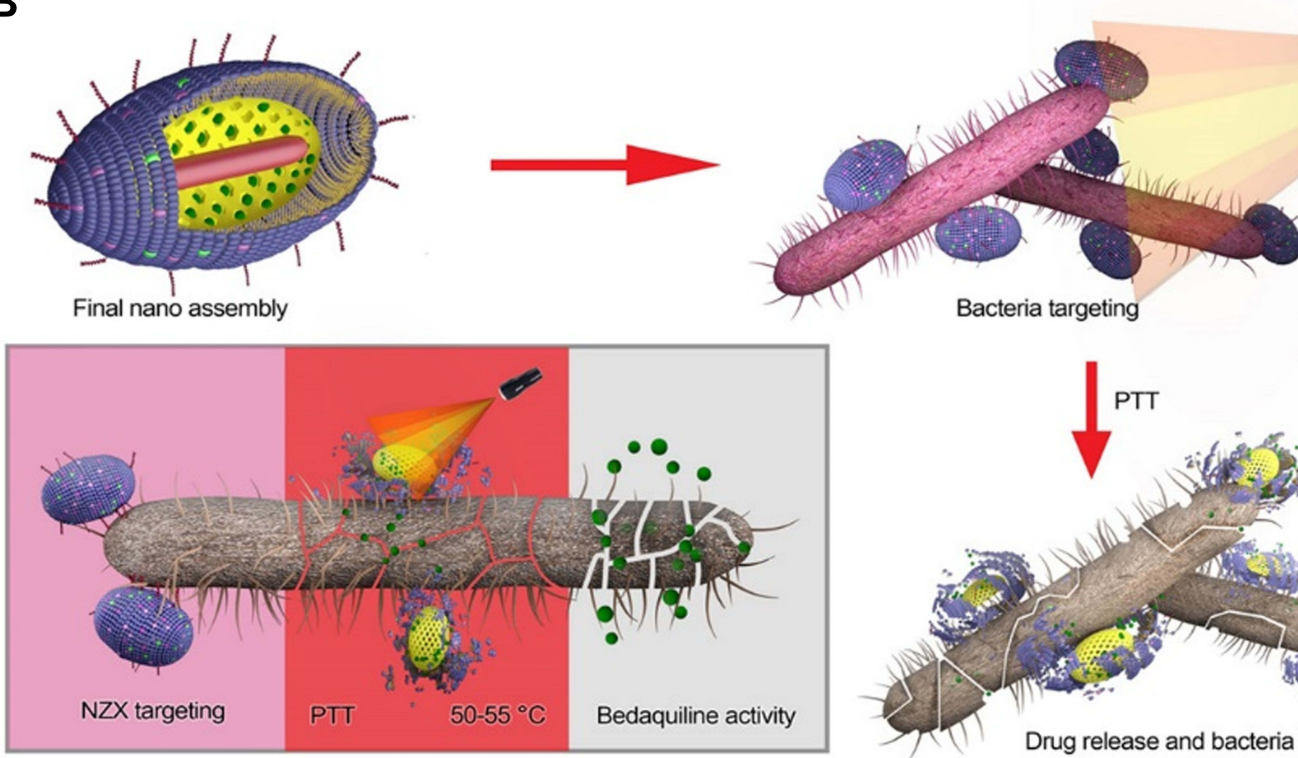

Bacteria targeting

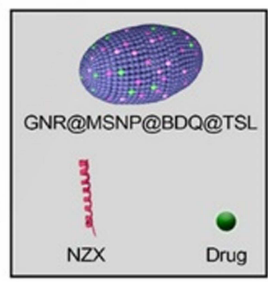

Figure 24 (A) Schematic illustration of stepwise synthesis of the final nano-assembly. (B) Application of final nano-assembly (GNR@MSNP@BDQ@TSL@NZX) for targeting and killing M. smegmatis using 808-nm NIR laser. Reprinted with permission from Patel U, Rathnayake K, Jani H, et al. Near-infrared responsive targeted drug delivery system that offer chemo-phototherma therapy against bacterial infection. Nano Select. 202I. @ 2021 The Authors. Nano Select published by Wiley-VCH GmbH. ${ }^{218}$

effect. $^{230}$ The principle of this design is shown in Figure $27 .^{231}$ The photothermal conversion efficiency of AMNSs was evaluated to be $45.2 \%$. The synergistic antibacterial effect including capture, intrinsic antibacterial effect, and photothermal performance killed $97 \%$ of $E$. coli and $100 \%$ of S. aureus. In Table 3, we have collected several important studies based on the applications of nanomaterials for photothermal killing of bacteria.

\section{Challenges and Opportunities}

Recent advances in photothermal, photodynamic, and ion release antibacterial therapies using nanomaterials were brought together in the present review article. The nanostructures reported in these studies could soon be potential antibacterial candidates in food protection, water purification, and medicine. Metal, metal-polymer nanocomposites, bimetallic nanoparticles and polymer nanoparticles are 


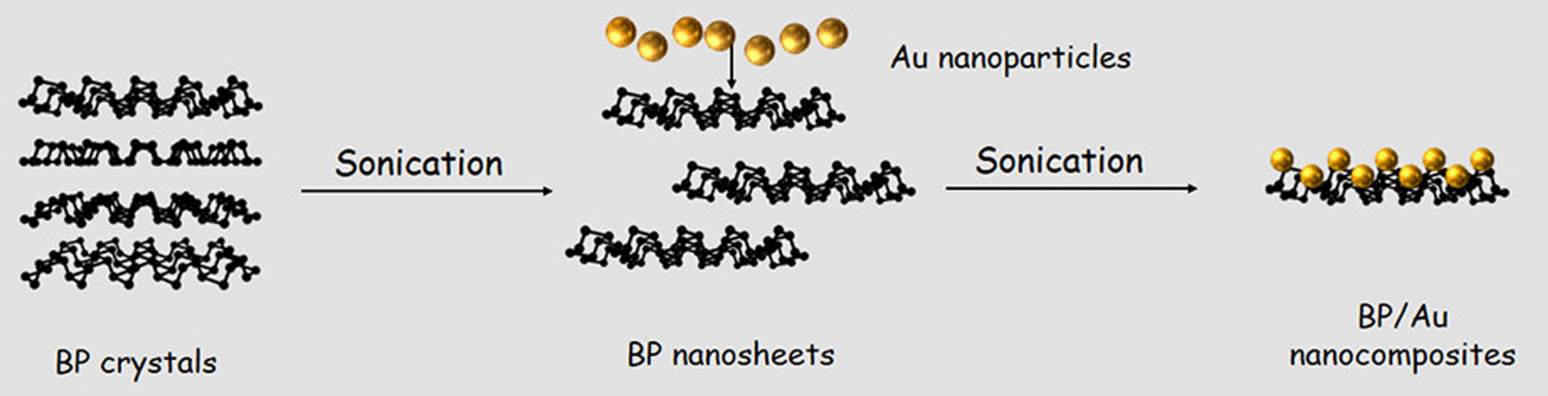

NIR

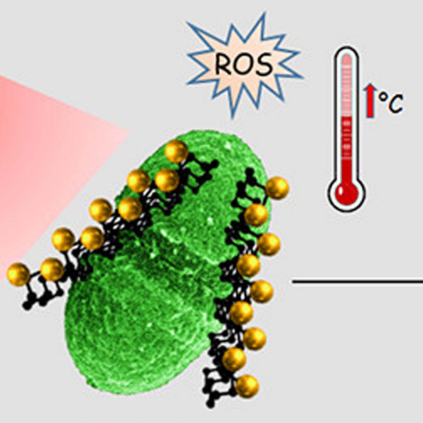

Bacteria

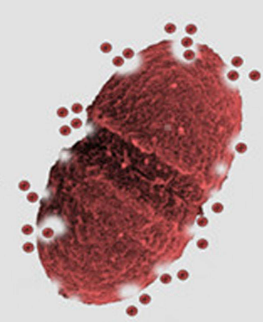

Killed Bacteria

Figure 25 Design of BP/Au nanocomposite and its photothermal killing of bacteria. Reprinted with permission from Aksoy I, Kucukkececi H, Sevgi F, et al. Photothermal antibacterial and antibiofilm activity of black phosphorus/gold nanocomposites against pathogenic bacteria. ACS Appl Mater Interfaces. 2020;12:26822-26831. Copyright (2020), American Chemical Society. ${ }^{223}$

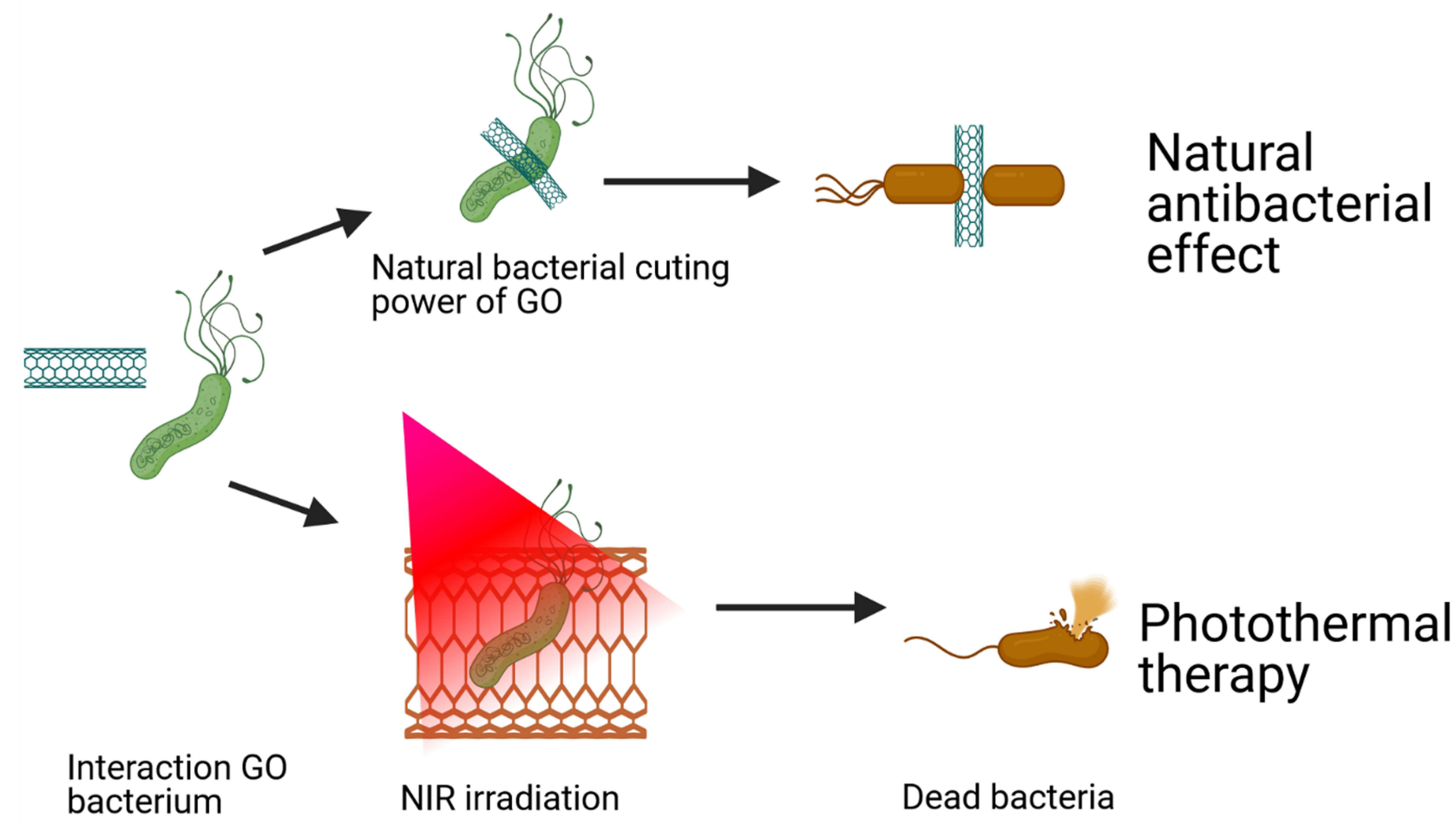

Figure 26 Schematic illustration of natural and photothermal antibacterial effect of AGO based on its positive charge, natural cutting effect, and photothermal property. 


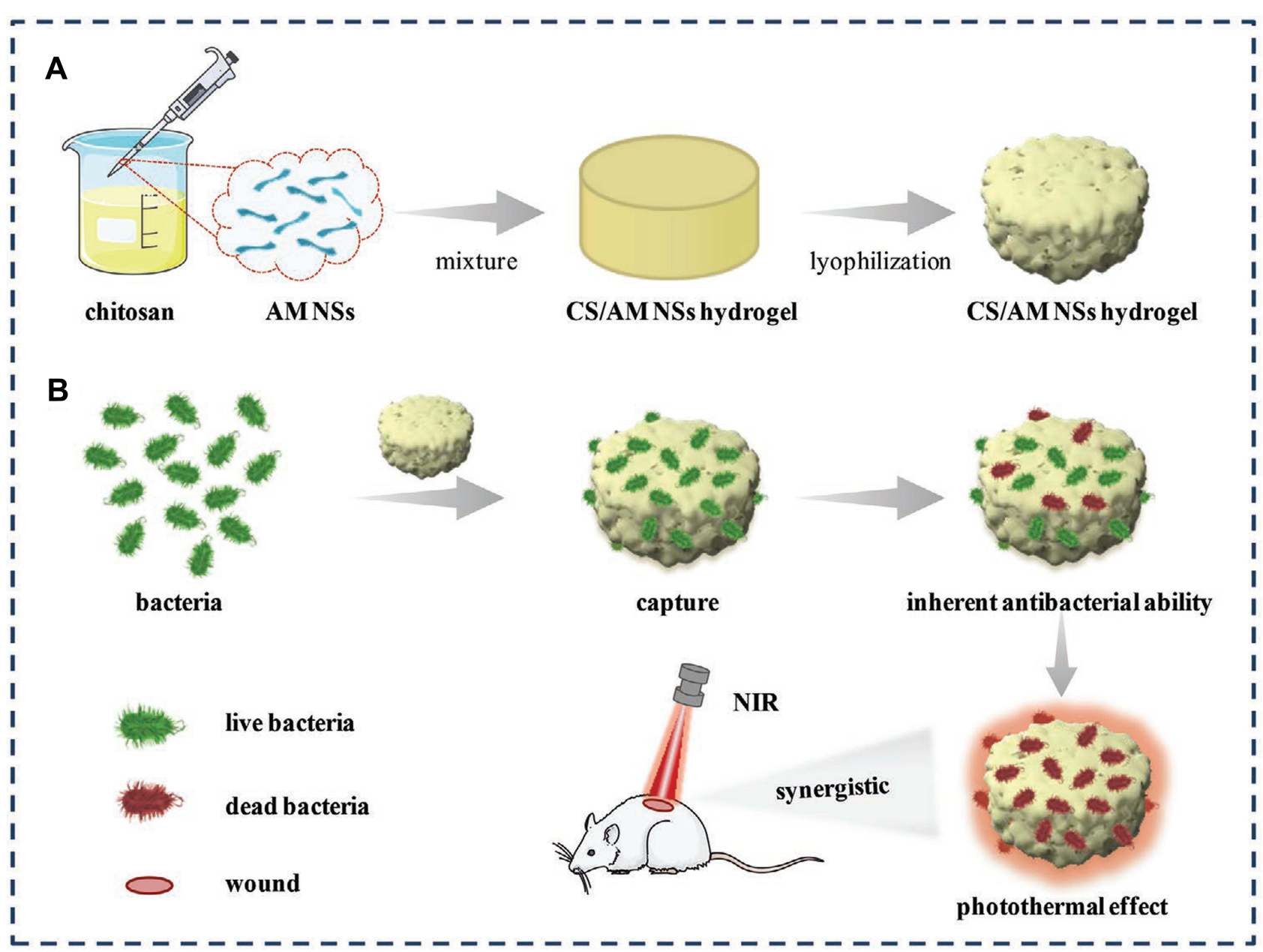

Figure 27 Schematic illustration of (A) the preparation of CS/AM NSs hydrogel and (B) its use in treating bacterial wound infection. Reproduced with permission from Liu Y, Xiao Y, Cao Y, et al. Construction of chitosan-based hydrogel incorporated with antimonene nanosheets for rapid capture and elimination of bacteria. Adv Funct Mater. 2020;30:2003196. (c) 2020 WILEY-VCH Verlag GmbH \& Co. KGaA, Weinheim.Reproduced with permission from ref ${ }^{231}$

promising antibacterial agents that can be harnessed for this purpose. The photothermal effects shown by the nanomaterials were presented by describing the mechanism of action and thermal efficiencies to show microbial inhibition in vitro and in vivo. Through their photothermal effect, the nanostructures affect the biological activities of bacteria to foster bacterial inhibition in addition to their enhanced thermal efficiencies under NIR light irradiation. The photodynamically active nanostructures recently investigated were demonstrated with their antibacterial mechanisms, ROS production abilities, and microbial inhibition under simulated solar light or similar light sources. Metal ion release is similar to photodynamic activity under dark conditions and completely depends on the dissolution and dissociation of metal nanostructures to produce ROS and show potential bacteriostatic and bactericidal effects. One of the crucial unanswered questions is clinical acceptance of these metallic nanostructures and their bacterial inhibition capacity (they are required to exhibit 4-log reduction or about $99.99 \%$ efficiency). Another crucial question is the cytotoxicity and biocompatibility of these metallic nanostructures which also remain unanswered. PTT can also be coupled with other therapies such as metal ion release, PDT, chemotherapy, radiation, and so on to improve treatment outcomes. Bacterial pestilences are likely to be the most frequent 
Table 3 Recap of Photothermal Bacterial Killing with Different Photothermal Agents (PTAs)

\begin{tabular}{|c|c|c|c|c|}
\hline Nanomaterial & Mechanism & Light Source & Bacteria & Reference \\
\hline $2 \mathrm{D} \mathrm{C} / \mathrm{Cu}$ & PTT, $\mathrm{Cu}^{2+}$ release & $808 \mathrm{~nm}$ & $\begin{array}{l}\text { E coli } \\
\text { S. aureus } \\
\text { MRSA }\end{array}$ & [7I] \\
\hline $\mathrm{Au} @ \mathrm{~A} \beta \mathrm{NCs}$ & PTT, binding affinity to bacteria & $808 \mathrm{~nm}$ & $\begin{array}{l}\text { S. aureus } \\
\text { MRSA } \\
\text { E. coli }\end{array}$ & [232] \\
\hline HAuNS@PVP & PTT & $808 \mathrm{~nm}$ & E. coli & [233] \\
\hline VAT hydrogel & PTT, spatiotemporal antibiotics release & $808 \mathrm{~nm}$ & S. aureus & [234] \\
\hline $\mathrm{Y}_{2} \mathrm{O}_{3}: \mathrm{Yb} / \mathrm{Er} @ \mathrm{SiO}_{2} / \mathrm{SiO}_{2} @ \mathrm{Cu}_{2} \mathrm{~S}$ & PTT & $980 \mathrm{~nm}$ & $\begin{array}{l}\text { S. aureus } \\
\text { E. coli }\end{array}$ & [235] \\
\hline $\mathrm{NbTe}_{2} / \mathrm{TA}$ & PTT & $808 \mathrm{~nm}$ & E. coli & [236] \\
\hline Tet-SiPc@AuNR@SiO 2 & PTT & $808 \mathrm{~nm}$ & $\begin{array}{l}\text { E. coli } \\
\text { Antibiotic-resistant E. coli }\end{array}$ & [237] \\
\hline AgNPs/N-CD@ZnO & PTT, $\mathrm{Ag}^{+}$and $\mathrm{Zn}^{2+}$ release & $808 \mathrm{~nm}$ & $\begin{array}{l}\text { E. coli } \\
\text { S. aureus }\end{array}$ & [238] \\
\hline $\mathrm{Au}-\mathrm{ZnO}-\mathrm{BP}(\mathrm{AZB})$ & PTT & $808 \mathrm{~nm}$ & $\begin{array}{l}\text { S. aureus } \\
\text { MRSA }\end{array}$ & [239] \\
\hline $\mathrm{Bi}_{2} \mathrm{~S}_{3} / \mathrm{Ti}_{3} \mathrm{C}_{2} \mathrm{~T}_{\mathrm{x}}-5 \mathrm{MXene}$ & PTT, ROS generation & $808 \mathrm{~nm}$ & $\begin{array}{l}\text { E. coli } \\
\text { S. aureus }\end{array}$ & [240] \\
\hline Gel-PDA@Cur & PTT, curcumin release & $808 \mathrm{~nm}$ & $\begin{array}{l}\text { E. coli } \\
\text { S. aureus }\end{array}$ & [24I] \\
\hline
\end{tabular}

Abbreviations: Au@A $\beta$ NCs, gold and amyloid peptide A $\beta 25-35$ nanocomposite; HAuNS@PVP, hollow gold nanosphere conjugated with polyvinylpyrrolidone; VAT hydrogel, vancomycin-agarose-ferric tannate; $\mathrm{Y}_{2} \mathrm{O}_{3}: \mathrm{Yb} / \mathrm{Er} @ \mathrm{SiO}_{2} / \mathrm{SiO}_{2} @ \mathrm{Cu}_{2} \mathrm{~S}$, nanocomposite from yttrium oxide $\left(\mathrm{Y}_{2} \mathrm{O}_{3}\right)$, yttrium/erbium conjugated with silicon dioxide $\left(\mathrm{Yb} / \mathrm{Er} @ \mathrm{SiO}_{2}\right)$, and silicon dioxide conjugated with copper sulfide $\left(\mathrm{SiO}_{2} @ \mathrm{Cu}_{2} \mathrm{~S}\right)$; NbTe2/TA, tannic acid (TA)-modified NbTe2 nanosheet; Tet-SiPc@AuNR@SiO, mesoporous silica-coated gold nanorod loaded with tetrazolyl phthalocyanine; 2DC/Cu, two-dimensional carbon nanosheet (2D C) decorated with Cu nanoparticles (NPs); CNSs@FeS 2 , carbon nanospheres (CNSs) decorated with ultrasmall FeS 2 NPs; AgNPs/N-CD@ZnO, Ag NPs and ZnO NPs decorated by N-doped carbon dots (N$\mathrm{CD} @ Z n O) ; A Z B$, black phosphorus nanosheets conjugated with gold NPs and assembled with $\mathrm{ZnO} \mathrm{NPs;} \mathrm{Bi}_{2} \mathrm{~S}_{3} / \mathrm{Ti}_{3} \mathrm{C}_{2} \mathrm{~T}_{x}-5$, bismuth sulfide (Bi $\mathrm{S}_{3}$ ) conjugated with titanium carbide $\left(\mathrm{Ti}_{3} \mathrm{C}_{2} \mathrm{~T}_{\mathrm{x}}-5\right)$ MXene; Gel-PDA@Cur, dibenzaldehyde-grafted poly (ethylene glycol) (PEGDA), lauric acid-terminated chitosan (Chi-LA), and curcumin (Cur)-loaded mesoporous polydopamine nanoparticles (PDA@Cur); PTT, photothermal therapy; MRSA, methicillin-resistant Staphylococcus aureus.

diseases globally which will need to be contained, and evaluating the safety and efficacy of available nanomaterials will play a crucial role before their administration in living beings and may have significant impact surrounding environment.

\section{Acknowledgments}

We acknowledge support from the Ministry of Science and Technology, Taiwan (Contracts MOST 109-2113-M-038005-MY2), the Higher Education Sprout Project from the Ministry of Education (MOE) in Taiwan and Taipei Medical University. We acknowledge the academic and science graphic illustration service provided by TMU Office of Research and Development and Ms. Pei-Hsuan
Tseng for her graphic illustration support at TMU Office of Research and Development.

\section{Disclosure}

The authors report no conflicts of interest in this work.

\section{References}

1. Singer A, Markoutsa E, Limayem A, et al. Nanobiotechnology medical applications: overcoming challenges through innovation. Eurobiotech J. 2018;2:146-160.

2. Willyard C. The drug-resistant bacteria that pose the greatest health threats. Nature. 2017;543:15. doi:10.1038/nature.2017.21550

3. Teng SO, Yen MY, Ou TY, et al. Comparison of pneumonia- and nonpneumonia-related acinetobacter baumannii bacteremia: impact on empiric therapy and antibiotic resistance. J Microbiol Immunol Infect. 2015;48:525-530. doi:10.1016/j.jmii.2014.06.011 
4. $\mathrm{Ku} \mathrm{YH,} \mathrm{Chuang} \mathrm{YC}$, Chen $\mathrm{CC}$, et al. Klebsiella pneumoniae isolates from meningitis: epidemiology, virulence and antibiotic resistance. Sci Rep. 2017;7:6634. doi:10.1038/s41598-01706878-6

5. Kenny RG, Marmion CJ. Toward multi-targeted platinum and ruthenium drugs - a new paradigm in cancer drug treatment regimens? Chem Rev. 2019;119:1058-1137. doi:10.1021/acs.chemrev.8b00271

6. Biot C, Nosten F, Fraisse L, et al. The antimalarial ferroquine: from bench to clinic. Parasite. 2011;18:207. doi:10.1051/parasite/ 2011183207

7. Jia Q, Song Q, Li P, et al. Rejuvenated photodynamic therapy for bacterial infections. Adv Healthc Mater. 2019;8:1900608. doi:10.1002/adhm.201900608

8. Qing G, Zhao X, Gong N, et al. Thermo-responsive triple-function nanotransporter for efficient chemo-photothermal therapy of multidrug-resistant bacterial infection. Nat Commun. 2019;10:112. doi:10.1038/s41467-019-12313-3

9. Liu W, Pan Y, Zhong Y, et al. A multifunctional aminated uio-67 metal-organic framework for enhancing antitumor cytotoxicity through bimodal drug delivery. Chem Eng J. 2021;412:127899. doi:10.1016/j.cej.2020.127899

10. Zhong $\mathrm{Y}, \mathrm{Li} \mathrm{X}$, Chen $\mathrm{J}$, et al. Recent advances in mof-based nanoplatforms generating reactive species for chemodynamic therapy. Dalton Trans. 2020;49:11045-11058. doi:10.1039/ D0DT01882A

11. Tan G, Zhong Y, Yang L, et al. A multifunctional mof-based nanohybrid as injectable implant platform for drug synergistic oral cancer therapy. Chem Eng J. 2020;390:124446. doi:10.1016/j.cej.2020.124446

12. Zhang $\mathrm{Y}$, Lin $\mathrm{C}$, Lin $\mathrm{Q}$, et al. Cui-bioi/Cu film for enhanced photo-induced charge separation and visible-light antibacterial activity. Appl Catal B. 2018;235:238-245. doi:10.1016/j. apcatb.2018.05.001

13. Elabbasy M, Abd El-Kader M, Ismail A, et al. Regulating the function of bismuth (iii) oxide nanoparticles scattered in chitosan/poly (vinyl pyrrolidone) by laser ablation on electrical conductivity characterization and antimicrobial activity. $J$ Mater Res Technol. 2021;10:1348-1354. doi:10.1016/j. jmrt.2020.12.109

14. Ezzat H, Menazea A, Omara W, et al. Dft: b3lyp/lanl2dz study for the removal of $\mathrm{fe}, \mathrm{ni}, \mathrm{Cu}$, as, $\mathrm{cd}$ and $\mathrm{pb}$ with chitosan. Biointerface Res Appl Chem. 2020;10:7002-7010.

15. Menazea A, Ahmed M. Wound healing activity of chitosan/polyvinyl alcohol embedded by gold nanoparticles prepared by nanosecond laser ablation. J Mol Struct. 2020;1217:128401. doi:10.1016/j.molstruc.2020.128401

16. Tommalieh M, Ismail A, Awwad NS, et al. Investigation of electrical conductivity of gold nanoparticles scattered in polyvinylidene fluoride/polyvinyl chloride via laser ablation for electrical applications. $J$ Electron Mater. 2020;49:7603-7608. doi:10.1007/s11664-020-08459-2

17. Menazea A, Awwad NS. Antibacterial activity of $\mathrm{TiO} 2$ doped $\mathrm{ZnO}$ composite synthesized via laser ablation route for antimicrobial application. J Mater Res Technol. 2020;9:9434-9441. doi:10.1016/j.jmrt.2020.05.103

18. Menazea A, Ismail A, Awwad NS, et al. Physical characterization and antibacterial activity of pva/chitosan matrix doped by selenium nanoparticles prepared via one-pot laser ablation route. $J$ Mater Res Technol. 2020;9:9598-9606. doi:10.1016/j. jmrt.2020.06.077

19. Morsi M, Rajeh A, Menazea A. Nanosecond laser-irradiation assisted the improvement of structural, optical and thermal properties of polyvinyl pyrrolidone/carboxymethyl cellulose blend filled with gold nanoparticles. J Mater Sci: Mater Electron. 2019;30:2693-2705.
20. Menazea A, Ahmed M. Synthesis and antibacterial activity of graphene oxide decorated by silver and copper oxide nanoparticles. J Mol Struct. 2020;1218:128536. doi:10.1016/j. molstruc.2020.128536

21. Menazea A, El-Newehy MH, Thamer BM, et al. Preparation of antibacterial film-based biopolymer embedded with vanadium oxide nanoparticles using one-pot laser ablation. J Mol Struct. 2021;1225:129163. doi:10.1016/j.molstruc.2020.129163

22. Tommalieh M, Ibrahium HA, Awwad NS, et al. Gold nanoparticles doped polyvinyl alcohol/chitosan blend via laser ablation for electrical conductivity enhancement. $J$ Mol Struct. 2020;1221:128814. doi:10.1016/j.molstruc.2020.128814

23. Menazea A, Awwad NS, Ibrahium HA, et al. Casted polymeric blends of carboxymethyl cellulose/polyvinyl alcohol doped with gold nanoparticles via pulsed laser ablation technique; morphological features, optical and electrical investigation. Radiat Phys Chem. 2020;177:109155. doi:10.1016/j.radphyschem.2020.109155

24. Tommalieh M, Awwad NS, Ibrahium HA, et al. Characterization and electrical enhancement of pvp/pva matrix doped by gold nanoparticles prepared by laser ablation. Radiat Phys Chem. 2021;179:109195. doi:10.1016/j.radphyschem.2020.109195

25. Chang PH, Chao HM, Chern E, et al. Chitosan 3d cell culture system promotes naive-like features of human induced pluripotent stem cells: a novel tool to sustain pluripotency and facilitate differentiation. Biomaterials. 2021;268:120575. doi:10.1016/j. biomaterials.2020.120575

26. Chou CM, Mi FL, Horng JL, et al. Characterization and toxicology evaluation of low molecular weight chitosan on zebrafish. Carbohydr Polym. 2020;240:116164. doi:10.1016/j. carbpol.2020.116164

27. Lin $\mathrm{MH}$, Wang $\mathrm{YH}$, Kuo $\mathrm{CH}$, et al. Hybrid $\mathrm{ZnO}$ /chitosan antimicrobial coatings with enhanced mechanical and bioactive properties for titanium implants. Carbohydr Polym. 2021;257:117639. doi:10.1016/j.carbpol.2021.117639

28. Don TM, Chang WJ, Jheng PR, et al. Curcumin-laden dualtargeting fucoidan/chitosan nanocarriers for inhibiting brain inflammation via intranasal delivery. Int $J$ Biol Macromol. 2021;181:835-846. doi:10.1016/j.ijbiomac.2021.04.045

29. Huang YM, Lin YC, Chen CY, et al. Thermosensitive chitosangelatin-glycerol phosphate hydrogels as collagenase carrier for tendon-bone healing in a rabbit model. Polymers. 2020;12:436. doi:10.3390/polym 12020436

30. Mutalik C, Krisnawati DI, Patil SB, et al. Phase-dependent MoS2 nanoflowers for light-driven antibacterial application. ACS Sustain Chem Eng. 2021;9:7904-7912. doi:10.1021/ acssuschemeng.1c01868

31. Liu WC, Yan QW, Xia C, et al. Recent advances in cell membrane coated metal-organic frameworks (mofs) for tumor therapy. $J$ Mater Chem B. 2021;9:4459-4474. doi:10.1039/D1TB00453K

32. Pan Y, Luo ZD, Wang XX, et al. A versatile and multifunctional metal-organic framework nanocomposite toward chemo-photodynamic therapy. Dalton Trans. 2020;49:5291-5301. doi:10.1039/ C9DT04804A

33. Frei A, Zuegg J, Elliott AG, et al. Metal complexes as a promising source for new antibiotics. Chem Sci. 2020;11:2627-2639. doi:10.1039/C9SC06460E

34. Chang TK, Cheng TM, Chug HL, et al. Metabolic mechanism investigation of antibacterial active cysteine-conjugated gold nanoclusters in Escherichia coli.. ACS Sustain Chem Eng. 2019;7:15479-15486. doi:10.1021/acssuschemeng.9b03048

35. Yougbare S, Chang TK, Tan SH, et al. Antimicrobial gold nanoclusters: recent developments and future perspectives. Int $J$ Mol Sci. 2019;20:2924. doi:10.3390/ijms20122924

36. Chen J, Fan T, Xie Z, et al. Advances in nanomaterials for photodynamic therapy applications: status and challenges. Biomaterials. 2020;237:119827. 
37. Kaur N, Aditya RN, Singh A, et al. Biomedical applications for gold nanoclusters: recent developments and future perspectives. Nanoscale Res Lett. 2018;13:1-12. doi:10.1186/s11671-018-2725-9

38. Wei MF, Chen MW, Chen KC, et al. Autophagy promotes resistance to photodynamic therapy-induced apoptosis selectively in colorectal cancer stem-like cells. Autophagy. 2014;10:1179-1192. doi:10.4161/auto.28679

39. Chung CH, Lu KY, Lee WC, et al. Fucoidan-based, tumor-activated nanoplatform for overcoming hypoxia and enhancing photodynamic therapy and antitumor immunity. Biomaterials 2020;257:120227. doi:10.1016/j.biomaterials.2020.120227

40. Chen CT, Peng PC, Tsai T, et al. A novel treatment modality for malignant peripheral nerve sheath tumor using a dual-effect liposome to combine photodynamic therapy and chemotherapy. Pharmaceutics. 2020;12(4):317. doi:10.3390/ pharmaceutics 12040317

41. Lee MJ, Hung SH, Huang MC, et al. Doxycycline potentiates antitumor effect of 5aminolevulinic acid-mediated photodynamic therapy in malignant peripheral nerve sheath tumor cells. PLoS One. 2017;12:e0178493.

42. Hamblin MR. Antimicrobial photodynamic inactivation: a bright new technique to kill resistant microbes. Curr Opin Microbiol. 2016;33:67-73. doi:10.1016/j.mib.2016.06.008

43. Tavares A, Carvalho C, Faustino MA, et al. Antimicrobial photodynamic therapy: study of bacterial recovery viability and potential development of resistance after treatment. Mar Drugs. 2010;8:91-105. doi:10.3390/md8010091

44. Maisch T, Hackbarth S, Regensburger J, et al. Photodynamic inactivation of multi-resistant bacteria (pib)-a new approach to treat superficial infections in the 21 st century. $J$ Dtsch Dermatol Ges. 2011;9:360-366.

45. Wainwright M, Maisch T, Nonell S, et al. Photoantimicrobialsare we afraid of the light? Lancet Infect Dis. 2017;17:e49-e55. doi:10.1016/S1473-3099(16)30268-7

46. Yougbaré S, Mutalik C, Krisnawati DI, et al. Nanomaterials for the photothermal killing of bacteria. Nanomaterials. 2020;10:1123. doi:10.3390/nano10061123

47. Carrillo-Carrión C, Nazarenus M, Paradinas SS, et al. Metal ions in the context of nanoparticles toward biological applications. Curr Opin Chem Eng. 2014;4:88-96. doi:10.1016/j. coche.2013.11.006

48. Faisal M, Saquib Q, Alatar AA, et al. Phytotoxic hazards of nionanoparticles in tomato: a study on mechanism of cell death. J Hazard Mater. 2013;250:318-332. doi:10.1016/j.jhazmat.2013.01.063

49. Thakur S, Neogi S. Effect of doped $\mathrm{ZnO}$ nanoparticles on bacterial cell morphology and biochemical composition. Appl Nanosci. 2021;11:159-171. doi:10.1007/s13204-020-01592-8

50. Fu PP, Xia Q, Hwang H-M, et al. Mechanisms of nanotoxicity: generation of reactive oxygen species. J Food Drug Anal. 2014;22:64-75. doi:10.1016/j.jfda.2014.01.005

51. Slavin YN, Asnis J, Häfeli UO, et al. Metal nanoparticles: understanding the mechanisms behind antibacterial activity. $J$ Nanobiotechnology. 2017;15:1-20. doi:10.1186/s12951-017-0308-Z

52. Stanić V, Tanasković SB. Antibacterial activity of metal oxide nanoparticles. In: Nanotoxicity. Elsevier; 2020:241-274.

53. Alqahtany M, Khadka P, Niyonshuti I, et al. Nanoscale reorganizations of histone-like nucleoid structuring proteins in Escherichia coli are caused by silver nanoparticles. Nanotechnology. 2019;30:385101. doi:10.1088/1361-6528/ ab2a9f

54. Zhang S, Ye J, Liu Z, et al. Superior antibacterial activity of $\mathrm{Fe}_{3} \mathrm{O}_{4} @$ copper (ii) metal-organic framework core-shell magnetic microspheres. Dalton Trans. 2020;49:13044-13051. doi:10.1039/ D0DT02417A
55. Xue JJ, Bigdeli F, Liu JP, et al. Ultrasonic-assisted synthesis and DNA interaction studies of two new ru complexes; ruo2 nanoparticles preparation. Nanomedicine. 2018;13:2691-2708. doi:10.2217/nnm-2018-0174

56. Gonzalez L, Lison D, Kirsch-Volders M. Genotoxicity of engineered nanomaterials: a critical review. Nanotoxicology. 2008;2:252-273. doi:10.1080/17435390802464986

57. He W, Zhou YT, Wamer WG, et al. Mechanisms of the ph dependent generation of hydroxyl radicals and oxygen induced by Ag nanoparticles. Biomaterials. 2012;33:7547-7555. doi:10.1016/j.biomaterials.2012.06.076

58. Wang B, Yin JJ, Zhou X, et al. Physicochemical origin for free radical generation of iron oxide nanoparticles in biomicroenvironment: catalytic activities mediated by surface chemical states. J Phys Chem C. 2013;117:383-392. doi:10.1021/ jp3101392

59. Lu W, Senapati D, Wang S, et al. Effect of surface coating on the toxicity of silver nanomaterials on human skin keratinocytes. Chem Phys Lett. 2010;487:92-96. doi:10.1016/j. cplett.2010.01.027

60. Shaligram S, Campbell A. Toxicity of copper salts is dependent on solubility profile and cell type tested. Toxicol in Vitro. 2013;27:844-851. doi:10.1016/j.tiv.2012.12.026

61. Wang S, Lu W, Tovmachenko O, et al. Challenge in understanding size and shape dependent toxicity of gold nanomaterials in human skin keratinocytes. Chem Phys Lett. 2008;463:145-149. doi:10.1016/j.cplett.2008.08.039

62. Ning $\mathrm{C}$, Wang $\mathrm{X}, \mathrm{Li} \mathrm{L}$, et al. Concentration ranges of antibacterial cations for showing the highest antibacterial efficacy but the least cytotoxicity against mammalian cells: implications for a new antibacterial mechanism. Chem Res Toxicol. 2015;28:18151822. doi:10.1021/acs.chemrestox.5b00258

63. Wang $\mathrm{X}$, Liu S, Li M, et al. The synergistic antibacterial activity and mechanism of multicomponent metal ions-containing aqueous solutions against staphylococcus aureus. J Inorg Biochem. 2016;163:214-220. doi:10.1016/j.jinorgbio.2016.07.019

64. Rawashdeh RY, Sawafta R, Malkawi HI. Dental materials incorporated with nanometals and their effect on the bacterial growth of staphylococcus aureus. Int J Nanomed. 2020;15:4325. doi:10.2147/ IJN.S251573

65. Fei X, Li Y, Weir MD, et al. Novel pit and fissure sealant containing nano-caf ${ }_{2}$ and dimethylaminohexadecyl methacrylate with double benefits of fluoride release and antibacterial function. Dent Mater. 2020;36:1241-1253. doi:10.1016/j.dental.2020.05.010

66. Kumar A, Behl T, Chadha S. Synthesis of physically crosslinked pva/chitosan loaded silver nanoparticles hydrogels with tunable mechanical properties and antibacterial effects. Int $J$ Biol Macromol. 2020;149:1262-1274. doi:10.1016/j. ijbiomac.2020.02.048

67. Li R, Xu Z, Jiang Q, et al. Characterization and biological evaluation of a novel silver nanoparticle-loaded collagen-chitosan dressing. Regen Biomater. 2020;7:371-380. doi:10.1093/rb/ rbaa008

68. Paterson TE, Bari A, Bullock AJ, et al. Multifunctional coppercontaining mesoporous glass nanoparticles as antibacterial and proangiogenic agents for chronic wounds. Front Bioeng Biotechnol. 2020;8:246. doi:10.3389/fbioe.2020.00246

69. van Hengel I, Tierolf M, Valerio V, et al. Self-defending additively manufactured bone implants bearing silver and copper nanoparticles. J Mater Chem B. 2020;8:1589-1602.

70. Javadhesari SM, Alipour S, Akbarpour M. Effects of sic nanoparticles on synthesis and antimicrobial activity of ticu nanocrystalline powder. Ceram Int. 2020;46:114-120. doi:10.1016/j. ceramint.2019.08.240 
71. Song J, Li J, Bai X, et al. Cu nanoparticle-decorated two-dimensional carbon nanosheets with superior photothermal conversion efficiency of $65 \%$ for highly efficient disinfection under nearinfraed light. J Mater Res Technol. 2021;87:83-94. doi:10.1016/ j.jmst.2021.01.057

72. Shankar S, Rhim JW. Eco-friendly antimicrobial nanoparticles of keratin-metal ion complex. Mater Sci Eng C. 2019;105:110068. doi:10.1016/j.msec.2019.110068

73. Irfan M, Polonskyi O, Hinz A, et al. Antibacterial, highly hydrophobic and semi transparent Ag/plasma polymer nanocomposite coating on cotton fabric obtained by plasma based co-deposition. Cellulose. 2019;26:8877-8894. doi:10.1007/s10570-019-02685-6

74. Mokabber T, Cao H, Norouzi N, et al. Antimicrobial electrodeposited silver-containing calcium phosphate coatings. ACS Appl Mater Interfaces. 2020;12:5531-5541. doi:10.1021/ acsami.9b20158

75. Gokcekaya O, Ergun C, Webster TJ, et al. Effect of precursor deficiency induced $\mathrm{ca} / \mathrm{p}$ ratio on antibacterial and osteoblast adhesion properties of Ag-incorporated hydroxyapatite: reducing Ag toxicity. Materials. 2021;14:3158. doi:10.3390/ ma14123158

76. Gokcekaya O, Ueda K, Ogasawara K, et al. Antibacterial activity of Ag nanoparticle-containing hydroxyapatite powders in simulated body fluids with Cl ions. Mater Chem Phys. 2019;223:473478. doi:10.1016/j.matchemphys.2018.11.015

77. Horie M, Fujita K, Kato H, et al. Association of the physical and chemical properties and the cytotoxicity of metal oxidenanoparticles: metal ion release, adsorption ability and specific surface area. Metallomics. 2012;4:350-360. doi:10.1039/c2mt20016c

78. Schiavo S, Oliviero M, Li J, et al. Testing $\mathrm{ZnO}$ nanoparticle ecotoxicity: linking time variable exposure to effects on different marine model organisms. Environ Sci Pollut Res. 2018;25:48714880. doi:10.1007/s11356-017-0815-3

79. Xia T, Kovochich M, Liong M, et al. Comparison of the mechanism of toxicity of zinc oxide and cerium oxide nanoparticles based on dissolution and oxidative stress properties. ACS Nano. 2008;2:2121-2134. doi:10.1021/nn800511k

80. Brown JL. Zinc fume fever. Brit J Radiol. 1988;61:327-329. doi:10.1259/0007-1285-61-724-327

81. Lin Y, Taylor S, Li H, et al. Advances toward bioapplications of carbon nanotubes. J Mater Chem. 2004;14:527-541. doi:10.1039/ b314481j

82. Chang YN, Zhang M, Xia L, et al. The toxic effects and mechanisms of cuo and $\mathrm{ZnO}$ nanoparticles. Materials. 2012;5:28502871. doi:10.3390/ma5122850

83. Huang CC, Aronstam RS, Chen DR, et al. Oxidative stress, calcium homeostasis, and altered gene expression in human lung epithelial cells exposed to $\mathrm{ZnO}$ nanoparticles. Toxicol in Vitro. 2010;24:45-55. doi:10.1016/j.tiv.2009.09.007

84. Sharifi S, Behzadi S, Laurent S, et al. Toxicity of nanomaterials. Chem Soc Rev. 2012;41:2323-2343. doi:10.1039/C1CS15188F

85. Brandenberger C, Mühlfeld C, Ali Z, et al. Quantitative evaluation of cellular uptake and trafficking of plain and polyethylene glycol-coated gold nanoparticles. Small. 2010;6:1669-1678. doi:10.1002/smll.201000528

86. Hua M, Zhang S, Pan B, et al. Heavy metal removal from water/ wastewater by nanosized metal oxides: a review. J Hazard Mater. 2012;211:317-331. doi:10.1016/j.jhazmat.2011.10.016

87. Iversen TG, Skotland T, Sandvig K. Endocytosis and intracellular transport of nanoparticles: present knowledge and need for future studies. Nano Today. 2011;6:176-185. doi:10.1016/j. nantod.2011.02.003

88. Zhao F, Zhao Y, Liu Y, et al. Cellular uptake, intracellular trafficking, and cytotoxicity of nanomaterials. small. 2011;7:13221337. doi:10.1002/smll.201100001
89. Hemeg HA. Nanomaterials for alternative antibacterial therapy. Int J Nanomed. 2017;12:8211. doi:10.2147/IJN.S132163

90. Wang D, Lin Z, Wang T, et al. Where does the toxicity of metal oxide nanoparticles come from: the nanoparticles, the ions, or a combination of both? J Hazard Mater. 2016;308:328-334. doi:10.1016/j.jhazmat.2016.01.066

91. Baek YW, An YJ. Microbial toxicity of metal oxide nanoparticles (cuo, nio, $\mathrm{ZnO}$, and $\mathrm{sb}_{2} \mathrm{O}_{3}$ ) to Escherichia coli, bacillus subtilis, and streptococcus aureus. Sci Total Environ. 2011;409:16031608. doi:10.1016/j.scitotenv.2011.01.014

92. Misra SK, Dybowska A, Berhanu D, et al. The complexity of nanoparticle dissolution and its importance in nanotoxicological studies. Sci Total Environ. 2012;438:225-232. doi:10.1016/j. scitotenv.2012.08.066

93. Tang R, Orme CA, Nancollas GH. Dissolution of crystallites: surface energetic control and size effects. ChemPhysChem. 2004;5:688-696. doi:10.1002/cphc.200300956

94. Tinke A, Vanhoutte K, De Maesschalck R, et al. A new approach in the prediction of the dissolution behavior of suspended particles by means of their particle size distribution. J Pharm Biomed Anal. 2005;39:900-907. doi:10.1016/j.jpba.2005.05.014

95. Borm P, Klaessig FC, Landry TD, et al. Research strategies for safety evaluation of nanomaterials, part $\mathrm{v}$ : role of dissolution in biological fate and effects of nanoscale particles. Toxicol Sci. 2006;90:23-32. doi:10.1093/toxsci/kfj084

96. Przybyszewska M, Zaborski M. The effect of zinc oxide nanoparticle morphology on activity in crosslinking of carboxylated nitrile elastomer. Express Polym Lett. 2009;3:542-552. doi:10.3144/expresspolymlett.2009.68

97. Mclaren A, Valdes-Solis T, Li G, et al. Shape and size effects of $\mathrm{ZnO}$ nanocrystals on photocatalytic activity. $\mathrm{J}$ Am Chem Soc. 2009;131:12540-12541. doi:10.1021/ja9052703

98. Cha SH, Hong J, McGuffie M, et al. Shape-dependent biomimetic inhibition of enzyme by nanoparticles and their antibacterial activity. ACS Nano. 2015;9:9097-9105. doi:10.1021/acsnano.5b03247

99. Choi O, Hu Z. Size dependent and reactive oxygen species related nanosilver toxicity to nitrifying bacteria. Environ Sci Technol. 2008;42:4583-4588. doi:10.1021/es703238h

100. Ivask A, ElBadawy A, Kaweeteerawat C, et al. Toxicity mechanisms in Escherichia coli vary for silver nanoparticles and differ from ionic silver. ACS Nano. 2014;8:374-386. doi:10.1021/ nn4044047

101. Padmavathy N, Vijayaraghavan R. Enhanced bioactivity of $\mathrm{ZnO}$ nanoparticles - an antimicrobial study. Adv Mater Technol. 2008;9:035004. doi:10.1088/1468-6996/9/3/035004

102. Stoimenov PK, Klinger RL, Marchin GL, et al. Metal oxide nanoparticles as bactericidal agents. Langmuir. 2002;18:66796686. doi:10.1021/la0202374

103. Shamaila S, Zafar N, Riaz S, et al. Gold nanoparticles: an efficient antimicrobial agent against enteric bacterial human pathogen. Nanomaterials. 2016;6:71. doi:10.3390/nano6040071

104. Wong MS, Chen CW, Hsieh CC, et al. Antibacterial property of Ag nanoparticle-impregnated n-doped titania films under visible light. Sci Rep. 2015;5:1-11. doi:10.1038/srep11978

105. Dakal TC, Kumar A, Majumdar RS, et al. Mechanistic basis of antimicrobial actions of silver nanoparticles. Front Microbiol. 2016;7:1831.

106. Durán N, Durán M, De Jesus MB, et al. Silver nanoparticles: a new view on mechanistic aspects on antimicrobial activity. Nanomedicine. 2016;12:789-799. doi:10.1016/j. nano.2015.11.016

107. Ivask A, Suarez E, Patel T, et al. Genome-wide bacterial toxicity screening uncovers the mechanisms of toxicity of a cationic polystyrene nanomaterial. Environ Sci Technol. 2012;46:23982405. doi:10.1021/es203087m 
108. Dorobantu LS, Fallone C, Noble AJ, et al. Toxicity of silver nanoparticles against bacteria, yeast, and algae. $J$ Nanoparticle Res. 2015;17:1-13. doi:10.1007/s11051-015-2984-7

109. Wang X, Sun T, Zhu H, et al. Roles of ph, cation valence, and ionic strength in the stability and aggregation behavior of zinc oxide nanoparticles. J Environ Manage. 2020;267:110656. doi:10.1016/j.jenvman.2020.110656

110. Bian SW, Mudunkotuwa IA, Rupasinghe T, et al. Aggregation and dissolution of $4 \mathrm{~nm} \mathrm{ZnO}$ nanoparticles in aqueous environments: influence of ph, ionic strength, size, and adsorption of humic acid. Langmuir. 2011;27:6059-6068. doi:10.1021/la200570n

111. Dong C, Cairney J, Sun Q, et al. Investigation of $\mathrm{mg}(\mathrm{oh})_{2}$ nanoparticles as an antibacterial agent. $J$ Nanoparticle Res. 2010;12:2101-2109. doi:10.1007/s11051-009-9769-9

112. Bae DH, Yeon JH, Park SY, et al. Bactericidal effects of cao (scallop-shell powder) on foodborne pathogenic bacteria. Arch Pharm Res. 2006;29:298-301. doi:10.1007/BF02968574

113. Zhou W, Peng X, Zhou X, et al. In vitro evaluation of composite containing dmahdm and calcium phosphate nanoparticles on recurrent caries inhibition at bovine enamel-restoration margins. Dent Mater. 2020;36:1343-1355. doi:10.1016/j.dental.2020.07.007

114. Kim JH, Cho H, Ryu SE, et al. Effects of metal ions on the activity of protein tyrosine phosphatase vhr: highly potent and reversible oxidative inactivation by cu2+ ion. Arch Biochem Biophys. 2000;382:72-80. doi:10.1006/abbi.2000.1996

115. Brayner R, Ferrari-Iliou R, Brivois N, et al. Toxicological impact studies based on Escherichia coli bacteria in ultrafine $\mathrm{ZnO}$ nanoparticles colloidal medium. Nano Lett. 2006;6:866-870. doi:10.1021/n1052326h

116. Sirelkhatim A, Mahmud S, Seeni A, et al. Review on zinc oxide nanoparticles: antibacterial activity and toxicity mechanism. Micro Nano Lett. 2015;7:219-242. doi:10.1007/s40820-0150040-x

117. Zhang L, Jiang Y, Ding Y, et al. Investigation into the antibacterial behaviour of suspensions of $\mathrm{ZnO}$ nanoparticles ( $\mathrm{ZnO}$ nanofluids). J Nanoparticle Res. 2007;9:479-489. doi:10.1007/ s11051-006-9150-1

118. Pan X, Redding JE, Wiley PA, et al. Mutagenicity evaluation of metal oxide nanoparticles by the bacterial reverse mutation assay. Chemosphere. 2010;79:113-116. doi:10.1016/j. chemosphere.2009.12.056

119. Saleh NB, Chambers B, Aich N, et al. Mechanistic lessons learned from studies of planktonic bacteria with metallic nanomaterials: implications for interactions between nanomaterials and biofilm bacteria. Front Microbiol. 2015;6:677. doi:10.3389 fmicb.2015.00677

120. Edelson RL. Light-activated drugs. Sci Am. 1988;259:68-75. doi:10.1038/scientificamerican0888-68

121. Josefsen LB, Boyle RW. Photodynamic therapy and the development of metal-based photosensitisers. Met Based Drugs. 2008;2008:1-23. doi:10.1155/2008/276109

122. Wang R, Zhang B, Liang Z, et al. Insights into rapid photodynamic inactivation mechanism of staphylococcus aureus via rational design of multifunctional nitrogen-rich carbon-coated bismuth/cobalt nanoparticles. Appl Catal B. 2019;241:167-177. doi:10.1016/j.apcatb.2018.09.030

123. Min D, Boff J. Chemistry and reaction of singlet oxygen in foods. Compr Rev Food Sci Food Saf. 2002;1:58-72. doi:10.1111/ j.1541-4337.2002.tb00007.x

124. DeRosa MC, Crutchley RJ. Photosensitized singlet oxygen and its applications. Coord Chem Rev. 2002;233:351-371. doi:10.1016/ S0010-8545(02)00034-6

125. Liu Q, Liu E, Li J, et al. Rapid ultrasonic-microwave assisted synthesis of spindle-like $\mathrm{Ag} / \mathrm{ZnO}$ nanostructures and their enhanced visible-light photocatalytic and antibacterial activities. Catal Today. 2020;339:391-402. doi:10.1016/j.cattod.2019.01.017
126. Zhang Z, Zhang L, Hedhili MN, et al. Plasmonic gold nanocrystals coupled with photonic crystal seamlessly on $\mathrm{TiO} 2$ nanotube photoelectrodes for efficient visible light photoelectrochemical water splitting. Nano Lett. 2013;13:14-20. doi:10.1021/ nl3029202

127. $\mathrm{Xu} \mathrm{X}, \mathrm{Chen} \mathrm{D}$, Yi Z, et al. Antimicrobial mechanism based on $\mathrm{h}_{2} \mathrm{O}_{2}$ generation at oxygen vacancies in $\mathrm{ZnO}$ crystals. Langmuir. 2013;29:5573-5580. doi:10.1021/la400378t

128. Lakshmi Prasanna V, Vijayaraghavan R. Insight into the mechanism of antibacterial activity of $\mathrm{ZnO}$ : surface defects mediated reactive oxygen species even in the dark. Langmuir. 2015;31:9155-9162. doi:10.1021/acs.langmuir.5b02266

129. Liu Q, Li J, Zhong X, et al. Enhanced antibacterial activity and mechanism studies of $\mathrm{Ag} / \mathrm{bi}_{2} \mathrm{O}_{3}$ nanocomposites. Adv Powder Tech. 2018;29:2082-2090. doi:10.1016/j.apt.2018.05.015

130. Hao YJ, Liu B, Tian LG, et al. Synthesis of $\{111\}$ facet-exposed mgo with surface oxygen vacancies for reactive oxygen species generation in the dark. ACS Appl Mater Interfaces. 2017;9:12687-12693. doi:10.1021/acsami.6b16856

131. Setvín M, Aschauer U, Scheiber $P$, et al. Reaction of $\mathrm{o}_{2}$ with subsurface oxygen vacancies on $\mathrm{TiO}_{2}$ anatase (101). Science. 2013;341:988-991. doi:10.1126/science.1239879

132. Mutalik C, Hsiao YC, Chang YH, et al. High uv-vis-nir lightinduced antibacterial activity by heterostructured $\mathrm{TiO}_{2}-\mathrm{FeS}_{2}$ nanocomposites. Int J Nanomed. 2020;15:8911. doi:10.2147/IJN. S282689

133. Mutalik C, Wang DY, Krisnawati DI, et al. Light-activated heterostructured nanomaterials for antibacterial applications. Nanomaterials. 2020;10:643. doi:10.3390/nano10040643

134. Akhavan $\mathrm{O}$. Lasting antibacterial activities of $\mathrm{Ag}-\mathrm{TiO}_{2} / \mathrm{Ag} / \mathrm{a}-$ $\mathrm{TiO}_{2}$ nanocomposite thin film photocatalysts under solar light irradiation. $J$ Colloid Interface Sci. 2009;336:117-124. doi:10.1016/j.jcis.2009.03.018

135. Su HL, Chou CC, Hung DJ, et al. The disruption of bacterial membrane integrity through ROS generation induced by nanohybrids of silver and clay. Biomaterials. 2009;30:5979-5987. doi:10.1016/j.biomaterials.2009.07.030

136. Ma S, Zhan S, Jia Y, et al. Superior antibacterial activity of $\mathrm{Fe}_{3} \mathrm{O}_{4}-\mathrm{TiO}_{2}$ nanosheets under solar light. ACS Appl Mater Interfaces. 2015;7:21875-21883. doi:10.1021/acsami.5b06264

137. Xiang Y, Mao C, Liu X, et al. Rapid and superior bacteria killing of carbon quantum dots/ $\mathrm{ZnO}$ decorated injectable folic acid-conjugated pda hydrogel through dual-light triggered ROS and membrane permeability. Small. 2019;15:1900322. doi:10.1002/ smll.201900322

138. Deng W, Ning S, Lin Q, et al. I-TiO2/pve film with highly photocatalytic antibacterial activity under visible light. Colloids Surf B. 2016;144:196-202. doi:10.1016/j.colsurfb.2016.03.085

139. Abutaha N, Hezam A, Almekhlafi FA, et al. Rational design of $\mathrm{Ag}-\mathrm{ZnO}-\mathrm{Fe}_{3} \mathrm{O}_{4}$ nanocomposite with promising antimicrobial activity under led light illumination. Appl Surf Sci. 2020;527:146893. doi:10.1016/j.apsusc.2020.146893

140. Yin Q, Tan L, Lang Q, et al. Plasmonic molybdenum oxide nanosheets supported silver nanocubes for enhanced near-infrared antibacterial activity: synergism of photothermal effect, silver release and photocatalytic reactions. Appl Catal B. 2018;224:671-680. doi:10.1016/j.apcatb.2017.11.024

141. Xu J, Dai G, Chen B, et al. Construction of $\mathrm{ti}^{3+}-\mathrm{TiO}^{2-} \mathrm{c}_{3} \mathrm{n}_{4}$ por compound coupling photocatalysis and fenton-like process: self-driven fenton-like process without extra $\mathrm{h}_{2} \mathrm{O}_{2}$ addition. Chemosphere. 2020;241:125022. doi:10.1016/j.chemosphere.2019.125022

142. Sun $\mathrm{H}$, Yang $\mathrm{Z}, \mathrm{Pu} \mathrm{Y}$, et al. Zinc oxide/vanadium pentoxide heterostructures with enhanced day-night antibacterial activities. $J$ Colloid Interface Sci. 2019;547:40-49. doi:10.1016/j. jcis.2019.03.061 
143. Babu AT, Sebastian M, Manaf O, et al. Heterostructured nanocomposites of $\mathrm{Ag}$ doped $\mathrm{Fe}_{3} \mathrm{O}_{4}$ embedded in $\mathrm{ZnO}$ for antibacterial applications and catalytic conversion of hazardous wastes. $J$ Inorg Organomet Polym Mater. 2020;30:1944-1955. doi:10.1007/s10904-019-01366-y

144. Touati D. Iron and oxidative stress in bacteria. Arch Biochem Biophys. 2000;373:1-6. doi:10.1006/abbi.1999.1518

145. Kaushik M, Niranjan R, Thangam R, et al. Investigations on the antimicrobial activity and wound healing potential of $\mathrm{ZnO}$ nanoparticles. Appl Surf Sci. 2019;479:1169-1177. doi:10.1016/j. apsusc.2019.02.189

146. Ju P, Wang Y, Sun Y, et al. In-situ green topotactic synthesis of a novel z-scheme Ag@agvo $3 /$ bivo $_{4}$ heterostructure with highly enhanced visible-light photocatalytic activity. J Colloid Interface Sci. 2020;579:431-447. doi:10.1016/j.jcis.2020.06.094

147. Pal S, Tak YK, Song JM. Does the antibacterial activity of silver nanoparticles depend on the shape of the nanoparticle? A study of the gram-negative bacterium Escherichia coli. Appl Environ Microbiol. 2007;73:1712-1720. doi:10.1128/AEM.02218-06

148. Liang J, Shan C, Zhang X, et al. Bactericidal mechanism of bioiagi under visible light irradiation. Chem Eng J. 2015;279:277285. doi:10.1016/j.cej.2015.05.024

149. Wang W, Yu Y, An T, et al. Visible-light-driven photocatalytic inactivation of e. Coli k-12 by bismuth vanadate nanotubes: bactericidal performance and mechanism. Environ Sci Technol. 2012;46:4599-4606. doi:10.1021/es2042977

150. Xiang Y, Ju P, Wang Y, et al. Chemical etching preparation of the $\mathrm{Bi}_{2} \mathrm{WO}_{6}$ /bioi $\mathrm{p}-\mathrm{n}$ heterojunction with enhanced photocatalytic antifouling activity under visible light irradiation. Chem Eng J. 2016;288:264-275. doi:10.1016/j.cej.2015.11.103

151. Shi H, Li G, Sun H, et al. Visible-light-driven photocatalytic inactivation of e. Coli by $\mathrm{Ag} / \mathrm{AgX}$-cnts $(\mathrm{X}=\mathrm{Cl}, \mathrm{Br}$, i) plasmonic photocatalysts: bacterial performance and deactivation mechanism. Appl Catal B. 2014;158:301-307. doi:10.1016/j. apcatb.2014.04.033

152. Huh AJ, Kwon YJ. "Nanoantibiotics": a new paradigm for treating infectious diseases using nanomaterials in the antibiotics resistant era. J Control Release. 2011;156:128-145.

153. Ahmad A, Ullah S, Ahmad W, et al. Zinc oxide-selenium heterojunction composite: synthesis, characterization and photo-induced antibacterial activity under visible light irradiation. $J$ Photochem Photobiol B. 2020;203:111743. doi:10.1016/j.jphotobiol.2019.111743

154. Huang Y, He L, Liu W, et al. Selective cellular uptake and induction of apoptosis of cancer-targeted selenium nanoparticles. Biomaterials. 2013;34:7106-7116. doi:10.1016/j. biomaterials.2013.04.067

155. Chang Y, He L, Li Z, et al. Designing core-shell gold and selenium nanocomposites for cancer radiochemotherapy. ACS Nano. 2017;11:4848-4858. doi:10.1021/acsnano.7b01346

156. Xie Y, He Y, Irwin PL, et al. Antibacterial activity and mechanism of action of zinc oxide nanoparticles against campylobacter jejuni. Appl Environ Microbiol. 2011;77:2325-2331. doi:10.1128/AEM.02149-10

157. Pasquet J, Chevalier Y, Pelletier J, et al. The contribution of zinc ions to the antimicrobial activity of zinc oxide. Colloids Surf, A Physicochem Eng Asp. 2014;457:263-274. doi:10.1016/j. colsurfa.2014.05.057

158. Qamar MA, Shahid S, Javed M, et al. Highly efficient g- $\mathrm{C}_{3} \mathrm{~N}_{4} / \mathrm{cr}-$ $\mathrm{ZnO}$ nanocomposites with superior photocatalytic and antibacterial activity. J Photochem Photobiol A. 2020;401:112776. doi:10.1016/j.jphotochem.2020.112776

159. Wu Y, Zhou Y, Xu H, et al. Highly active, superstable, and biocompatible $\mathrm{Ag} /$ polydopamine/g- $\mathrm{C}_{3} \mathrm{~N}_{4}$ bactericidal photocatalyst: synthesis, characterization, and mechanism. ACS Sustain Chem Eng. 2018;6:14082-14094. doi:10.1021/ acssuschemeng.8b02620
160. Yang Y, Zhang C, Huang D, et al. Boron nitride quantum dots decorated ultrathin porous $\mathrm{g}-\mathrm{C}_{3} \mathrm{~N}_{4}$ : intensified exciton dissociation and charge transfer for promoting visible-light-driven molecular oxygen activation. Appl Catal B. 2019;245:87-99. doi:10.1016/j.apcatb.2018.12.049

161. Mohsen RM, Morsi SM, Selim MM, et al. Electrical, thermal, morphological, and antibacterial studies of synthesized polyaniline/zinc oxide nanocomposites. Polym Bull. 2019;76:1-21. doi:10.1007/s00289-018-2348-4

162. Liu W, Wang $M, X u C$, et al. Facile synthesis of $g-C_{3} N_{4} / Z n O$ composite with enhanced visible light photooxidation and photoreduction properties. Chem Eng J. 2012;209:386-393. doi:10.1016/j.cej.2012.08.033

163. Ding H, Han D, Han Y, et al. Visible light responsive CuS/ protonated g-C3N4 heterostructure for rapid sterilization. $J$ Hazard Mater. 2020;393:122423. doi:10.1016/j. jhazmat.2020.122423

164. Huang H, Tu S, Zeng C, et al. Macroscopic polarization enhancement promoting photo-and piezoelectric-induced charge separation and molecular oxygen activation. Angew Chem Int Ed. 2017;56:11860-11864. doi:10.1002/anie.201706549

165. Fu J, Xu Q, Low J, et al. Ultrathin $2 \mathrm{D} / 2 \mathrm{D} \mathrm{wo}_{3} / \mathrm{g}-\mathrm{C}_{3} \mathrm{~N}_{4}$ stepscheme $\mathrm{h}_{2}$-production photocatalyst. Appl Catal B. 2019;243:556-565. doi:10.1016/j.apcatb.2018.11.011

166. Wang R, Zhang X, Li F, et al. Energy-level dependent $\mathrm{h}_{2} \mathrm{O}_{2}$ production on metal-free, carbon-content tunable carbon nitride photocatalysts. J Energy Chem. 2018;27:343-350. doi:10.1016/j. jechem.2017.12.014

167. Nosaka Y, Nosaka AY. Generation and detection of reactive oxygen species in photocatalysis. Chem Rev. 2017;117:11302-11336. doi:10.1021/acs.chemrev.7b00161

168. Mao K, Zhu Y, Zhang X, et al. Effective loading of well-doped $\mathrm{ZnO} / \mathrm{ag}_{3} \mathrm{po}_{4}$ nanohybrids on magnetic core via one step for promoting its photocatalytic antibacterial activity. Colloids Surf, A Physicochem Eng Asp. 2020;603:125187. doi:10.1016/j. colsurfa.2020.125187

169. Yang X, Qin J, Jiang Y, et al. Fabrication of p25/ag $\mathrm{apo}_{4} / \mathrm{graphene}$ oxide heterostructures for enhanced solar photocatalytic degradation of organic pollutants and bacteria. Appl Catal B. 2015;166167:231-240. doi:10.1016/j.apcatb.2014.11.028

170. Xu F, Yuan Y, Han $\mathrm{H}$, et al. Synthesis of $\mathrm{ZnO} / \mathrm{CdS}$ hierarchical heterostructure with enhanced photocatalytic efficiency under nature sunlight. CrystEngComm. 2012;14:3615-3622. doi:10.1039/c2ce06267d

171. Hajipour MJ, Fromm KM, Ashkarran AA, et al. Antibacterial properties of nanoparticles. Trends Biotechnol. 2012;30:499511. doi:10.1016/j.tibtech.2012.06.004

172. Redfern J, Geerts L, Seo JW, et al. Toxicity and antimicrobial properties of $\mathrm{ZnO} @$ zif-8 embedded silicone against planktonic and biofilm catheter-associated pathogens. ACS Appl Nano Mater. 2018;1:1657-1665. doi:10.1021/acsanm.8b00140

173. Naimi Joubani M, Zanjanchi MA, Sohrabnezhad S. A novel Ag/ $\mathrm{ag}_{3} \mathrm{po}_{4}$-irmof-1 nanocomposite for antibacterial application in the dark and under visible light irradiation. Appl Organomet Chem. 2020;34:e5575. doi:10.1002/aoc.5575

174. Cao J, Zhao Y, Lin H, et al. Facile synthesis of novel Ag/agi/bioi composites with highly enhanced visible light photocatalytic performances. J Solid State Chem. 2013;206:38-44. doi:10.1016/j. jssc.2013.07.028

175. Page K, Palgrave RG, Parkin IP, et al. Titania and silver-titania composite films on glass-potent antimicrobial coatings. J Mater Chem. 2007;17:95-104. doi:10.1039/B611740F

176. Liou JW, Chang HH. Bactericidal effects and mechanisms of visible light-responsive titanium dioxide photocatalysts on pathogenic bacteria. Arch Immunol Ther Exp. 2012;60:267-275. doi:10.1007/s00005-012-0178-x 
177. Radzig MA, Nadtochenko VA, Koksharova OA, et al. Antibacterial effects of silver nanoparticles on gram-negative bacteria: influence on the growth and biofilms formation, mechanisms of action. Colloids Surf B. 2013;102:300-306. doi:10.1016/j. colsurfb.2012.07.039

178. Eddaoudi M, Kim J, Rosi N, et al. Systematic design of pore size and functionality in isoreticular mofs and their application in methane storage. Science. 2002;295:469. doi:10.1126/ science. 1067208

179. Li H, Eddaoudi M, O’Keeffe M, et al. Design and synthesis of an exceptionally stable and highly porous metal-organic framework. nature. 1999;402:276-279. doi:10.1038/46248

180. Xu X, Wang S, Yu X, et al. Biosynthesis of Ag deposited phosphorus and sulfur co-doped $\mathrm{g}-\mathrm{C}_{3} \mathrm{~N}_{4}$ with enhanced photocatalytic inactivation performance under visible light. Appl Surf Sci. 2020;501:144245. doi:10.1016/j.apsusc.2019.144245

181. Li Y, Wang H, Huang L, et al. Promoting led light driven photocatalytic inactivation of bacteria by novel $\beta-\mathrm{bi}_{2} \mathrm{O}_{3} @$ biobr core/ shell photocatalyst. $J$ Alloys Compd. 2020;816:152665. doi:10.1016/j.jallcom.2019.152665

182. Jaffari ZH, Lam SM, Sin JC, et al. Boosting visible light photocatalytic and antibacterial performance by decoration of silver on magnetic spindle-like bismuth ferrite. Mater Sci Semicond Process. 2019;101:103-115. doi:10.1016/j.mssp.2019.05.036

183. Wang X, Sui Y, Jian J, et al. Ag@agcl nanoparticles in-situ deposited cellulose acetate/silk fibroin composite film for photocatalytic and antibacterial applications. Cellulose. 2020;27:77217737. doi:10.1007/s10570-020-03321-4

184. Dong P, Yang F, Cheng X, et al. Plasmon enhanced photocatalytic and antimicrobial activities of Ag-TiO2 nanocomposites under visible light irradiation prepared by dbd cold plasma treatment. Mater Sci Eng C. 2019;96:197-204. doi:10.1016/j.msec.2018.11.005

185. Kokilavani S, Syed A, Thomas AM, et al. Integrating $\mathrm{ag}_{2} \mathrm{WO}_{4}$ on $\mathrm{vs}_{4}$ nanoplates with synergy of plasmonic photocatalysis and boosted visible-light harvesting and its antibacterial applications. J Alloys Compd. 2021;865:158810. doi:10.1016/j.jallcom.2021.158810

186. Rahman A, Zulfiqar S, Haq AU, et al. Cd-gd-doped nickel spinel ferrite nanoparticles and their nanocomposites with reduced graphene oxide for catalysis and antibacterial activity studies. Ceram Int. 2021;47:9513-9521. doi:10.1016/j.ceramint.2020.12.085

187. Devi AP, Padhi DK, Mishra PM, et al. Bio-surfactant assisted room temperature synthesis of cubic $\mathrm{Ag} / \mathrm{rgo}$ nanocomposite for enhanced photoreduction of cr (vi) and antibacterial activity. J Environ Chem Eng. 2021;9:104778. doi:10.1016/j.jece.2020.104778

188. Raj RB, Umadevi M, Parimaladevi R. Effect of $\mathrm{ZnO} / \mathrm{Ag}$ nanocomposites against anionic and cationic dyes as photocatalysts and antibacterial agents. J Inorg Organomet Polym Mater. 2021;31:500-510. doi:10.1007/s10904-020-01717-0

189. Ashraf MA, Li C, Zhang D, et al. Fabrication of silver phosphateilmenite nanocomposites supported on glycol chitosan for visible light-driven degradation, and antimicrobial activities. Int $J$ Biol Macromol. $\quad 2021 ; 169: 436-442$.

doi:10.1016/j. ijbiomac.2020.12.049

190. Jin Y, Long J, Ma X, et al. Synthesis of caged iodine-modified $\mathrm{ZnO}$ nanomaterials and study on their visible light photocatalytic antibacterial properties. Appl Catal B. 2019;256:117873. doi:10.1016/j.apcatb.2019.117873

191. Lu TY, Chiang CY, Fan YJ, et al. Dual-targeting glycol chitosan/ heparin-decorated polypyrrole nanoparticle for augmented photothermal thrombolytic therapy. ACS Appl Mater Interfaces. 2021;13:10287-10300. doi:10.1021/acsami.0c20940

192. Lu KY, Jheng PR, Lu LS, et al. Enhanced anticancer effect of ROS-boosted photothermal therapy by using fucoidan-coated polypyrrole nanoparticles. Int J Biol Macromol. 2021;166:98107. doi:10.1016/j.ijbiomac.2020.10.091
193. Liao YT, Liu CH, Chin Y, et al. Biocompatible and multifunctional gold nanorods for effective photothermal therapy of oral squamous cell carcinoma. J Mater Chem B. 2019;7:4451-4460. doi:10.1039/C9TB00574A

194. Yousefi M, Dadashpour M, Hejazi M, et al. Anti-bacterial activity of graphene oxide as a new weapon nanomaterial to combat multidrug-resistance bacteria. Mater Sci Eng C. 2017;74:568581. doi:10.1016/j.msec.2016.12.125

195. Behzadpour N, Sattarahmady N, Akbari N. Antimicrobial photothermal treatment of pseudomonas aeruginosa by a carbon nanoparticles-polypyrrole nanocomposite. $J$ Biomed Phys Eng. 2019;9:661. doi:10.31661/JBPE.V0I0.1024

196. Xu JW, Yao K, Xu ZK. Nanomaterials with a photothermal effect for antibacterial activities: an overview. Nanoscale. 2019;11:8680-8691. doi:10.1039/C9NR01833F

197. Chen Y, Gao Y, Chen Y, et al. Nanomaterials-based photothermal therapy and its potentials in antibacterial treatment. J Control Release. 2020;328:251-262. doi:10.1016/j.jconrel.2020.08.055

198. Zhou Z, Li B, Shen C, et al. Metallic 1T phase enabling MoS2 nanodots as an efficient agent for photoacoustic imaging guided photothermal therapy in the near-infrared-ii window. Small. 2020;16:2004173. doi:10.1002/smll.202004173

199. Zhou Z, Wang X, Zhang H, et al. Activating layered metal oxide nanomaterials via structural engineering as biodegradable nanoagents for photothermal cancer therapy. Small. 2021;17:2007486. doi:10.1002/smll.202007486

200. Yougbaré S, Chou HL, Yang CH, et al. Facet-dependent gold nanocrystals for effective photothermal killing of bacteria. J Hazard Mater. 2021;407:124617. doi:10.1016/j.jhazmat.2020.124617

201. Cao W, Yue L, Khan IM, et al. Polyethylenimine modified $\mathrm{MoS}_{2}$ nanocomposite with high stability and enhanced photothermal antibacterial activity. $J$ Photochem Photobiol A. 2020;401:112762. doi:10.1016/j.jphotochem.2020.112762

202. Wang H, Zhang J, Song Z, et al. An intelligent platform based on acidity-triggered aggregation of gold nanoparticles for precise photothermal ablation of focal bacterial infection. Chem Eng J. 2021;407:127076. doi:10.1016/j.cej.2020.127076

203. Zhang $\mathrm{P}, \mathrm{Li} \mathrm{S}, \mathrm{Chen} \mathrm{H}$, et al. Biofilm inhibition and elimination regulated by cationic conjugated polymers. ACS Appl Mater Interfaces. 2017;9:16933-16938. doi:10.1021/ acsami.7b05227

204. Xi Y, Wang Y, Gao J, et al. Dual corona vesicles with intrinsic antibacterial and enhanced antibiotic delivery capabilities for effective treatment of biofilm-induced periodontitis. ACS Nano. 2019;13:13645-13657. doi:10.1021/acsnano.9b03237

205. Zhao Z, Ding C, Wang Y, et al. Ph-responsive polymeric nanocarriers for efficient killing of cariogenic bacteria in biofilms. Biomater Sci. 2019;7:1643-1651. doi:10.1039/ C8BM01640B

206. Hu D, Deng Y, Jia F, et al. Surface charge switchable supramolecular nanocarriers for nitric oxide synergistic photodynamic eradication of biofilms. ACS Nano. 2019;14:347-359. doi:10.1021/acsnano.9b05493

207. Wang C, Zhao W, Cao B, et al. Biofilm-responsive polymeric nanoparticles with self-adaptive deep penetration for in vivo photothermal treatment of implant infection. Chem Mater. 2020;32:7725-7738. doi:10.1021/acs.chemmater.0c02055

208. Thavanathan J, Huang NM, Thong KL. Colorimetric detection of DNA hybridization based on a dual platform of gold nanoparticles and graphene oxide. Biosens Bioelectron. 2014;55:91-98. doi:10.1016/j.bios.2013.11.072

209. Farokhnezhad M, Esmaeilzadeh M. Graphene coated gold nanoparticles: an emerging class of nanoagents for photothermal therapy applications. Phys Chem Chem Phys. 2019;21:18352-18362. doi:10.1039/C9CP03126J 
210. Kaushal S, Pinnaka AK, Soni S, et al. Antibody assisted graphene oxide coated gold nanoparticles for rapid bacterial detection and near infrared light enhanced antibacterial activity. Sens Actuators B Chem. 2021;329:129141. doi:10.1016/j. snb.2020.129141

211. Prusty K, Swain SK. Polypropylene oxide/polyethylene oxidecellulose hybrid nanocomposite hydrogels as drug delivery vehicle. J Appl Polym Sci. 2021;138:49921. doi:10.1002/app.49921

212. Ye S, Wang F, Fan Z, et al. Light/ph-triggered biomimetic red blood cell membranes camouflaged small molecular drug assemblies for imaging-guided combinational chemo-photothermal therapy. ACS Appl Mater Interfaces. 2019;11:15262-15275. doi:10.1021/acsami.9b00897

213. Xuan M, Shao J, Dai L, et al. Macrophage cell membrane camouflaged mesoporous silica nanocapsules for in vivo cancer therapy. Adv Healthc Mater. 2015;4:1645-1652. doi:10.1002/ adhm.201500129

214. Ying M, Zhuang J, Wei X, et al. Remote-loaded platelet vesicles for disease-targeted delivery of therapeutics. Adv Funct Mater. 2018;28:1801032. doi:10.1002/adfm.201801032

215. Sun H, Su J, Meng Q, et al. Cancer-cell-biomimetic nanoparticles for targeted therapy of homotypic tumors. Adv Mater. 2016;28:9581-9588. doi:10.1002/adma.201602173

216. Ran L, Lu B, Qiu H, et al. Erythrocyte membrane-camouflaged nanoworms with on-demand antibiotic release for eradicating biofilms using near-infrared irradiation. Bioact Mater. 2021;6:2956-2968. doi:10.1016/j.bioactmat.2021.01.032

217. Yang X, Xia P, Zhang Y, et al. Photothermal nano-antibiotic for effective treatment of multidrug-resistant bacterial infection. ACS Appl Bio Mater. 2020;3:5395-5406. doi:10.1021/acsabm.0c00702

218. Patel U, Rathnayake K, Jani H, et al. Near-infrared responsive targeted drug delivery system that offer chemo-photothermal therapy against bacterial infection. Nano Select. 2021. doi:10.1002/nano.202000271

219. Wei G, Yang G, Wang Y, et al. Phototherapy-based combination strategies for bacterial infection treatment. Theranostics. 2020;10:12241. doi: $10.7150 /$ thno.52729

220. Yang D, Yang G, Yang P, et al. Assembly of Au plasmonic photothermal agent and iron oxide nanoparticles on ultrathin black phosphorus for targeted photothermal and photodynamic cancer therapy. Adv Funct Mater. 2017;27:1700371. doi:10.1002/adfm.201700371

221. Wang H, Yang X, Shao W, et al. Ultrathin black phosphorus nanosheets for efficient singlet oxygen generation. $\mathrm{J} \mathrm{Am} \mathrm{Chem}$ Soc. 2015;137:11376-11382. doi:10.1021/jacs.5b06025

222. Chen W, Ouyang J, Liu H, et al. Black phosphorus nanosheetbased drug delivery system for synergistic photodynamic/photothermal/chemotherapy of cancer. Adv Mater. 2017;29:1603864. doi:10.1002/adma.201603864

223. Aksoy I, Kucukkececi H, Sevgi F, et al. Photothermal antibacterial and antibiofilm activity of black phosphorus/gold nanocomposites against pathogenic bacteria. ACS Appl Mater Interfaces. 2020;12:26822-26831. doi:10.1021/acsami.0c02524

224. Hong L, Luo SH, Yu CH, et al. Functional nanomaterials and their potential applications in antibacterial therapy. Pharm Nanotechnol. 2019;7:129-146. doi:10.2174/2211738507666190320160802

225. Xia MY, Xie Y, Yu CH, et al. Graphene-based nanomaterials: the promising active agents for antibiotics-independent antibacterial applications. J Control Release. 2019;307:16-31. doi:10.1016/j. jconrel.2019.06.011

226. Yu CH, Chen GY, Xia MY, et al. Understanding the sheet sizeantibacterial activity relationship of graphene oxide and the nanobio interaction-based physical mechanisms. Colloids Surf $B$. 2020;191:111009. doi:10.1016/j.colsurfb.2020.111009
227. Lu BY, Zhu GY, Yu CH, et al. Functionalized graphene oxide nanosheets with unique three-in-one properties for efficient and tunable antibacterial applications. Nano Res. 2021;14:185-190. doi:10.1007/s12274-020-3064-6

228. Abdelhamid $\mathrm{HN}$, Wu HF. Multifunctional graphene magnetic nanosheet decorated with chitosan for highly sensitive detection of pathogenic bacteria. J Mater Chem B. 2013;1:3950-3961. doi:10.1039/c3tb20413h

229. Ares P, Palacios JJ, Abellán G, et al. Recent progress on antimonene: a new bidimensional material. Adv Mater. 2018;30:1703771. doi:10.1002/adma.201703771

230. Zheng Y, Wang W, Zhao J, et al. Preparation of injectable temperature-sensitive chitosan-based hydrogel for combined hyperthermia and chemotherapy of colon cancer. Carbohydr Polym. 2019;222:115039. doi:10.1016/j.carbpol.2019.115039

231. Liu Y, Xiao Y, Cao Y, et al. Construction of chitosan-based hydrogel incorporated with antimonene nanosheets for rapid capture and elimination of bacteria. Adv Funct Mater. 2020;30:2003196. doi:10.1002/adfm.202003196

232. Gui H, Feng Y, Qiang L, et al. Core/shell structural ultra-small gold and amyloid peptide nanocomposites with effective bacterial surface adherence and enhanced antibacterial photothermal ablation. Smart Mater Med. 2021;2:46-55. doi:10.1016/j. smaim.2020.12.001

233. Choi W, Park JY, Kim Y. Photothermal sterilization cellulose patch with hollow gold nanoparticles. J Ind Eng Chem. 2021;95:120-125. doi:10.1016/j.jiec.2020.12.012

234. Deng H, Sun J, Yu Z, et al. Low-intensity near-infrared lighttriggered spatiotemporal antibiotics release and hyperthermia by natural polysaccharide-based hybrid hydrogel for synergistic wound disinfection. Mater Sci Eng C. 2021;118:111530. doi:10.1016/j.msec.2020.111530

235. Zhang Z, Zhao X, Suo H, et al. Thermal monitoring treatment nano-mixture based on $\mathrm{y}_{2} \mathrm{O}_{3}: \mathrm{yb}^{3+} / \mathrm{er}^{3+} @ \mathrm{sio}_{2} / \mathrm{sio}_{2} @ \mathrm{cu}_{2} \mathrm{~s}$. Opt Mater. 2021;113:110875. doi:10.1016/j.optmat.2021.110875

236. Liu H, Liu Z, Liu X, et al. Facile synthesis of tannic acid modified nbte $_{2}$ nanosheets for effective photothermal ablation of bacterial pathogens. Colloids Interface Sci Commun. 2021;41:100383. doi:10.1016/j.colcom.2021.100383

237. Ye Q, Xiao S, Lin T, et al. Mesoporous silica-coated gold nanorods loaded with tetrazolyl phthalocyanine as NIR light-activated nano-switches for synergistic photothermal and photodynamic inactivation of antibiotic-resistant Escherichia coli. Mater Adv. 2021;2:1695-1705. doi:10.1039/D0MA00782J

238. Huang B, Liu X, Li Z, et al. Rapid bacteria capturing and killing by agnps/n-cd@ZnO hybrids strengthened photo-responsive xerogel for rapid healing of bacteria-infected wounds. Chem Eng J. 2021;414:128805. doi:10.1016/j.cej.2021.128805

239. Naskar A, Lee S, Kim KS. Au-ZnO conjugated black phosphorus as a near-infrared light-triggering and recurrence-suppressing nanoantibiotic platform against staphylococcus aureus. Pharmaceutics. 2021;13:52. doi:10.3390/pharmaceutics13010052

240. Patil SB, Chou HL, Chen YM, et al. Enhanced n 2 affinity of 1Tmos 2 with a unique pseudo-six-membered ring consisting of $\mathrm{N}-$ Li-S-Mo-S-Mo for high ambient ammonia electrosynthesis performance. J Mater Chem A. 2021;9:1230-1239. doi:10.1039/ D0TA10696H

241. Tao B, Lin C, Yuan Z, et al. Near infrared light-triggered ondemand cur release from gel-pda@ cur composite hydrogel for antibacterial wound healing. Chem Eng J. 2021;403:126182. doi:10.1016/j.cej.2020.126182 


\section{Publish your work in this journal}

The International Journal of Nanomedicine is an international, peerreviewed journal focusing on the application of nanotechnology in diagnostics, therapeutics, and drug delivery systems throughout the biomedical field. This journal is indexed on PubMed Central, MedLine, CAS, SciSearch ${ }^{\mathbb{B}}$, Current Contents ${ }^{\mathbb{B}} /$ Clinical Medicine,
Journal Citation Reports/Science Edition, EMBase, Scopus and the Elsevier Bibliographic databases. The manuscript management system is completely online and includes a very quick and fair peer-review system, which is all easy to use. Visit http://www.dovepress.com/ testimonials.php to read real quotes from published authors.

Submit your manuscript here: https://www.dovepress.com/international-journal-of-nanomedicine-journal 